\title{
Summary of Oceanographic and Water-Quality Measurements in Chincoteague Bay, Maryland and Virginia, 2014-15
}
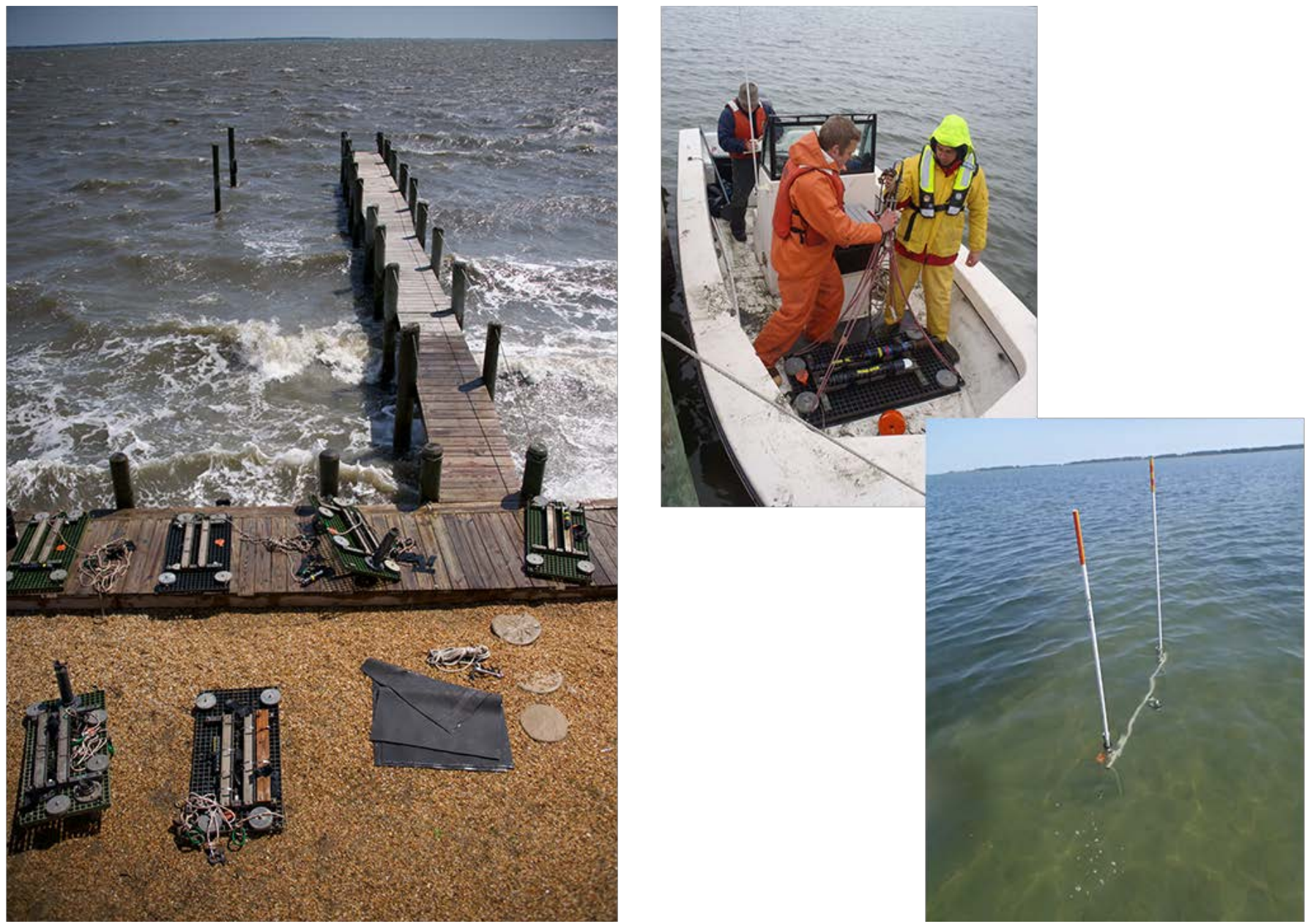

Open-File Report 2017-1032

U.S. Department of the Interior

U.S. Geological Survey 
Cover. Photographs from U.S. Geological Survey (USGS) field study in Chincoteague Bay, Maryland and Virginia. From left-hand side going clockwise: stormy day on April 22, 2015, during final turnaround of instruments, viewed from second story of rental house in Greenbackville, Virginia; USGS personnel preparing bottom platform for deployment; altimeter H-frame with installed altimeter after initial deployment on August 16, 2014. All photographs by USGS personnel. 


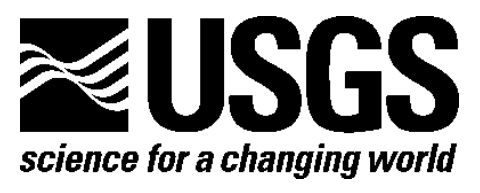

\section{Summary of Oceanographic and Water-Quality Measurements in Chincoteague Bay, Maryland and Virginia, 2014-15}

By Steven E. Suttles, Neil K. Ganju, Sandra M. Brosnahan, Ellyn T. Montgomery, Patrick J. Dickhudt, Alexis Beudin, Daniel J. Nowacki, and Marinna A. Martini

Open-File Report 2017-1032

U.S. Department of the Interior U.S. Geological Survey 


\section{U.S. Department of the Interior \\ RYAN K. ZINKE, Secretary}

\section{U.S. Geological Survey \\ William H. Werkheiser, Acting Director}

U.S. Geological Survey, Reston, Virginia: 2017

For more information on the USGS—-the Federal source for science about the Earth, its natural and living resources, natural hazards, and the environment-visit https://www.usgs.gov/ or call 1-888-ASK-USGS (1-888-275-8747).

For an overview of USGS information products, including maps, imagery, and publications, visit https://store.usgs.gov/

Any use of trade, firm, or product names is for descriptive purposes only and does not imply endorsement by the U.S. Government.

Although this information product, for the most part, is in the public domain, it also may contain copyrighted materials as noted in the text. Permission to reproduce copyrighted items must be secured from the copyright owner.

Suggested citation:

Suttles, S.E., Ganju, N.K., Brosnahan, S.M., Montgomery, E.T., Dickhudt, P.J., Beudin, Alexis, Nowacki, D.J., and Martini, M.A., 2017, Summary of oceanographic and water-quality measurements in Chincoteague Bay, Maryland and Virginia, 2014-15: U.S. Geological Survey Open-File Report 2017-1032, 95 p.,

https://doi.org/10.3133/ofr20171032.

ISSN 2331-1258 (online) 


\section{Acknowledgments}

This study was part of the Estuarine Physical Response to Storms project (GS2-2D), supported by the Department of the Interior Hurricane Sandy Recovery program. Nicholas Nidzieko and David Loewensteiner of the University of Maryland Center for Environmental Science, Horn Point Laboratory (UMCES-HPL), provided vessel and field support that were an essential part of this work. Analytical support was provided by UMCES-HPL Analytical Services Laboratory. Eric Sherry and Neil Winn of the National Park Service, Assateague Island National Seashore Office, provided additional vessel and field support that were very helpful to this project. Jeremy Testa of the University of Maryland Center for Environmental Science, Chesapeake Biological Laboratory, was a collaborator on the project and participated in the field sampling. We are grateful to Carol Pauley and George Hogeboom at the Mansion House Bed \& Breakfast at Public Landing for the use of their dock for the weather station installation. The authors would also like to acknowledge the field and analytical support provided by Jonathan Borden, Christine Sabens, and Wally Brooks, all of the U.S. Geological Survey. 


\section{Contents}

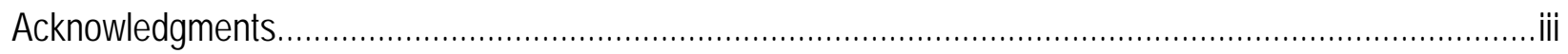

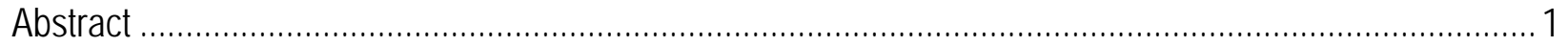

Introduction

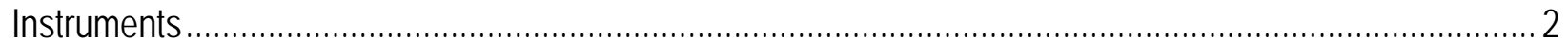

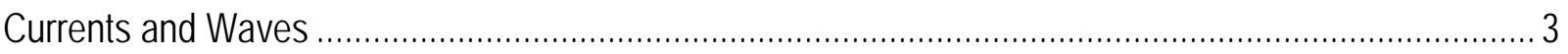

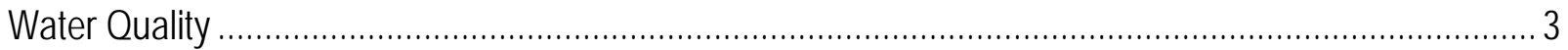

Seabed Elevation and Meteorological Observations........................................................................ 3

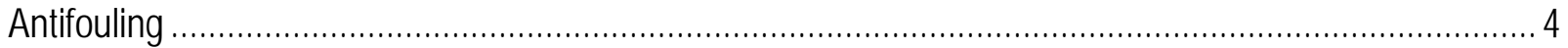

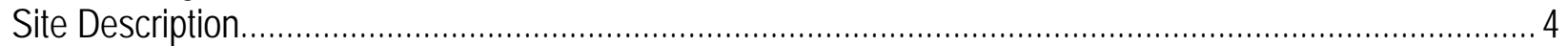

Shoal/Channel Paired Interior Sites-Moorings 1019, 1020, 1023, 1024, 1027, and 1028..................... 5

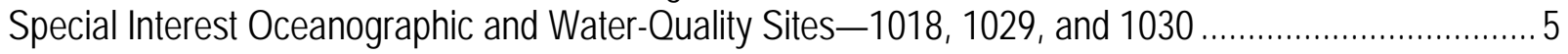

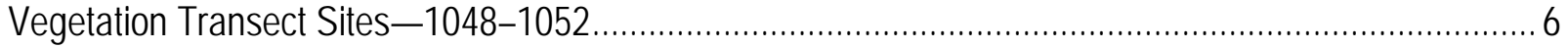

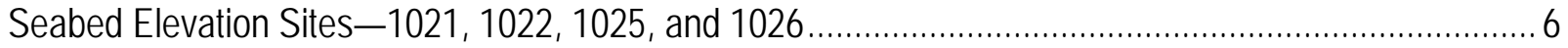

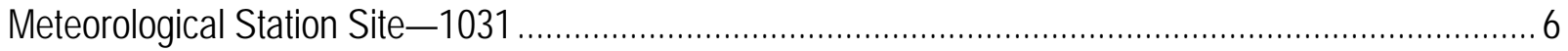

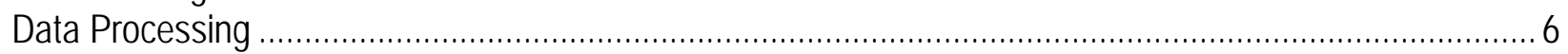

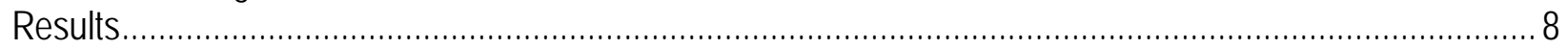

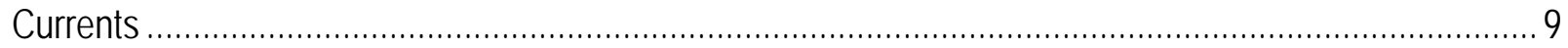

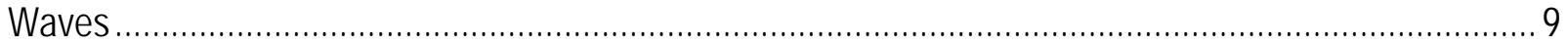

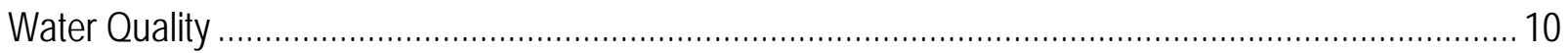

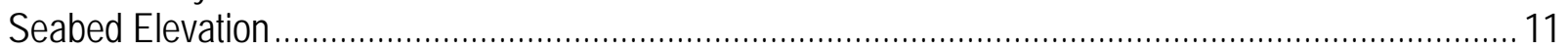

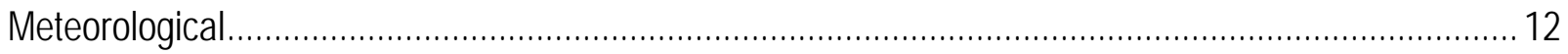

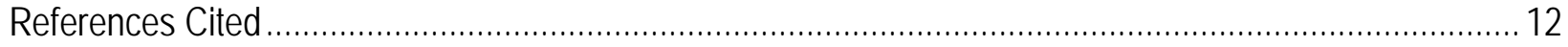

Appendix 1. Burst Current and Pressure Data, Chincoteague Bay, Maryland and Virginia, 2014-15 ........ 94

\section{Figures}

Figure 1. Regional map of study area in Chincoteague Bay, Maryland and Virginia. Red circles $(\bullet)$ are shown at time series station locations; see figures 2 and 3 for more detailed maps of locations.

Figure 2. Map showing locations (red circles) and identifiers of time series stations in the Virginia part of Chincoteague Bay. Mooring numbers are shown for each location; see table 1 for coordinates, nominal depths, and time periods of deployments. For instrumentation information, sensor elevation, and associated data files, by mooring identification number, see tables 2-6. Elevations are referenced to NAVD 88. m, meter. 15

Figure 3. Map showing locations (red circles) and identifiers of time series stations in the Maryland part of Chincoteague Bay. Mooring numbers are shown for each location; see table 1 for coordinates, nominal depths, and time periods of deployments. For instrumentation information, sensor elevation, and associated data files, by mooring identification number, see tables 2-6. Elevations are referenced to NAVD 88. m, meter......

Figure 4. Photograph showing shallow water irradiance platform ready for initial deployment at mooring 1020 (CB03) on August 13, 2014. Instruments: ECO-PARSB light sensors (mounted vertically), Aquadopp highresolution pulse coherent acoustic Doppler current profiler (center), EXO2 multi-parameter sonde (copper mesh guard), and D|wave pressure logger (mounted opposite to EXO2).

Figure 5. Photograph showing U.S. Geological Survey personnel preparing release bridle on bottom platform for deployment at mooring 1019 (CB02) on April 25, 2015.

Figure 6. Photograph showing shallow water irradiance platform deployed in bare patch of a dense seagrass bed at mooring 1020 (CB03) on August 13, 2014. Water depth at the time of deployment was approximately 1.5 meters. 
Figure 7. Photograph showing bottom platform with 1-megahertz Aquadopp acoustic Doppler current profiler (center), YSI 6600 sonde (with copper mesh), and D|wave pressure logger (opposite YSI 6600) ready for deployment at 1027 (CB09) on August 14, 2014. The white paste on Aquadopp transducer face and the copper mesh guard on the YSI 6600 are part of the antifouling controls. The YSI 6600 also had a mechanical wiper to clean sensor faces during the 2- to 3-month-long deployments.

Figure 8. Photograph showing deployment of installed seabed altimeter at mooring 1021 (CB04) on August 15, 2014. An Echologger AA400 altimeter is mounted in the center of the aluminum $\mathrm{H}$-frame cross bar with the transducer pointing straight down toward the seabed, which is nominally 0.50 meter below the altimeter transducer.

Figure 9. Photograph showing Onset Hobo U30 weather station on private dock at Public Landing, Maryland, mooring 1031 (CBWS), just after installation on August 16, 2014. The weather station measured wind speed and direction, air temperature, relative humidity, barometric pressure, photosynthetically active radiation, and shortwave irradiance.

Figure 10. Photograph showing Mooring 1018 (CB01) mounted to an old Coast Guard station piling at Toms Cove near Chincoteague Inlet on August 15, 2014. A YSI 6600 multiparameter water-quality sonde is mounted to the aluminum channel, about 0.5 meter below the water level at time of the photograph.....

Figure 11. Photograph showing heavy biological and sediment fouling that occurred on a platform recovered at mooring 1029 (CB11) in Newport Bay on October 14, 2014. Copper mesh and guard kept the EXO2 sonde sampling chamber relatively clean. Despite the heavy fouling, the Aquadopp acoustic Doppler current profiler collected usable data for the entire deployment. The EXO2 sonde stopped working 11 days before recovery because of a power issue; however, it collected usable data until that time.

Figure 12. Photographs showing a comparison of fouling on EXO2 sensors from moorings $A, 1028$ and $B, 1029$ upon recovery in October 2014 during the first turnaround of the deployed instruments. Sensor faces are clean on the sensors from mooring 1028 (CB10) with the exception of some fouling on the conductivity cell (third sensor counterclockwise from left, approximately 6 o'clock) where the wiper was not effective. All sensors are heavily fouled from the EXO2 sonde at 1029 (CB11), where the sonde ran out of battery power 11 days prior to recovery,

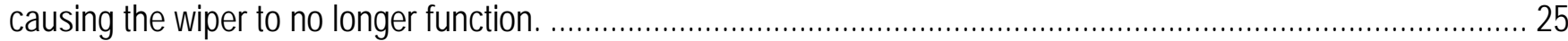

Figure 13. Photographs showing seabed altimeter at mooring 1026 (CB08) heavily encrusted in barnacles at time of recovery in October 2014 on the first instrument turnaround; $A$, the sensor mounted in the $\mathrm{H}$-frame just prior to recovery; $B$, sensor topside just after recovery. Zinc oxide paste kept the transducer face on altimeter clean

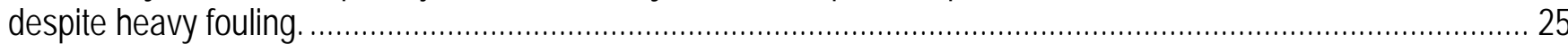

Figure 14. Photograph showing YSI 6600 sonde from mooring 1018 (CB01) just after recovery in October 2014. Some moderate biological fouling was present on the instrument body and mount, but the sampling chamber with copper mesh and copper-taped guard were clean.....

Figure 15. Photograph showing shallow water irradiance platform at mooring 1020 (CB03), a shoal site with dense seagrass coverage, just after recovery on October 16, 2014. Only light fouling was observed on this deployment; some seagrass is attached to the upper photosynthetically active radiation sensor........................ 27 Figure 16. Photograph showing bottom platform at 1019 (CB02) upon recovery on October 16, 2014. Moderate sediment fouling was observed during this deployment......

Figure 17. Chart showing the availability of current velocity data for Chincoteague Bay, Maryland and Virginia, for the Estuarine Physical Response to Storms study from August 2014 to July 2015. aqd, Nortek Aquadopp; HRaqd, Nortek Aquadopp high resolution; ID, identification number.

Figure 18. Graphs showing pressure (atmospherically corrected), current speed, and current direction (traveling towards convention) from 1-megahertz Aquadopp acoustic Doppler current profiler, bin 2, at mooring 1019 (CB02) from August 13, 2014, to July 12, 2015. dbar, decibar; cm/s, centimeter per second; ${ }^{\circ}$, degree true..................... 30 Figure 19. Graphs showing pressure (atmospherically corrected), current speed, and current direction (traveling towards convention) from 1-megahertz Aquadopp high resolution acoustic Doppler current profiler, bin 8, at 
mooring 1020 (CB03) from August 13, 2014, to July 12, 2015. dbar, decibar; cm/s, centimeter per second; ${ }^{\circ}$, degree true.

Figure 20. Graphs showing pressure (atmospherically corrected), current speed, and current direction (traveling towards convention) from 1-megahertz Aquadopp acoustic Doppler current profiler, bin 2, at mooring 1023 (CB06) from August 13, 2014, to July 12, 2015. dbar, decibar; $\mathrm{cm} / \mathrm{s}$, centimeter per second; ${ }^{\circ}$, degrees true. 32 Figure 21. Graphs showing pressure (atmospherically corrected), current speed, and current direction (traveling towards convention) from 2-megahertz Aquadopp acoustic Doppler current profiler, bin 2, at mooring 1024 (CB07) from August 13, 2014, to April 21, 2015. dbar, decibar; cm/s, centimeter per second; ${ }^{\circ}$, degree true.

Figure 22. Graphs showing pressure (atmospherically corrected), current speed, and current direction (traveling towards convention) from 2-megahertz Aquadopp acoustic Doppler current profiler, bin 2, at mooring 1027 (CB09) from August 13, 2014, to April 21, 2015. dbar, decibar; cm/s, centimeter per second; ${ }^{\circ}$, degree true.

Figure 23. Graphs showing pressure (atmospherically corrected), current speed, and current direction (traveling towards convention) from 2-megahertz Aquadopp acoustic Doppler current profiler, bin 2, at mooring 1028 (CB10) from August 14, 2014, to Jul 12, 2015. dbar, decibar; cm/s, centimeter per second; ${ }^{\circ}$, degree true...... 35 Figure 24. Graphs showing pressure (atmospherically corrected), current speed, and current direction (traveling towards convention) from 2-megahertz Aquadopp acoustic Doppler current profiler, bin 2, at mooring 1029 (CB11) from August 13, 2014, to April 21, 2015. dbar, decibar; $\mathrm{cm} / \mathrm{s}$, centimeter per second; ${ }^{\circ}$, degree true.

Figure 25. Graphs showing pressure (atmospherically corrected), current speed, and current direction (traveling towards convention) from 2-megahertz Aquadopp acoustic Doppler current profiler, bin 2, at mooring 1030 (CB12) from August 14, 2014, to April 21, 2015. dbar, decibar; cm/s, centimeter per second; ${ }^{\circ}$, degree true.

Figure 26. Graphs showing pressure (atmospherically corrected), current speed, and current direction (traveling towards convention) from 2-megahertz Aquadopp acoustic Doppler current profiler, bin 2, at mooring 1048 (V1) from April 25 to July 12, 2015. dbar, decibar; $\mathrm{cm} / \mathrm{s}$, centimeter per second; ${ }^{\circ}$, degree true.

Figure 27. Chart showing the availability of wave data for Chincoteague Bay, Maryland and Virginia, for the estuarine physical response study from August 2014 to July 2015. aqd, Nortek Aquadopp; dw, RBR D|wave; ID, identification number.

Figure 28. Graphs showing significant wave height, peak wave period, and mean wave direction (traveling from convention) from 1-megahertz Aquadopp acoustic Doppler current profiler wave burst data at mooring 1019 (CB02) from August 13, 2014, to July 12, 2015. Wave directions are shown for significant wave heights greater than or equal to 0.10 meter. m, meter; s, second; ${ }^{\circ}$, degrees true.

Figure 29. Graphs showing significant wave height and peak wave period from D/wave pressure logger wave burst data at mooring 1019 (CB02) from August 13, 2014, to April 20, 2015. m, meter; s, second.

Figure 30. Graphs showing significant wave height and peak wave period from D/wave pressure logger wave burst data at mooring 1020 (CB03) from August 13, 2014, to July 12, 2015. m, meter; s, second.

Figure 31. Graphs showing significant wave height, peak wave period, and mean wave direction (traveling from convention) from 1-megahertz Aquadopp acoustic Doppler current profiler wave burst data at mooring 1023 (CB06) from August 13, 2014, to July 12, 2015. Wave directions are shown for significant wave heights greater than or equal to 0.10 meter. m, meter; $\mathrm{s}$, second; ${ }^{\circ}$, degree true.

Figure 32. Graphs showing significant wave height, peak wave period, and mean wave direction (traveling from convention) from 2-megahertz Aquadopp acoustic Doppler current profiler wave burst data at mooring 1024 (CB07) from August 13, 2014, to April 21, 2015. Wave directions are shown for significant wave heights greater than or equal to 0.10 meter. m, meter; $\mathrm{s}$, second; ${ }^{\circ}$, degree true.

Figure 33. Graphs showing significant wave height and peak wave period from D/wave pressure logger wave burst data at mooring 1024 (CB07) from August 13, 2014, to April 21, 2015. m, meter; s, second.

Figure 34. Graphs showing significant wave height, peak wave period, and mean wave direction (traveling from convention) from 1-megahertz Aquadopp acoustic Doppler current profiler wave burst data at mooring 1027 (CB09) 
from August 13, 2014, to April 21, 2015. Wave directions are shown for significant wave heights greater than or equal to 0.10 meter. m, meter; s, second; ${ }^{\circ}$, degree true.

Figure 35. Graphs showing significant wave height and peak wave period from D|wave pressure logger wave burst data at mooring 1027 (CB09) from August 13, 2014, to April 21, 2015. m, meter; s, second.

Figure 36. Graphs showing significant wave height, peak wave period, and mean wave direction (traveling from convention) from 2-megahertz Aquadopp acoustic Doppler current profiler wave burst data at mooring 1028 (CB10) from April 25 to July 12,2015 . Wave directions are shown for significant wave heights greater than or equal to 0.10 meter. m, meter; s, second; ${ }^{\circ}$, degree true.

Figure 37. Graphs showing significant wave height and peak wave period from D|wave pressure logger wave burst data at mooring 1028 (CB10) from August 14, 2014, to April 21, 2015. m, meter; s, second. 49

Figure 38. Graphs showing significant wave height and peak wave period from $D \mid$ wave pressure logger wave burst data at mooring 1029 (CB11) from August 13, 2014, to April 21, 2015. m, meter; s, second.

Figure 39. Graphs showing significant wave height, peak wave period, and mean wave direction (traveling from convention) from 2-megahertz Aquadopp acoustic Doppler current profiler wave burst data at mooring 1048 (V1) from April 25 to July 12, 2015. Wave directions are shown for significant wave heights greater than or equal to 0.10 meter. m, meter; s, second; ${ }^{\circ}$, degree true.

Figure 40. Graphs showing significant wave height and peak wave period from wave burst data collected with D|wave pressure loggers at moorings 1049-1052 (V2-V5) from April 26 to July 12, 2015. m, meter; s, second.... 52 Figure 41. Chart showing the availability of water-quality data for Chincoteague Bay, Maryland and Virginia, for the Estuarine Physical Response to Storms study from August 2014 to July 2015. ysi, YSI 6600 sonde; ecn, WET Labs ECO-NTUSB; ecp, WET Labs ECO-PARSB; exo, YSI EXO2 sonde; mc, Sea-Bird SBE 37-SM MicroCAT; ID, identification number.

Figure 42. Graphs showing sensor depth, water temperature, and salinity from YSI EXO2 multiparameter sonde data at mooring 1019 (CB02) from April 25 to July 12, 2015. m, meter; ${ }^{\circ} \mathrm{C}$, degree Celsius; PSU, practical salinity unit.

Figure 43. Graphs showing turbidity, chlorophyll-a, and fluorescent dissolved organic matter (fDOM) from YSI EXO2 multiparameter sonde data at mooring 1019 (CB02) from April 25 to July 12, 2015. NTU, nephelometric turbidity unit; RFU, relative fluorescence unit; QSU, quinine sulfate unit.

Figure 44. Graphs showing oxygen saturation, $\mathrm{pH}$, and battery power from YSI EXO2 multiparameter sonde data at mooring 1019 (CB02) from April 25 to July 12, 2015. \% sat, percent saturation; pH, pH unit; V, volt......... 56 Figure 45. Graphs showing sensor depth, water temperature, and salinity from YSI EXO2 multiparameter sonde data at mooring 1020 (CB03) from August 13, 2014, to July 12, 2015. m, meter; ${ }^{\circ} \mathrm{C}$, degree Celsius; PSU, practical salinity unit.

Figure 46. Graphs showing turbidity, chlorophyll-a, and fluorescent dissolved organic matter (fDOM) from YSI EXO2 multiparameter sonde data at mooring 1020 (CB03) from August 13, 2014, to July 12, 2015. NTU, nephelometric turbidity unit; RFU, relative fluorescence unit; QSU, quinine sulfate unit.

Figure 47. Graphs showing oxygen saturation, $\mathrm{pH}$, and battery power from YSI EXO2 multiparameter sonde data at mooring 1020 (CB03) from August 13, 2014, to July 12, 2015. \% sat, percent saturation; pH, pH unit; V, volt.

Figure 48. Graphs showing sensor depth, water temperature, and salinity from YSI EXO2 multiparameter sonde data at mooring 1023 (CB06) from August 13, 2014, to July 12, 2015. m, meter; ${ }^{\circ} \mathrm{C}$, degree Celsius; PSU, practical salinity unit.

Figure 49. Graphs showing turbidity, chlorophyll-a, and fluorescent dissolved organic matter (fDOM) from YSI EXO2 multiparameter sonde data at mooring 1023 (CB06) from August 13, 2014, to July 12, 2015. NTU, nephelometric turbidity unit; RFU, relative fluorescence unit; QSU, quinine sulfate unit...... 
Figure 50. Graphs showing oxygen saturation, $\mathrm{pH}$, and battery power from YSI EXO2 multiparameter sonde data at mooring 1023 (CB06) from August 13, 2014, to July 12, 2015. \% sat, percent saturation; pH, pH unit; V, volt.

Figure 51. Graphs showing sensor depth, water temperature, and salinity from YSI EXO2 multiparameter sonde data at mooring 1028 (CB10) from August 14, 2014, to July 12, 2015. m, meter; ${ }^{\circ} \mathrm{C}$, degree Celsius; PSU, practical salinity unit.

Figure 52. Graphs showing turbidity, chlorophyll-a, and fluorescent dissolved organic matter (fDOM) from YSI EXO2 multiparameter sonde data at mooring 1028 (CB10) from August 14, 2014, to July 12, 2015. NTU, nephelometric turbidity unit; RFU, relative fluorescence unit; QSU, quinine sulfate unit.....

Figure 53. Graphs showing oxygen saturation, $\mathrm{pH}$, and battery power from YSI EXO2 multiparameter sonde data at mooring 1028 (CB10) from August 14, 2014, to July 12, 2015. \% sat, percent saturation; pH, pH unit; V, volt.

Figure 54. Graphs showing sensor depth, water temperature, and salinity from YSI EXO2 multiparameter sonde data at mooring 1029 (CB11) from August 13, 2014, to April 21, 2015. m, meter; ${ }^{\circ} \mathrm{C}$, degree Celsius; PSU, practical salinity unit.

Figure 55. Graphs showing turbidity, chlorophyll-a, and fluorescent dissolved organic matter (fDOM) from YSI EXO2 multiparameter sonde data at mooring 1029 (CB11) from August 14, 2014, to April 21, 2015. NTU, nephelometric turbidity unit; RFU, relative fluorescence unit; QSU, quinine sulfate unit......

Figure 56. Graphs showing oxygen saturation, $\mathrm{pH}$, and battery power from YSI EXO2 multiparameter sonde data at mooring 1029 (CB11) from August 13, 2014, to April 21, 2015. \% sat, percent saturation; pH, pH unit; V, volt.

Figure 57. Graphs showing sensor depth, water temperature, and salinity from YSI 6600 multiparameter sonde data at mooring 1018 (CB01) from August 15, 2014, to October 16, 2014. m, meter; ${ }^{\circ} \mathrm{C}$, degree Celsius; ppt, part per thousand.......

Figure 58. Graphs showing turbidity and oxygen saturation from YSI 6600 multiparameter sonde data at mooring 1018 (CB01) from August 15, 2014, to October 16, 2014. NTU, nephelometric turbidity unit; \% sat, percent saturation.

Figure 59. Graphs showing sensor depth, water temperature, and salinity from YSI 6600 multiparameter sonde data at mooring 1027 (CB09) from August 13, 2014, to April 21, 2015. m, meter; ${ }^{\circ} \mathrm{C}$, degree Celsius; ppt, part per thousand.

Figure 60. Graphs showing turbidity, oxygen saturation, and battery voltage from YSI 6600 multiparameter sonde data at mooring 1027 (CB09) from August 13, 2014, to April 21, 2015. NTU, nephelometric turbidity unit; \% sat, percent saturation; $\mathrm{V}$, volt.

Figure 61. Graphs showing sensor depth, water temperature, and salinity from YSI 6600 multiparameter sonde data at mooring 1030 (CB12) from August 14, 2014, to April 21, 2015. m, meter; ${ }^{\circ} \mathrm{C}$, degree Celsius; ppt, part per thousand.

Figure 62. Graphs showing turbidity, oxygen saturation, and battery voltage from YSI 6600 multiparameter sonde data at mooring 1030 (CB12) from August 14, 2014, to April 21, 2015. NTU, nephelometric turbidity unit; \% sat, percent saturation; $\mathrm{V}$, volt.

Figure 63. Graphs showing water temperature and salinity from Sea-Bird SBE 37-SM MicroCAT at mooring 1019 (CB02) from October 21, 2014, to April 20, 2015. ${ }^{\circ} \mathrm{C}$, degree Celsius; PSU, practical salinity unit. .............. 75 Figure 64. Graphs showing water temperature and salinity from Sea-Bird SBE 37-SM MicroCAT at mooring 1020 (CB03) from October 21, 2014, to January 19, 2015. ${ }^{\circ} \mathrm{C}$, degree Celsius; PSU, practical salinity unit.......... 76 Figure 65. Graphs showing water temperature and salinity from Sea-Bird SBE 37-SM MicroCAT at mooring 1028 (CB10) from October 21, 2014, to January 18, 2015. ${ }^{\circ} \mathrm{C}$, degree Celsius; PSU, practical salinity unit.......... 77 Figure 66. Graphs showing turbidity from WET Labs ECO-NTUSB at moorings 1019 (CB02) and 1024 (CB07) from August 13, 2014, to April 21, 2015. NTU, nephelometric turbidity unit..... 
Figure 67. Graphs showing turbidity from WET Labs ECO-NTUSB at moorings 1048 (V1) and 1051 (V4) from April 25 to July 12, 2015. NTU, nephelometric turbidity unit.

Figure 68. Graphs showing upper (top panel) and lower (bottom panel) light (photosynthetically active radiation [PAR]) data from WET Labs ECO-PARSB on shallow water irradiance platform deployments at mooring 1020 (CB03) from August 13, 2014, to July 12, 2015. $\mu \mathrm{E} / \mathrm{m}^{2} / \mathrm{s}$, microeinstein per square meter per second.

Figure 69. Graphs showing upper (top panel) and lower (bottom panel) light (photosynthetically active radiation [PAR]) data from WET Labs ECO-PARSB on shallow water irradiance platform deployments at mooring 1028 (CB10) from August 14, 2014, to July 12, 2015. $\mu \mathrm{E} / \mathrm{m}^{2} / \mathrm{s}$, microeinstein per square meter per second.

Figure 70. Chart showing the availability of seabed altimeter and meteorological data for Chincoteague Bay, Maryland and Virginia, for the Estuarine Physical Response to Storms study from August 2014 to July 2015. alt, Echologger AA400 altimeter; hlm, Hobo U30 weather station; ID, identification number.

Figure 71. Graphs showing seabed elevation data from Echologger AA400 altimeters at moorings 1021 (CB04) and 1022 (CB05) from August 15, 2014, to July 13, 2015. Ice disturbed the altimeter mounting frame at mooring 1021 in February 2015. m, meter.

Figure 72. Graphs showing seabed elevation data from Echologger AA400 altimeters at moorings 1025 (CB07) and 1026 (CB08) from August 14, 2014, to July 13, 2015. Ice disturbed both altimeter mounting frames in February 2015; mooring 1026 was reestablished on April 25, 2015. The offset in altitude from the end of $1026 \mathrm{C}$ data in midFebruary to the beginning of $1026 \mathrm{D}$ data in April 2015 is due to resetting the frame and not any measured change in the seabed. $\mathrm{m}$, meter.

Figure 73. Graphs showing barometric pressure and wind data from Onset Hobo U30 weather station at mooring 1031 (CBWS) from August 16, 2014, to July 14, 2015. mbar, millibar; ${ }^{\circ}$, degree true; $\mathrm{m} / \mathrm{s}$, meter per second. ...... 85 Figure 74. Graphs showing air temperature, relative humidity, solar irradiance, and photosynthetically active radiation (PAR) data from Onset Hobo U30 weather station at mooring 1031 (CBWS) from August 16, 2014, to July $14,2015 .{ }^{\circ} \mathrm{C}$, degree Celsius; $\%$, percent; $\mathrm{W} / \mathrm{m}^{2}$, watt per square meter; $\mu \mathrm{E} / \mathrm{m}^{2} / \mathrm{s}$, microeinstein per square meter per second.

\section{Tables}

Table 1. Sensor deployment and location information for platforms deployed in Chincoteague Bay, Maryland and Virginia, August 2014 to July 2015.

Table 2. Links to processed water flow (current velocity) data, by site and instrument, for platforms deployed in Chincoteague Bay, Maryland and Virginia.

Table 3. Links to processed wave (directional and nondirectional) data, by site and instrument, for platforms deployed in Chincoteague Bay, Maryland and Virginia.

Table 4. Links to processed water-quality data, by site and instrument, for platforms deployed in Chincoteague Bay, Maryland and Virginia.

Table 5. Links to processed seabed elevation data, by site and instrument, for frames deployed in Chincoteague Bay, Maryland and Virginia.

Table 6. Links to meteorological data, by site and instrument, for weather stations deployed on a private dock at Public Landing, Maryland, on Chincoteague Bay. 


\section{Conversion Factors}

\begin{tabular}{|c|c|c|}
\hline Multiply & By & To obtain \\
\hline \multicolumn{3}{|c|}{ Length } \\
\hline centimeter $(\mathrm{cm})$ & 0.3937 & inch (in) \\
\hline millimeter (mm) & 0.03937 & inch (in) \\
\hline meter (m) & 3.281 & foot $(\mathrm{ft})$ \\
\hline kilometer (km) & 0.6214 & mile (mi) \\
\hline kilometer (km) & 0.5400 & mile, nautical (nmi) \\
\hline \multicolumn{3}{|c|}{ Pressure } \\
\hline decibar (dbar) & 1.450 & pound per square inch $\left(\mathrm{lb} / \mathrm{in}^{2}\right)$ \\
\hline millibar (mbar) & 0.02953 & inch of mercury (inHg) \\
\hline
\end{tabular}

Temperature in degrees Celsius $\left({ }^{\circ} \mathrm{C}\right)$ may be converted to degrees Fahrenheit $\left({ }^{\circ} \mathrm{F}\right)$ as ${ }^{\circ} \mathrm{F}=\left(1.8 \times{ }^{\circ} \mathrm{C}\right)+32$.

\section{Datum}

Vertical coordinate information is referenced to the North American Vertical Datum of 1988 (NAVD 88) where noted only; otherwise no datum is used.

Horizontal coordinate information is referenced to the World Geodetic System of 1984 (WGS 84).

\section{Supplemental Information}

Pressure measured underwater is given in decibars (dbar).

Current speed is given in centimeters per second $(\mathrm{cm} / \mathrm{s})$.

Wind speed is given in meters per second $(\mathrm{m} / \mathrm{s})$.

Turbidity is given as nephelometric turbidity units (NTU).

Salinity is given as practical salinity units (PSU) or parts per thousand (ppt).

Photosynthetically active radiation is given in microeinsteins per square meter per second $\left(\mu \mathrm{E} / \mathrm{m}^{2} / \mathrm{s}\right)$.

Chlorophyll-a given as relative fluorescence units (RFU).

Fluorescent dissolved organic matter is given as quinine sulfate units (QSU).

Irradiance is given in watts per square meter $\left(\mathrm{W} / \mathrm{m}^{2}\right)$.

\section{Abbreviations}

ADCP

Chla

CT

EPIC

fDOM

$\mathrm{HR}$

$\mathrm{Hz}$

IMLM

$\mathrm{MHz}$

NetCDF

PAR

SWIP

SSC

THREDDS

USB

UTC acoustic Doppler current profiler

chlorophyll-a

conductivity and temperature

Equatorial Pacific Information Collection

fluorescent dissolved organic matter

high resolution

hertz

Iterative Maximum Likelihood Method

megahertz

Network Common Data Form

photosynthetically active radiation

shallow water irradiance platform

suspended-sediment concentration

thematic real-time distributed data services

universal serial bus

coordinated universal time 


\title{
Summary of Oceanographic and Water-Quality Measurements in Chincoteague Bay, Maryland and Virginia, 2014-15
}

By Steven E. Suttles, ${ }^{1}$ Neil K. Ganju, ${ }^{1}$ Sandra M. Brosnahan, ${ }^{1}$ Ellyn T. Montgomery, ${ }^{1}$ Patrick J. Dickhudt, ${ }^{2}$ Alexis Beudin, ${ }^{1}$ Daniel J. Nowacki, ${ }^{1}$ and Marinna A. Martini ${ }^{1}$

\begin{abstract}
U.S. Geological Survey scientists and technical support staff measured oceanographic, waterquality, seabed-elevation-change, and meteorological parameters in Chincoteague Bay, Maryland and Virginia, during the period of August 13, 2014, to July 14, 2015, as part of the Estuarine Physical Response to Storms project (GS2-2D) supported by the Department of the Interior Hurricane Sandy recovery program. These measurements provide time series data that quantify the response and can be used to better understand the resilience of this back-barrier estuarine system to storms. The Assateague Island National Seashore (National Park Service) and the Chincoteague National Wildlife Refuge (U.S. Fish and Wildlife Service) are on the east side of Chincoteague Bay.
\end{abstract}

\section{Introduction}

Coastal back-barrier estuaries, like Chincoteague Bay, are a prominent feature of the U.S. Atlantic coast that protects coastal communities from storms and provides critical habitat for living resources (Wazniak and others, 2005). To better understand these systems and how they respond to storm events, the U.S. Geological Survey made time series measurements of oceanographic, waterquality, seabed-elevation-change, and meteorological parameters from fixed stations in Chincoteague Bay, Maryland and Virginia, from August 13, 2014, to July 14, 2015, as part of the Estuarine Physical Response to Storms project (GS2-2D) supported by the Department of the Interior Hurricane Sandy recovery program. The parameters measured include profiled water velocity (currents), subsurface water pressure, seabed elevation, and the following water-quality parameters: turbidity, light (photosynthetically active radiation [PAR]), water temperature, salinity, dissolved oxygen, chlorophyll- $a$ (Chla) fluorescence, fluorescent dissolved organic matter (fDOM), and pH. Wave spectra and statistics were calculated from water velocity and subsurface pressure measurements.

Meteorological data were also collected as part of this study at a location on the west side of the middle part of Chincoteague Bay; parameters measured include wind speed and direction, air temperature, barometric pressure, relative humidity, incident PAR, and shortwave solar radiation.

A total of 19 stations were occupied for parts or the entire deployment period and are identified by mooring numbers and site names (table 1). All but three of the stations (moorings 1018, 1029, and

\footnotetext{
${ }^{1}$ U.S. Geological Survey.

${ }^{2}$ U.S. Army Corps of Engineers.
} 
1030) were located in the interior of Chincoteague Bay (see figs. 1-3). Deployments were segmented into 2- to 3-month-long subdeployments, after which instruments were recovered and cleaned, data were downloaded, batteries and antifouling controls were refreshed as necessary, and the instruments were redeployed at or near the same location. Each subdeployment segment is identified by letters A-D. Only a subset of the stations (moorings 1019, 1020, 1022, 1023, 1026, 1028, and 1031) were occupied for the entire study period; moorings 1021, 1024, 1025, 1027, 1029, and 1030 were occupied from August 2014 to April 2015 (segments A-C); moorings 1048-1052 were only occupied from April to July 2015 (segment D). The instrument used at mooring 1018 (CB01) failed at the beginning of the second subdeployment (B), and the station was not reoccupied afterward.

To supplement the data in this report, water samples were collected by using a van Dorn sampler and processed for suspended-sediment concentration (SSC) and loss-on-ignition (LOI) according to U.S. Geological Survey methods (Fishman and Friedman, 1989). The samples were used to calibrate deployed turbidity sensor data to SSC. Results of the laboratory analysis of water samples are available in a data release associated with U.S. Geological Survey Field Activity 2014-048-FA (Suttles and others, 2017).

\section{Instruments}

Autonomous instruments, with internal power and memory, were deployed at 19 sites in Chincoteague Bay, Maryland and Virginia (figs. 1-3), to quantify the response of this back-barrier estuary to periodic storm events. The deployed instruments collected oceanographic, water-quality, seabed-elevation-change, and meteorological data between August 13, 2014, and July 14, 2015. The processed time series data that are reported here are presented in five categories: (1) currents (profiled mean water velocities), (2) waves, (3) water-quality, (4) seabed elevation, and (5) meteorological observations. Stations measuring currents, waves, and water-quality parameters typically used lowprofile, bottom-landing deployment platforms (figs. 4-7) constructed of fiberglass grates with aluminum square tubing and channels for instrument mounts. Acoustic altimeters for measuring seabed elevation were mounted by using aluminum $\mathrm{H}$-shaped frames that were driven into the seabed for stability (fig. 8). The weather station was mounted on a mast that was attached to a pier piling on a private dock (fig. 9). Station 1018 had only a water-quality instrument and was deployed attached to an existing pier piling at a defunct Coast Guard station by means of an aluminum channel with an attached instrument mounting bracket (fig. 10).

The following instruments, with measured parameters shown, were used to collect time series data in this study:

- Nortek 1-megahertz (MHz) Aquadopp high-resolution (HR) acoustic Doppler current profiler (ADCP): currents

- Nortek 1-MHz Aquadopp ADCP: currents, waves (directional)

- Nortek 2-MHz Aquadopp ADCP: currents, waves (directional)

- $\quad$ RBR D|wave pressure logger: waves (nondirectional)

- YSI EXO2 multiparameter sonde (wiped): water quality (temperature, salinity, turbidity, dissolved oxygen, fDOM, Chla, and $\mathrm{pH}$ )

- YSI 6600 multiparameter sonde (wiped): water quality (temperature, salinity, turbidity, and dissolved oxygen)

- WET Labs ECO-NTUSB sensor (wiped): water quality (turbidity)

- WET Labs ECO-PARSB sensor (wiped): water quality (light [PAR])

- EofE Ultrasonics Echologger AA400 altimeter: seabed elevation (altitude) 
- Onset Hobo U30 weather station: meteorological (winds, barometric pressure, air temperature, relative humidity, light [PAR], and shortwave solar radiation)

- Sea-Bird SBE 37-SM MicroCAT conductivity and temperature (CT) sensor: water quality (temperature and salinity)

Tables 2-6 provide information on instruments used at each site, elevation above the seabed, and available processed results. All instruments recorded data every 15 minutes, with the exception of wave burst data from the Aquadopp ADCPs and the RBR D|wave pressure loggers, which were collected at 30-minute intervals.

\section{Currents and Waves}

The standard Aquadopp ADCP can be configured to measure current profiles at 15-minute intervals and collect bursts of velocity and pressure data at 30-minute intervals for directional wave analysis. Wave burst data of three radial beam velocities from a single bin and pressure at a 2-hertz $(\mathrm{Hz})$ sampling rate for 1,024 samples per burst were collected at locations where directional wave statistics were desired. The 2-MHz Aquadopps were used at the shallower sites (less than 2 meters [m]) because they can sample smaller velocity bin sizes, $0.20 \mathrm{~m}$ for current profiles and $0.50 \mathrm{~m}$ for wave bursts, with predicted accuracy equivalent to that of the standard 1-MHz Aquadopps using $0.40 \mathrm{~m}$ and $1.0 \mathrm{~m}$ bins for currents and wave bursts, respectively. The Aquadopp HR ADCP (pulse coherent) used at mooring 1020 (CB03) allows profiles of velocity data to be collected in much smaller bins $(0.03 \mathrm{~m}$ typically) and at greater accuracy than the standard (non-pulse coherent) version of the Aquadopp, but with the tradeoff that the Aquadopp HR cannot provide usable profile velocities in the upper part of the water column because of surface interference with the acoustic signal. The RBR D|wave pressure loggers were sampled in wave burst mode, in which 4,096 samples of 6-Hz data were collected at 30-minute intervals. The pressure burst data from the $\mathrm{D} \mid$ waves were used to calculate nondirectional wave statistics and power spectra.

\section{Water Quality}

Five instrument types were used to collect water-quality data, including the physical properties of water conductivity and temperature (CT), which are used to calculate salinity. The instruments used were the YSI EXO2 multiparameter sonde, YSI 6600 multiparameter sonde, WET Labs ECO-NTUSB, WET Labs ECO-PARSB, and Sea-Bird SBE 37-SM MicroCAT. The parameters measured by each instrument are listed previously (see bulleted part of this section). The SBE 37-SM was used to provide CT data where either an EXO2 CT sensor had failed or a site was missing these data where they were deemed important. The WET Labs ECO-PARSB instruments were used on the shallow water irradiance platforms (SWIPs) that, in addition to measuring currents, waves, and multiparameter water-quality data with an EXO2 sonde, utilize two PAR sensors with approximately 0.30 meters vertical separation to determine light attenuation in the water column (fig. 4). The WET Labs ECO-NTUSB sensors were used on platforms where no multiparameter sonde was available so that water column sediment concentrations and ultimately sediment fluxes could be quantified. Both the ECO-NTUSB and ECO-PARSB burst-sampled at $1 \mathrm{~Hz}$ for 10 seconds, every 15 minutes.

\section{Seabed Elevation and Meteorological Observations}

Echologger AA400 altimeters were used to measure vertical changes of the seabed. The AA400 uses a 450-kilohertz acoustic frequency to detect the distance to the seabed and was programmed to burst-sample at $1 \mathrm{~Hz}$ for 10 seconds, every 15 minutes, in the same manner as the ECO instruments. The 
instruments were securely mounted to an aluminum H-Frame (fig. 8), nominally 0.5 meter above the seabed. The manufacturer uses a fixed speed of sound of 1,500 meters per second $(\mathrm{m} / \mathrm{s})$ to calculate distance to the seabed.

An Onset Hobo U30 weather station (fig. 9) provided local meteorological conditions during the study period (see previous bulleted list for measured parameters). The Hobo U30 is equipped with a solar panel and rechargeable battery such that changing batteries is not routinely required at servicing turnarounds between deployment segments. For additional information on all instruments used, please consult the manufacturers' Web sites.

\section{Antifouling}

Antifouling controls were an important consideration because of the long deployments, high biological productivity, and episodic events of high suspended-sediment concentrations (SSC). The instruments most susceptible to fouling were the optical instruments such as the turbidity, light, dissolved oxygen, Chla, and fDOM sensors. The YSI (EXO2, 6600) and ECO (NTU, PAR) instruments were equipped with wipers that mechanically cleaned these sensors before every sampling interval. In addition, the body of each sensor on the YSI sondes was covered with copper tape, and fitted with a sensor chamber guard made of copper alloy wrapped with copper mesh (6-mm opening) to minimize biological fouling around the sampling volume. Each ECO had a copper face plate on the end with the optical sensor for this purpose. Instruments with acoustic transducers (Aquadopps and altimeters) were coated with a smooth layer of zinc oxide containing paste to minimize biological growth. Topside, the Hobo U30 weather station had a bird deterrent (metal spikes) integrated into the crossbar holding the wind speed and direction sensors.

\section{Site Description}

Chincoteague Bay is a shallow back-barrier estuary on the Atlantic coast of Maryland and Virginia (fig. 1). The primary axis of the estuary spans about 60 kilometers (km) from Ocean City Inlet in the northeast to Chincoteague Inlet in the southwest; it is bounded to the east by Assateague Island and to the west by the Virginia and Maryland mainland; the maximum width of the middle of the estuary is $8 \mathrm{~km}$. Mean depth is about $1.6 \mathrm{~m}$, and typical channel depths within the estuary are about $3 \mathrm{~m}$. The eastern, back-barrier side of the bay is characterized by numerous shoals and seagrass meadows, whereas the western side is deeper with no noticeable shoals or prominent seagrass meadows (Ganju and others, 2016). The sediments on the eastern side of the bay are predominately composed of sand (60-100 percent), and on the western side, especially in the interior channel, the sediments are dominated by fine-grained muds (silts and clays) with sand composition ranging from 3 to 33 percent (Wells and others, 1997). The entire bay is fringed in most areas by salt marsh, and the west side of the bay has some shoreline hardening. Tides are predominantly semidiurnal, with a range of approximately 1 meter near the inlets, but decrease rapidly moving into Chincoteague Bay, where low-frequency forcing dominates. There are no major freshwater river inputs, and the lowest salinities are in the northwest part of the bay where freshwater discharge from creeks is highest. Atmospheric forcing is characterized by episodic frontal passages in winter, which bring strong northeast winds; summer and fall are characterized by gentler southwest winds (Pritchard, 1960; Ganju and others, 2016). The region is sometimes affected by tropical systems in the late summer and fall, and although these storms are rare, their effects can be substantial (Orth and others, 2002).

Study sites for oceanographic and water-quality measurements were selected on the basis of multiple considerations: geomorphic type (shoal or channel), benthic substrate (vegetated or 
unvegetated), and location within the system (seaward or landward). Acoustic altimeters used to measure seabed elevation were deployed on shoals with large exposure to waves, sparse seagrass coverage, and bathymetric gradients suitable for two contrasting sites. The meteorological station was centrally located within Chincoteague Bay, had direct exposure to the shoreline and prevailing winds, and was mounted on an existing structure. Table 1 shows a complete list of the study sites, platform types, locations, and deployment time periods; tables 2-6 give a complete list of all available processed data for each instrument deployment.

\section{Shoal/Channel Paired Interior Sites-Moorings 1019, 1020, 1023, 1024, 1027, and 1028}

Three shoal/channel pairs of bottom platforms were deployed in the interior of Chincoteague Bay (1019-1020; 1023-1024; 1027-1028) to measure currents, waves, and water-quality parameters and to compare how they respond to storm events. SWIPs (fig. 4) were deployed at two of the shoal sites, moorings 1020 and 1028, which included two ECO-PARSB light sensors, either a 2-MHz Aquadopp profiler or 1-MHz Aquadopp HR profiler (1020), an EXO2 multiparameter water-quality sonde, and an RBR D|wave pressure logger. Mooring 1020 (CB03) was on the southeastern corner of a large shoal in the southeastern corner of Chincoteague Bay (figs. 1 and 2) and within a large, dense seagrass meadow. At mooring 1024 (CB07), a 2-MHz Aquadopp profiler measuring currents and directional waves was paired with an ECO-NTUSB turbidity sensor and an RBR D|wave pressure logger. Moorings 1024 and 1028 were both on shoals where seagrass was present, but at the time of this study coverage was considerably less dense than was observed at mooring 1020. Shoal sites 1020 and 1028 were occupied for the entire study period, August 2014 to July 2015, whereas mooring 1024 was occupied for the first three subdeployments (A-C) covering the period August 2014 to April 2015.

The three channel sites $(1019,1023$, and 1027) in the interior of Chincoteague Bay were west of a corresponding shoal site in the 2- to 3-m-deep muddy channel. At each channel site, a 1-MHz Aquadopp profiler measuring currents and directional waves was deployed. Turbidity was measured at all three of these channel sites for all deployments along with various other water-quality parameters that varied between sites and deployments; see tables 1-4 for a complete list of instruments and available data for each site. Moorings 1019 and 1023 were occupied for the entire study period, and mooring 1027 was occupied during the August 2014 to April 2015 period (A-C subdeployments).

\section{Special Interest Oceanographic and Water-Quality Sites-1018, 1029, and 1030}

Toms Cove (figs. 1 and 2) is as an area of special interest because of its location within the Chincoteague National Wildlife Refuge and is prone to overwash from the ocean during strong storms. Mooring 1018 (CB01) was located on a defunct Coast Guard station pier piling (fig. 10) in a small embayment east of Chincoteague Inlet at the end of Assateague Island on the Virginia coast. A YSI 6600 sonde was deployed at the Toms Cove site for the August 2014 to January 2015 period (A and B), but because of instrument failure the sonde had to be abandoned for the remainder of the study.

Newport Bay (figs. 1 and 3) in the northwest corner of Chincoteague Bay is also of special interest because it is more affected by watershed inputs of nutrients than the rest of Chincoteague Bay (Wazniak and others, 2007). A 2-MHz Aquadopp profiler, an EXO2 multiparameter sonde, and an RBR $\mathrm{D} \mid$ wave pressure logger were deployed at mooring 1029 in Newport Bay for the August 2014 to April 2015 (A-C) period of this study.

Mooring 1030 (CB12) was located in the Sinepuxent Bay (figs. 1 and 3) channel that connects Chincoteague Bay to Ocean City Inlet and the Maryland coastal bays to the north. This location is prone to overwash from the ocean during storms, and the bottom sediments are composed almost entirely of 
sand. A 2-MHz Aquadopp profiler measured currents and a YSI 6600 sonde measured water-quality parameters at this site for the August 2014 to April 2015 (A-C) period.

\section{Vegetation Transect Sites-1048-1052}

During the last subdeployment (D), April-July 2015, a special study focused on the hydrodynamic effects of an emerging vegetated seagrass bottom was also conducted by occupying a transect starting just outside the southern edge of the large seagrass meadow in the vicinity of mooring 1020 (CB03) and moving northeastward into its interior with a total of five stations (10481052). At station 1048 (V1), a 2-MHz Aquadopp profiler measured currents and directional waves and an ECO-NTUSB sensor measured turbidity. Burst wave data were collected at stations 1049-1052 (V2-V5) by using RBR D|wave pressure loggers, and at mooring 1051 turbidity was also measured.

\section{Seabed Elevation Sites-1021, 1022, 1025, and 1026}

Two shoals were selected to deploy pairs of seabed altimeters (EofE Ultrasonics Echologger AA400) for the purpose of measuring seabed elevation change during storm events.

Moorings 1021 (CB04) and 1022 (CB05) were on the northeast margin of the large shoal on the eastern side of the Virginia part of Chincoteague Bay near Ragged Point (not shown). This location has a relatively long fetch for northwest to northeast wind conditions. The sites are only $0.25 \mathrm{~km}$ apart because of the rapid change in bathymetry across the edge of this shoal. Mooring 1022 was occupied for the entire deployment period (August 2014 to July 2015), and 1021 was occupied just for the August 2014 to April 2015 period (A-C). The H-frame mount at mooring 1021 was disturbed by ice in February 2015.

Altimeter moorings 1025 (CB07) and 1026 (CB08) were deployed on a shoal near Pirate Island (not shown) in the Maryland part of Chincoteague Bay with exposure to north to northeast and southsouthwest to southwest wind directions. These sites were approximately $1 \mathrm{~km}$ apart and aligned in a north-south direction across the shoal. Both sites were affected by ice in February 2015. Mooring 1026 (CB08) was reestablished in April 2015, whereas mooring 1025 was not. See tables 1 and 5 for additional information on altimeter deployments and available data.

\section{Meteorological Station Site-1031}

An Onset Hobo U30 weather station was deployed on a private dock at Public Landing, Maryland (figs. 1 and 3) on the western shoreline of Chincoteague Bay and adjacent to the widest section of open water in the bay. The mast of the weather station was secured to a dock piling on the outer part of the dock adjacent to a Maryland Department of Natural Resources water-quality monitoring station. This location is exposed to unobstructed fetch for wind directions between northnortheast to south-southwest, going clockwise. The wind speed and direction sensors were approximately $3.8 \mathrm{~m}$ above the water surface when the station was initially deployed on August 16, 2014, at 20:00 coordinated universal time (UTC). This site, mooring 1031 (CBWS), was occupied from August 16, 2014, until the end of the field study in July 2015. See tables 1 and 6 for additional information.

\section{Data Processing}

The data from all instruments were stored internally. After each recovery, the manufacturers' software was used to download the data, apply calibration coefficients, and convert the data to scientific units. These output files were then converted by custom, instrument-specific Matlab programs to 
Equatorial Pacific Information Collection (EPIC) convention-compliant Network Common Data Form (NetCDF) files for distribution on the U.S. Geological Survey Oceanographic Time-Series Data Collection Web site. Files listed in this report are linked to their locations on the distribution site. Additional information on data processing, quality assurance and control protocols, file formats, nomenclature, and access methods used is provided in Montgomery and others (2016).

All subsurface pressure data (data from Aquadopps, D|waves, EXOs, and YSI 6600s) were corrected for changes in atmospheric pressure by using local barometric pressure data, from the meteorological station at mooring 1031 when available, to give a more accurate representation of pressure caused by the overlying water. This corrected pressure record was saved in the EPIC NetCDF files with the variable name "P_1ac."

Estimates of directional wave energy spectra (dspec) were calculated by using atmospherically corrected pressure and three radial beam velocities from an Aquadopp profiler as input into a modified version of the DIWASP V1.1GD (Johnson, 2002; Dusek, 2011) wave analysis toolbox for Matlab. The Iterative Maximum Likelihood Method (IMLM) (Pawka, 1983) was selected in DIWASP to estimate the directional distribution of wave energy. At selected sites, Aquadopp profilers ( $1 \mathrm{or} 2 \mathrm{MHz}$ ) were used to collect wave burst data of 1,024 samples of pressure and radial beam velocities at a $2-\mathrm{Hz}$ sampling rate with a burst interval of 30 minutes, in addition to the current profiles. Bin sizes for burst velocity data for 1-MHz and 2-MHz Aquadopps were $1 \mathrm{~m}$ and $0.5 \mathrm{~m}$, respectively, centered at distances of $1.37 \mathrm{~m}$ and $0.64 \mathrm{~m}$, respectively, from the instruments' transducers. Mean current interaction was accounted for by Doppler-shifting the wave numbers, following the methods of Jones and Monismith (2007), and a cutoff was set by the pressure transfer function from linear wave theory $\left[K_{p}(z)<0.1\right]$ to remove high-frequency amplified noise from the surface-transformed spectra. The spectral tail past the cutoff to $1 \mathrm{~Hz}$ was generated by using $f^{4}$, per Jones and Monismith (2007), where $f$ is the wave frequency (hertz). The atmospherically corrected subsurface pressure was the first term input to DIWASP, which forces the 1-d frequency spectrum to be scaled by this term alone. All input terms were then used to distribute the energy from 1-d spectrum for each frequency across all directions by using IMLM. The following wave statistics were calculated from dspec:

1. significant wave height (wh_4061)

2. peak period (wp_peak)

3. mean period (wp_4060) from second moment of the power spectra

4. mean wave direction (wd_4062) (Kuik and others, 1988)

5. direction of the peak wave period (wvdir)

6. dominant direction of wave energy (dwvdir) from DIWASP, defined as the direction with the most total energy summed over all frequencies

Nondirectional wave energy spectra (pspec) were estimated from the RBR D|wave corrected pressure signal by using a similar approach to that used for the DIWASP-derived directional spectra, except that no directional estimator was used, and mean current interaction was not considered. Nondirectional wave statistics calculated from pspec were limited to items 1-3 from the list of wave statistics for directional processing output.

Quality control and quality assurance checks were performed on all the data. Data that did not pass the quality control and quality assurance process were replaced with fill values in the NetCDF output file. Fill values indicate a nonvalid data point and are assigned a value of $1 \times 10^{35}$ for floating point variables and -32,768 for integer variables. Obvious spikes in individual parameter time series were removed by using either a recursive filter or median filter technique, in which values that changed from one time point to the next by more than a set threshold were flagged and assigned a fill value. Velocity data from the Aquadopp HR (pulse coherent) were checked for low correlation values. For 
standard Aquadopps, velocity bins that were too close to or above the water surface were likewise assigned fill values. Special attention was given to the velocity data during the period of surface ice in Chincoteague Bay, mid-February to early March 2015, to identify questionable velocity data caused by the effect of the ice on the acoustic signal. Altimeter data were checked for onset of disturbance to the altimeter's mounting frame by surface ice, and data were filled for the remainder of that deployment when a disturbance was seen. WET Labs ECO-NTUSB and PARSB instruments were checked to verify counts were above their "dark" count (low-count) thresholds; for the PARSB instruments this meant that legitimate "dark" data collected during nighttime were also discarded.

When possible and if necessary, linear corrections were applied to conductivity (salinity) and $\mathrm{pH}$ sensor data (EXO2, YSI 6600, and SBE 37-SM MicroCATs) when apparent fouling occurred over the course of a deployment that affected the readings. Corrections were obtained from either postdeployment calibration checks or differences between in situ values from a fouled sensor and from a cleaned, calibrated sensor at the beginning of the next deployment. If data were obviously fouled and corrections were not possible, the data were replaced with fill values. Checks at the end of each deployment were made for instrument clock drift, and if the clock drifted more than 1 minute over the deployment, a linear correction was applied to the time variable.

\section{Results}

Time series data quantifying currents, waves, water quality, seabed elevation change, and meteorological conditions were collected in Chincoteague Bay, Maryland and Virginia, between August 13, 2014, and July 14, 2015, for the purpose of estimating how this back-barrier estuary responds to periodic storm events (tables 2-6). Fixed, moored deployments were made with turnaround intervals of 2 to 3 months; some sites had four separate deployments and spanned the entire study period, whereas other sites were occupied for only a subset of the study period (table 1). Despite biological and sediment-induced fouling, as well as ice disturbance, the overall data return of usable data exceeded 80 percent. The primary reason for the loss of data was instrument/sensor failures, most notably two ECO-PARSBs on the first deployment and a manufacturing problem with the CT sensors for the EXO2s discovered during this study. Another significant data loss was due to fouling of the CT sensors, especially on the EXO2s and YSI 6600s, due to inadequate wiper performance. The optical sensors (turbidity, dissolved oxygen, fDOM, Chla/total algae) performed well on the EXO2s and YSI 6600s, despite extreme fouling conditions at times on the surrounding deployment platforms (figs. 11 and 12). During the August-October 2014 deployment of the seabed altimeters, there was heavy barnacle fouling on the aluminum $\mathrm{H}$-frame mounts and the instrument housings (fig. 13); however, the zinc-oxide paste effectively prevented the barnacles from attaching to the transducer face, and the instrument collected valid data throughout the deployment. Three of the four seabed altimeters were affected by ice in mid-February 2015 and only collected a few weeks of usable data for the January-April 2015 deployment (C) before being disturbed. The water velocity data from the Aquadopps and pressure data from the Aquadopps and D|waves were mostly not affected by fouling. The only exception was pressure data from one Aquadopp (serial number 11507) that exhibited drift and required a correction using pressure data from another pressure logging instrument on the same platform. Figures 14-16 show examples of light to moderate fouling on instruments and mounting platforms at time of recovery. Plots of the data availability and time series data are presented in figures 17-74. Results from each data category are reviewed in the following subsections.

The landing page for these data (Suttles and others, 2016) contains details of all field activities associated with this project, Google Earth visualizations of deployment locations, and sampling interval information. The edited, final data can be downloaded from the catalog of data Web page or accessed 
directly at the "Data access via THREDDS" link on the landing page. File naming conventions for time series observations are described in appendix 1 of Montgomery and others (2016).

\section{Currents}

There were no significant instrument problems with the Aquadopp ADCPs during the study, and these instruments provided a nearly complete record of current velocities for all deployments. Table 2 lists all current velocity results with links to the locations of the processed NetCDF output files. The only location where there were significant loses of current velocity measurements was at mooring 1024 (CB07), where there were low-water elevation events in January 2015 and during the time of surface ice in mid-February 2015. As previously mentioned, the Aquadopp (serial number 11507) used for the three deployments at mooring 1024 and the last deployment at mooring 1028 (CB10) did show drift in the pressure data as compared to the other pressure sensors on the same platform. Accordingly, a correction offset was applied to the pressure data for each current profile and each wave burst by using co-located pressure data from either an RBR D|wave or an EXO2 as the reference. Figure 17 shows the availability of current velocity data when there was at least one valid water column velocity measurement.

Figures 18-26 are time series plots of pressure (corrected), current speed, and current direction from a single depth bin of the entire time series from each site where an Aquadopp ADCP was deployed. The intent of these plots is to give a broad overview of the data record and the range and general pattern of the measured parameters. Plots of the Aquadopp mean pressure and current velocity data show tidal cycle ranges and event changes in water level, typical range of current speeds, and principal axis direction. The pressure sensor on the Aquadopps is not compensated for temperature, and this fact needs to be considered when the pressure data are used. The Aquadopp HR at mooring 1020 (CB03) consistently produced a band of low-correlation data that tracked with changes in water level; however, because 3-cm (5-cm for deployment D) bin sizes were used for the Aquadopp HR, losing 2 or 3 bins in the profile did not affect the estimation of depth-averaged currents. Table 1-1 in appendix 1 provides links to burst pressure and current data for the Aquadopp HR deployed at mooring 1020 (A-D) used to calculate profiled currents at 1020.

\section{Waves}

Spectra and statistics for directional waves from Aquadopps and nondirectional waves from $\mathrm{D} \mid$ wave pressure loggers were calculated, and based on the availability of estimates of significant wave height, data recovery was 100 percent, as shown in figure 27. Table 3 contains a complete listing, with links, of the processed results of wave measurements, and figures 28-40 show time series of significant wave height, peak period, and mean wave direction (Aquadopps only) for all processed wave data. When wave energy was low, and significant wave heights small $(<0.02 \mathrm{~m})$, it was often not possible to get meaningful estimates of peak wave period and wave direction. As a result, peak period and direction estimates were often set to the fill value in the processed NetCDF result files during times of low wave energy. The primary interest in the wave results is storm events when wave energy is relatively high and significant wave heights are larger than average. In the plots with direction estimates, mean direction was plotted only when significant wave heights exceeded $0.10 \mathrm{~m}$ to make wave propagation directions clearer. Maximum significant wave height estimated by using data from all of the sites for the entire study period was approximately $0.8 \mathrm{~m}$, and the maximum estimated peak period was approximately 3 seconds. For the six channel/shoal paired sites, the significant wave heights during storm events were generally larger in the three channel sites (1019, 1023, and 1027), often exceeding $0.5 \mathrm{~m}$, whereas at the three shoal sites $(1020,1024$, and 1028) wave heights only occasionally reached $0.5 \mathrm{~m}$. The period of suspected ice coverage in Chincoteague Bay is apparent in the significant wave height data, which 
indicate a prolonged period of near-zero significant wave height at most of the sites between midFebruary 2015 and early March 2015. Figure 40 shows the processed wave results along the transect into the vegetated seagrass bed (moorings 1049-1052) from April to July 2015, from data collected with the RBR D|waves, and shows that wave heights are often larger at the edge of the seagrass bed (1049) than at the more interior sites (1050-1052). The pressure data from the $\mathrm{D} \mid$ wave pressure loggers were not temperature compensated, so the depth calculations derived from the corrected pressure data can be a source of error in the calculations of wave spectra and statistics. Table 1-1 in appendix 1 provides links to burst pressure (Aquadopps and D|waves) and radial beam velocity (Aquadopps only) data used to calculate the wave spectra and statistical results contained in table 3.

\section{Water Quality}

Processed water-quality data for this study include salinity, temperature, turbidity, photosynthetically active radiation (PAR), dissolved oxygen, Chla fluorescence, fDOM, and pH. Five different instruments were used to collect water-quality data: (1) YSI EXO2 sonde, (2) YSI 6600, (3) WET Labs ECO-NTUSB, (4) WET Labs ECO-PARSB, and (5) Sea-Bird SBE 37-SM MicroCAT. Table 4 contains a complete list of water-quality instrument deployments and output files of processed results; figure 41 shows available data from each of the water-quality deployments for this study. Overall usable data recovery was approximately 80 percent, despite the failure of two ECO-PARSB sensors on a deployment, problems with CT sensors failing on EXO2 instruments, and conductivity sensor fouling problems on YSI 6600 and EXO2 instruments.

Figures 42-56 show time series plots of data from the EXO2 sondes for moorings 1019D, 1020, 1023, 1028, and 1029. The optical sensor data (turbidity, dissolved oxygen, fDOM, and Chla) provided mostly complete, usable records, except for 1029B, where the sonde ran out of power halfway through the deployment. Elevated values of turbidity, usually associated with storms, reached the highest values at moorings 1023 (fig. 49) and 1019D (fig. 43), both in the channel. Turbidity values dropped to near zero at times of ice coverage (mid-February to early March 2015); ice seems to have been more persistent at the northern sites (1028 and 1029). Time series of dissolved oxygen saturation at moorings 1020 and 1028 show a pronounced seasonal response of the diel range; the range was amplified and reached higher values during the late spring to late fall. Mooring 1029 (CB11—Newport Bay) had higher fDOM signal (fig. 55) than the other three sites.

YSI 6600 sondes were used at moorings 1018, 1027, and 1030 to collect water-quality measurements of salinity, temperature, turbidity, and dissolved oxygen for this study. The corrected pressure from the sonde was also used to estimate water depth at each time point. Figures 57 and 58 show the time series plots from the 1018A (August-October 2014) deployment at the Toms Cove site; these are the only data available for this site because the instrument failed at the beginning of the second deployment on October 21, 2014. Maximum tidal amplitude is approximately $1 \mathrm{~m}$ at mooring 1018, which is the highest of all sites for this study, and maximum turbidity during storm events is typically less than at other sites. Figures 59 and 60 show the time series data for the YSI 6600 deployments at mooring 1027, in the interior of Chincoteague Bay where the semidiurnal tidal amplitude is approximately $0.25 \mathrm{~m}$ or less (shown in the depth time series). The turbidity record here shows a strong response to storm events, with maximum values exceeding $400 \mathrm{NTU}$ at times, which is similar to the records for the other exposed channel sites, 1023 and 1019. The usable temperature, salinity, and dissolved oxygen records were truncated for 1027B because of temperature sensor failure about two weeks into the deployment. Figures 61 and 62 show time series plots from YSI 6600 deployments at mooring 1030 in the Sinepuxent Bay channel at the north end of Chincoteague Bay. Other than needing to truncate the usable turbidity record at about the halfway point on the first deployment (1030A), the 
record is complete. At times the turbidity signal approached 400 NTU at 1030, similar to exposed channel sites in the interior of Chincoteague Bay, but fewer turbidity events of this magnitude were observed at 1030 than at moorings 1023 and 1027. During the last deployment (1030C), the platform was deployed in a deeper location, as is evident in the depth time series.

Sea-Bird SBE 37-SM MicroCAT instruments, measuring CT, were used for deployments 1019 (B and C), 1020B, and 1028B to provide temperature and salinity data where either a CT sensor on an EXO2 sonde had failed or the measurement was missing and deemed important. Figures 63-65 show the time series of water temperature and salinity from the MicroCAT deployments. These MicroCAT data can be compiled with the EXO2 data at these three sites for a more complete record of salinity and temperature.

Figures 66 and 67 show the usable time series data recovered from the WET Labs ECO-NTUSB deployments at moorings 1019 (A-C), 1024, 1048, and 1051. Deployments 1019A, 1024B, 1048, and 1051 provided nearly complete records of usable data. Deployments 1019C and 1024C provided usable data for about half of the 3-month deployment from late January to late April 2015. No usable data were recovered for deployment 1019B, and only one week of usable data for 1024A. Comparing the 1019C and 1024C turbidity time series shows a similar storm response between these two sites, up until the period when ice cover apparently shut down any response at site 1024 until early March, when site 1024 showed a large signal not seen at 1019. Mooring 1048 (edge of seagrass bed) and 1051 (interior of seagrass bed/shoal) showed a similar turbidity response during the April 26-July 12, 2015, deployment, with maximum values just over 100 NTU. The most notable difference between these sites occurred on June 21-22, when the peak turbidity signal was much higher at mooring 1048 than at 1051 .

Moorings 1020 and 1028 were selected for SWIP (fig. 4) deployments, which include two WET Labs PARSB sensors spaced $0.30 \mathrm{~m}$ apart (vertically) to quantify light attenuation through the water column. Figures 68 and 69 show the usable data for the upper and lower PAR sensors at the two SWIP sites. At 1020, deployments A and D have long usable records of both upper and lower sensors, allowing a proper estimation of light attenuation for those periods. There was a short segment in the beginning of the 1020C deployment where both PAR sensors were providing usable data, before the lower PAR data became questionable and was replaced with fill values for the remainder of 1020C deployment. Both upper and lower sensors provided only a couple of days of usable data for the 1020B deployment. At 1028, both PAR sensors failed at the start of 1028A deployment, and no data were recovered for that deployment. Only an upper PAR sensor was deployed for 1028B, which provided a full data record. Usable data are available for both PARs for the first three weeks of 1028C deployment before the upper sensor had a problem, while the lower PAR continued to provide useful data until the end of the deployment. Both PAR sensors provided a full data record for the last deployment at this site (1028D). The established practice has been to replace light data less than or equal to the low-count (or “dark") threshold for each PAR sensor with the fill value; this sometimes causes the nighttime data, when there is little to no light, to be replaced with the fill value.

\section{Seabed Elevation}

Pairs of Echologger AA400 altimeters were used to collect data to quantify event-scale and seasonal elevation changes to the seabed of two shoal areas on the eastern side of Chincoteague Bay. Table 5 lists the instrument deployments and processed output results files with download links. Figure 70 shows the data recovery from the four altimeter deployment sites (moorings 1021, 1022, 1025, and 1026). During the third deployment (C), in mid-February 2015, suspected ice in Chincoteague Bay disturbed three of the four altimeter mounting frames (1021, 1025, and 1026), making the remainder of the data at the three sites unusable for that deployment. The altimeter frame at 
1026 was reestablished in the same area in April 2015 for the final deployment, while sites 1021 and 1025 were not reoccupied. Occasionally, usable data were unavailable for short periods, possibly because of active storm conditions or the presence of obstructions like macroalgae, but these did not hinder measurements of event-scale and seasonal response of the seabed. Figures 71 and 72 show the paired usable results from the altimeters. The plotted parameter in the plots is the "brange" variable in the output NetCDF files (table 5). To verify that the altimeter mounting frames were not moving, personnel from Assateague Island National Seashore collected real-time kinematic Global Positioning System readings on the frames 1 month apart to confirm that the frames did not move over that period. The Echologger AA400 altimeters use a fixed speed of sound of 1,500 m/s, so changes of in situ speed of sound from this value need to be accounted for when these altimeter data are interpreted.

\section{Meteorological}

The Onset Hobo U30 weather station, deployed on a private dock on the western side of Chincoteague Bay at Public Landing, Maryland (mooring 1031), provided a nearly complete, usable data record for the continuous period from August 16, 2014, to July 14, 2015 (fig. 70). Parameters measured were barometric pressure, wind speed and direction, air temperature, relative humidity, shortwave solar radiation (irradiance), and incident PAR (figs. 73 and 74). The ability to recharge its battery using a solar panel and the incremental offloading ability via a universal serial bus (USB) shuttle allowed the U30 to collect data without interruption, although the processed data were sectioned according to when the incremental download took place during each site visit for congruence with the other deployments. The maximum reading of the wind direction sensor is 355.2 degrees, and because a resolution of 1.4 degrees was used, this created a gap in measureable wind directions between 355 and 360 degrees (magnetic). Raw wind direction data were recorded in reference to magnetic north and then rotated to true direction in the postprocessing step(s). Barometric pressure data from 1031 were used to correct subsurface pressure data from other instruments used in this study. Wind speed and gust records from mooring 1031 show the presence of several moderate wind/storm events during the study. It should be noted that because of the weather station's proximity to land with structures and wooded areas, it probably underrepresented the wind conditions in the open waters of Chincoteague Bay, especially when the wind was blowing offshore at the site (clockwise from south-southwest to northnortheast).

\section{References Cited}

Dusek, G.P., 2011, Daily to yearly variations in rip current activity over kilometer scales: Chapel Hill, N.C., University of North Carolina at Chapel Hill, Ph.D. dissertation, 200 p. [Also available at https://cdr.lib.unc.edu/record/uuid:599b8523-27ec-4fd9-ac43-778c1152a836.]

Fishman, M.J., and Friedman, L.C., eds., 1989, Methods for determination of inorganic substances in water and fluvial sediments: U.S. Geological Survey Techniques of Water-Resources Investigations, book 5, chap. A1, 560 p. [Also available at https://pubs.er.usgs.gov/publication/twri05A1.]

Ganju, N.K., Suttles, S.E., Beudin, Alexis, Nowacki, D.J., Miselis, J.L., and Andrews, B.D., 2017, Quantification of storm-induced bathymetric change in a back-barrier estuary: Estuaries and Coasts, v. 40, no. 1, p. 22-36. [Also available at https://doi.org/10.1007/s12237-016-0138-5.]

Johnson, David, 2002, DIWASP, a directional wave spectra toolbox for MATLAB®—User manual (ver. 1.1): Centre for Water Research, University of Western Australia Research Report WP-1601DJ, 18 p. [Also available at https://github.com/metocean/diwasp/blob/master/DIWASP_manual.pdf.] 
Jones, N.L., and Monismith, S.G., 2007, Measuring short-period wind waves in a tidally forced environment with a subsurface pressure gauge: Limnology and Oceanography Methods, v. 5, no. 10, p. 317-327. [Also available at https://doi.org/10.4319/lom.2007.5.317.]

Kuik, A.J., van Vledder, G.Ph., and Holthuijsen, L.H., 1988, A method for the routine analysis of pitchand-roll buoy wave data: Journal of Physical Oceanography, v. 18, p. 1020-1034. [Also available at https://doi.org/10.1175/1520-0485(1988)018\%3C1020:AMFTRA\%3E2.0.CO;2.]

Montgomery, E.T., Martini, M.A., Lightsom, F.L., and Butman, Bradford, 2016, Documentation of the U.S. Geological Survey Oceanographic Time-Series Measurement Database (ver. 2.0, April 2016): U.S. Geological Survey Open-File Report 2007-1194, accessed July 15, 2016 at https://doi.org/10.3133/ofr20071194.

Orth, R.J., Fishman, J.R., Wilcox, D.J., and Moore, K.A., 2002, Identification and management of fishing gear impacts in a recovering seagrass system in the coastal bays of the Delmarva Peninsula, USA: Journal of Coastal Research, Special Issue, no. 7, p. 111-129, accessed November 4, 2016, at http://www.jstor.org/stable/25736347.

Pawka, S.S., 1983, Island shadows in wave directional spectra: Journal of Geophysical Research: Oceans, v. 88, no. C4, p. 2579-2591. [Also available at https://doi.org/10.1029/JC088iC04p02579.]

Pritchard, D.W., 1960, Salt balance and exchange rate for Chincoteague Bay: Chesapeake Science, v. 1, no. 1, p. 48-57. [Also available at https://doi.org/10.2307/1350536.]

Suttles, S.E., Ganju, N.K., Brosnahan, S.M., Montgomery, E.T., Dickhudt, P.J., Borden, Jonathan, and Martini, M.A., 2016, Oceanographic and water-quality measurements in Chincoteague Bay, Maryland/Virginia, 2014-2015: U.S. Geological Survey data release, accessed June 14, 2016, at https://doi.org/10.5066/F7DF6PBV.

Suttles, S.E., Ganju, N.K., Brosnahan, S.M., Montgomery, E.T., Dickhudt, P.J., Borden, Jonathan, and Martini, M.A., 2017, Water samples in support of oceanographic and water-quality measurements in Chincoteague Bay, Maryland and Virginia 2014-15, U.S. Geological Survey Field Activity 2014-048FA: U.S. Geological Survey data release, accessed May 2017 at https://doi.org/10.5066/F7WD3XSF. Wazniak, C.E., Hall, M.R., Carruthers, T.J.B., Sturgis, Brian, Dennison, W.C., and Orth, R.J., 2007, Linking water quality to living resources in a mid-Atlantic lagoon system, USA: Ecological Applications, v. 17, no. sp5, p. s64-s78. [Also available at https://doi.org/10.1890/05-1554.1.]

Wazniak, C.E., Wells, D.V., and Hall, M.R., 2005, The Maryland coastal bays ecosystem, chap. 1.2 of Wazniak, C.E., and Hall, M.R., eds., Maryland's coastal bays-Ecosystem health assessment 2004: Maryland Department of Natural Resources DNR-12-1202-0009, p. 1-9-1-20. [Also available at http://dnr.maryland.gov/waters/coastalbays/Pages/2004_EcosystemHealthAssessment/2004Ecosystem-Health-Assessment.aspx.]

Wells, D.V., Harris, S.M., Hill, J.M., Park, M.J., and Williams, C.P., 1997, The shallow sediments of upper Chincoteague Bay area in Maryland-Physical and chemical characteristics: Maryland Geological Survey Coastal and Estuarine Geology File Report no. 97-2, 90 p. 


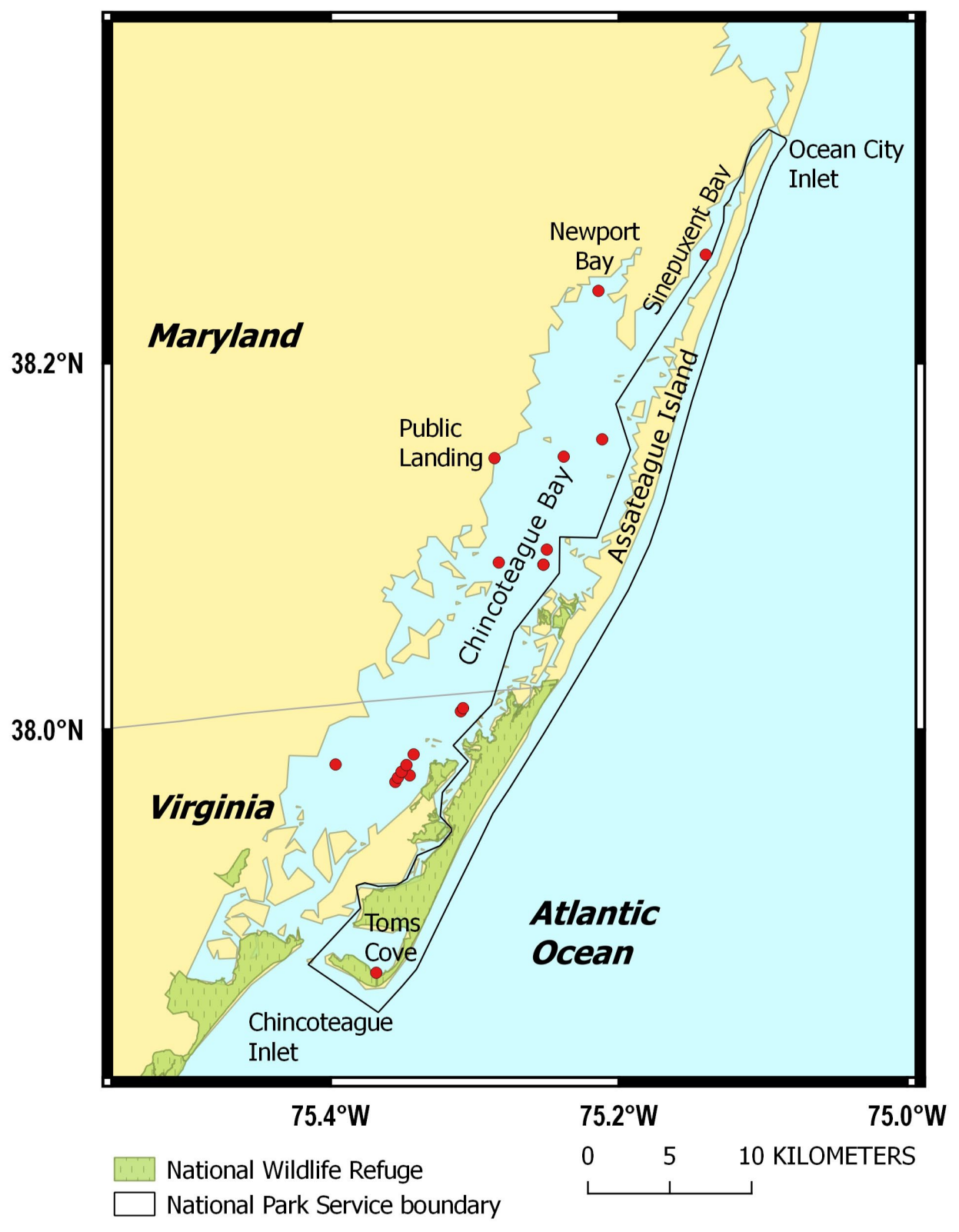

Figure 1. Regional map of study area in Chincoteague Bay, Maryland and Virginia. Red circles $(\bullet)$ are shown at time series station locations; see figures 2 and 3 for more detailed maps of locations. 


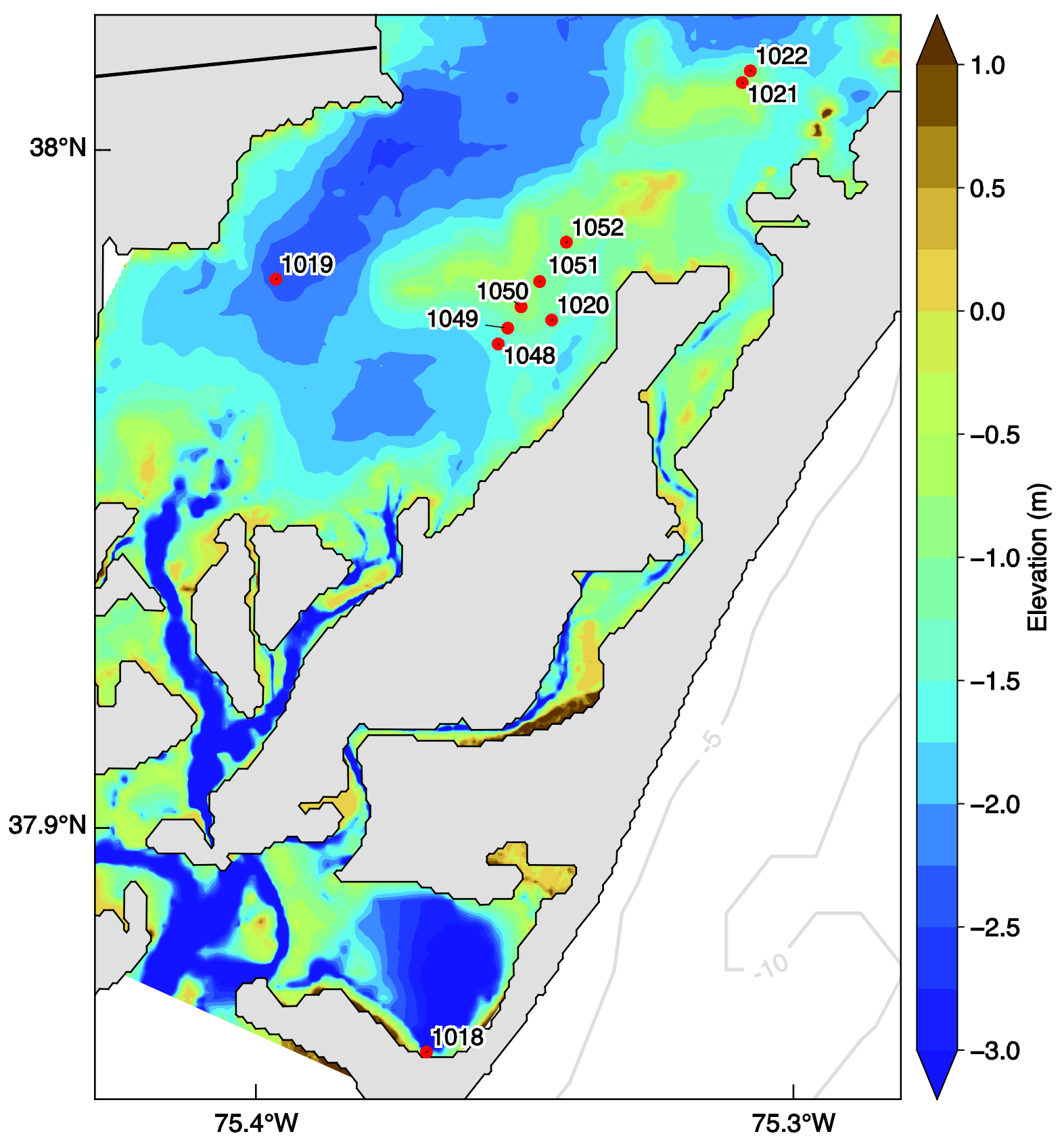

Figure 2. Map showing locations (red circles) and identifiers of time series stations in the Virginia part of Chincoteague Bay. Mooring numbers are shown for each location; see table 1 for coordinates, nominal depths, and time periods of deployments. For instrumentation information, sensor elevation, and associated data files, by mooring identification number, see tables 2-6. Elevations are referenced to NAVD 88. m, meter. 


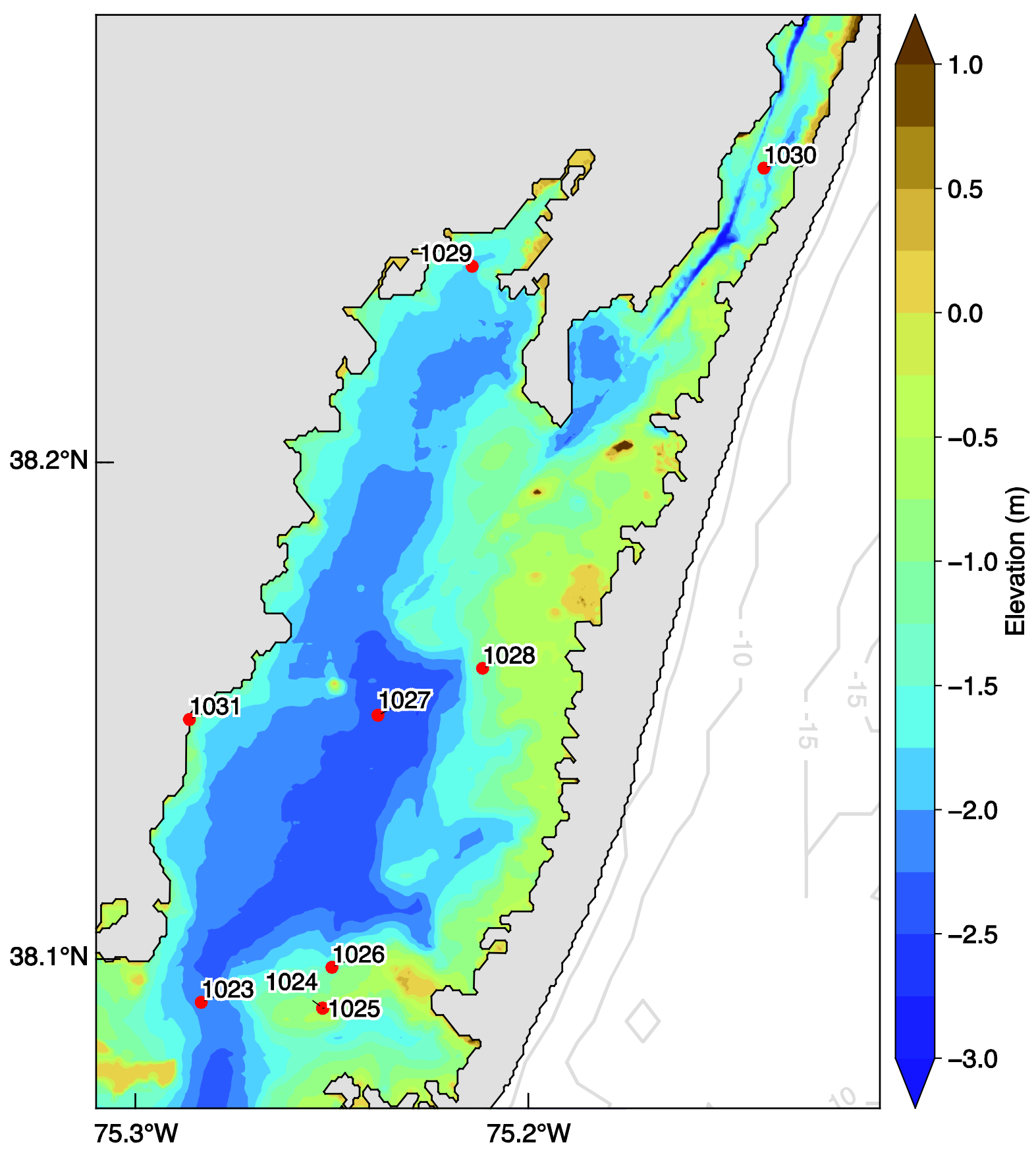

Figure 3. Map showing locations (red circles) and identifiers of time series stations in the Maryland part of Chincoteague Bay. Mooring numbers are shown for each location; see table 1 for coordinates, nominal depths, and time periods of deployments. For instrumentation information, sensor elevation, and associated data files, by mooring identification number, see tables 2-6. Elevations are referenced to NAVD 88. m, meter. 


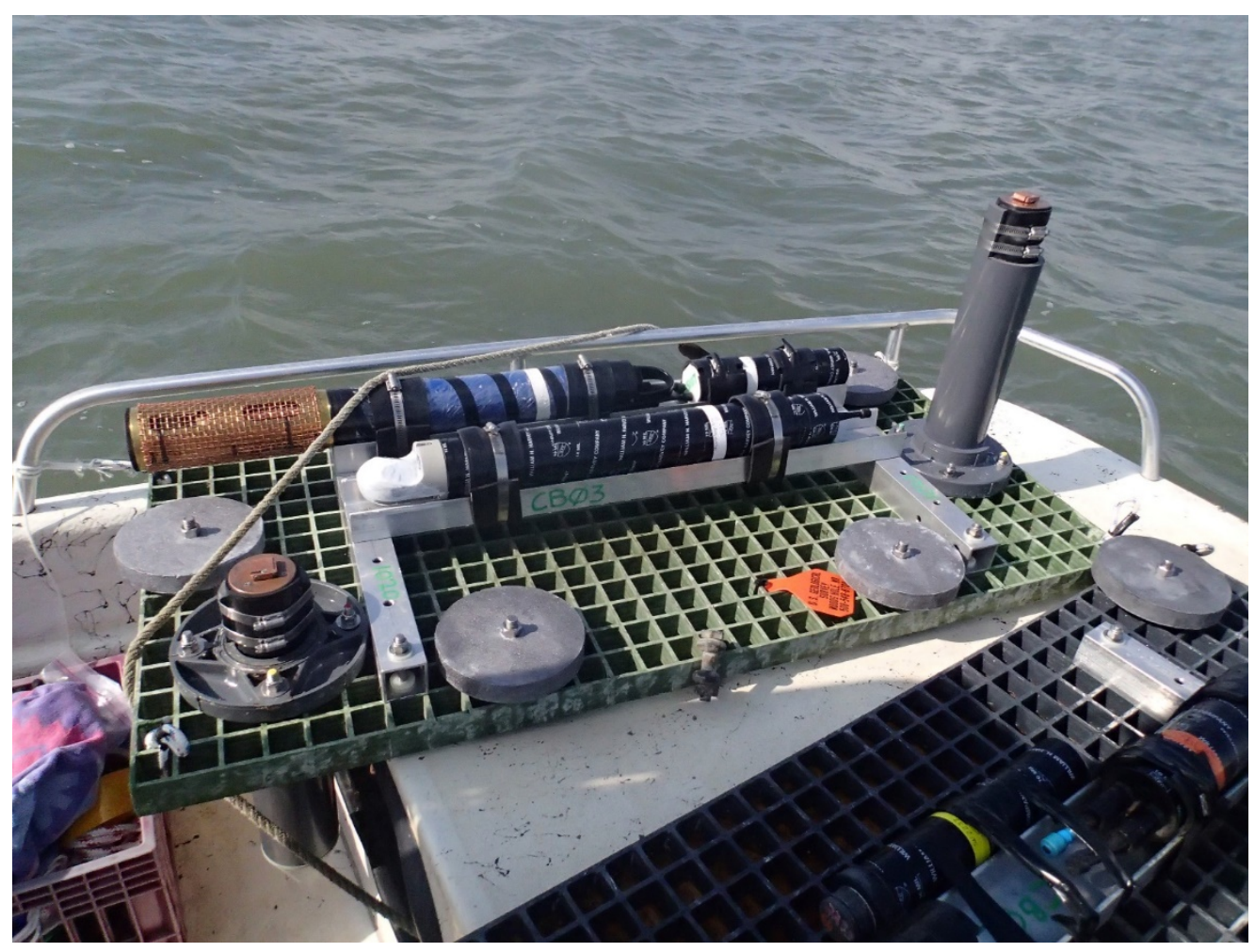

Figure 4. Photograph showing shallow water irradiance platform ready for initial deployment at mooring 1020 (CB03) on August 13, 2014. Instruments: ECO-PARSB light sensors (mounted vertically), Aquadopp highresolution pulse coherent acoustic Doppler current profiler (center), EXO2 multi-parameter sonde (copper mesh guard), and D|wave pressure logger (mounted opposite to EXO2). 


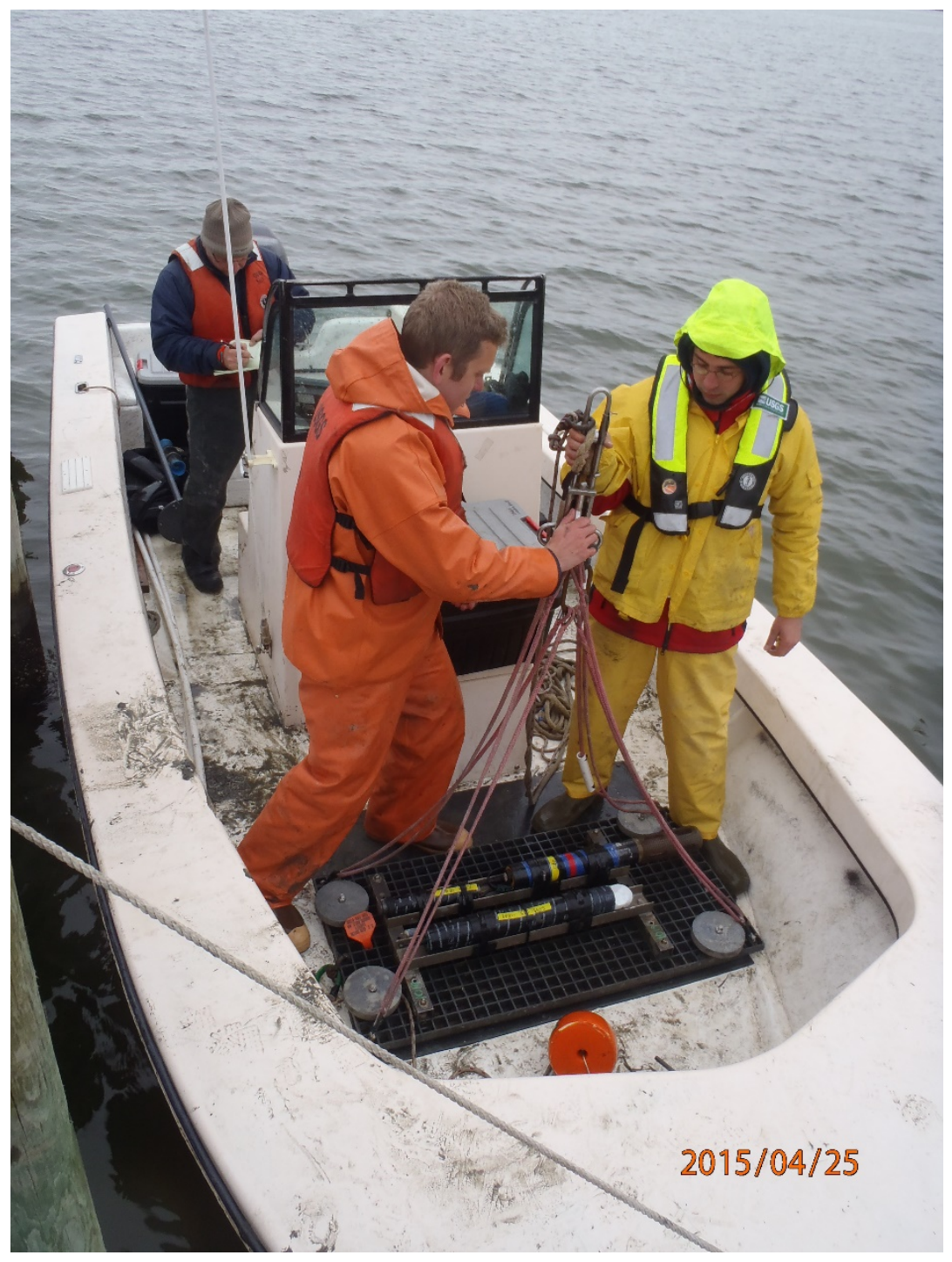

Figure 5. Photograph showing U.S. Geological Survey personnel preparing release bridle on bottom platform for deployment at mooring 1019 (CB02) on April 25, 2015. 


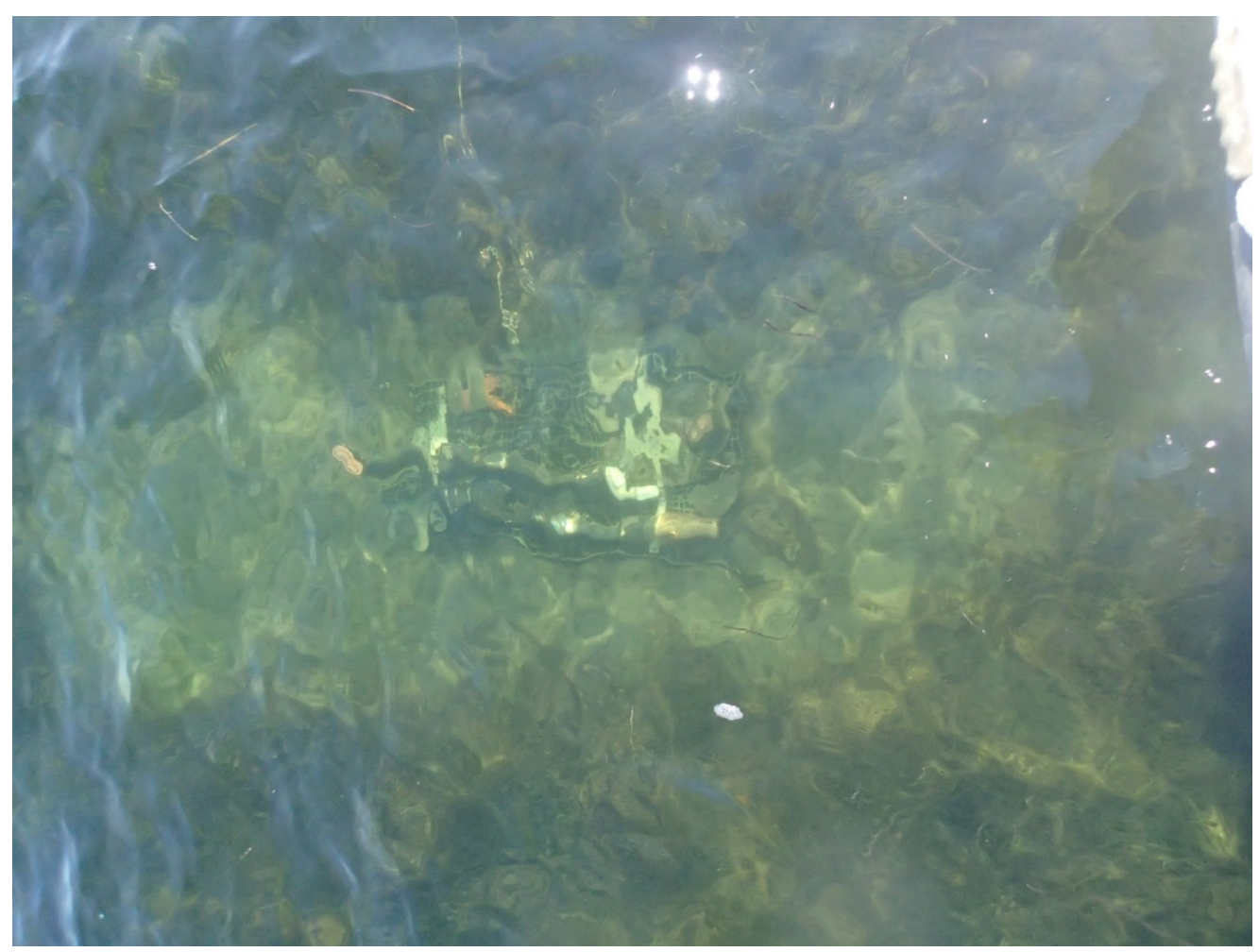

Figure 6. Photograph showing shallow water irradiance platform deployed in bare patch of a dense seagrass bed at mooring 1020 (CB03) on August 13, 2014. Water depth at the time of deployment was approximately 1.5 meters. 


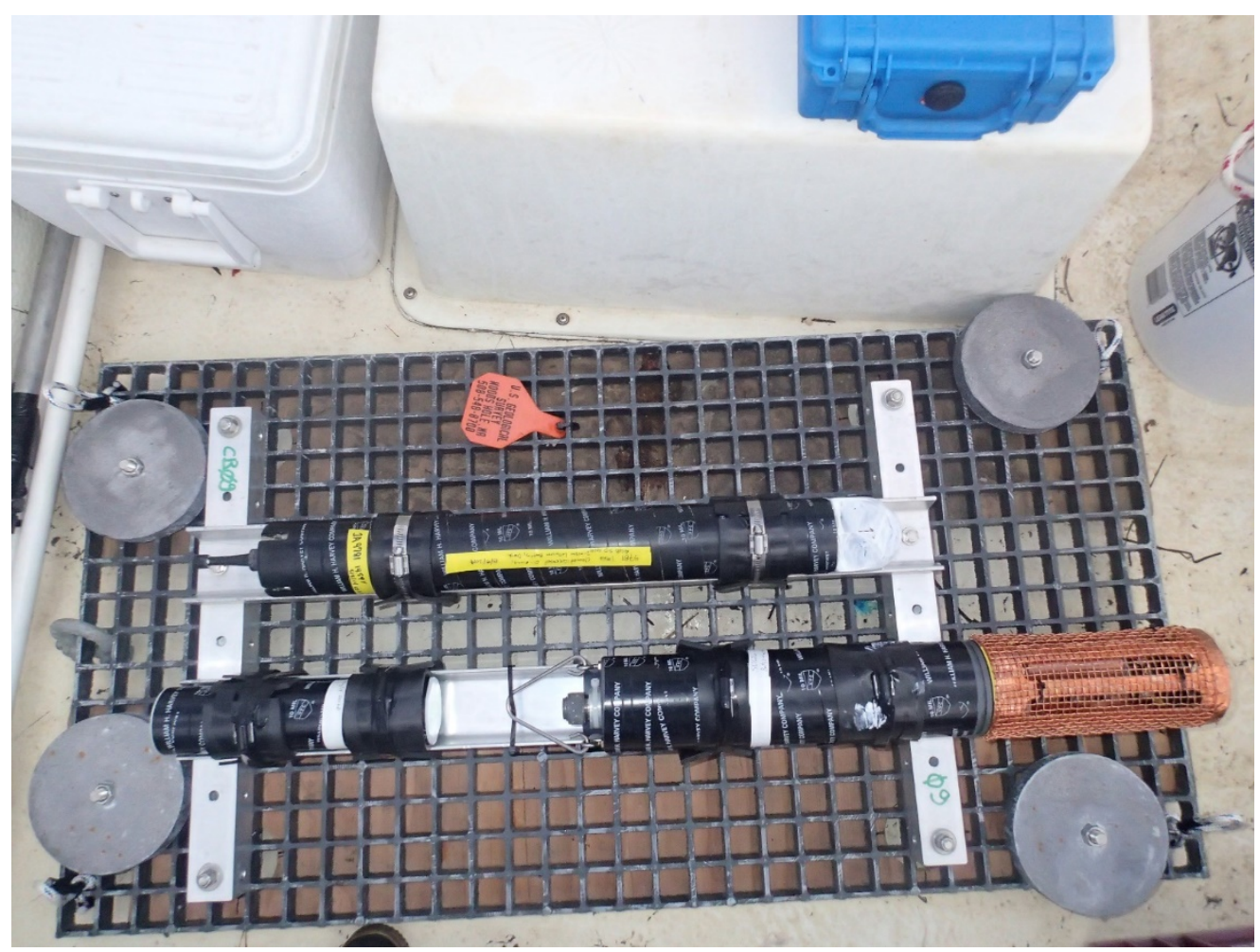

Figure 7. Photograph showing bottom platform with 1-megahertz Aquadopp acoustic Doppler current profiler (center), YSI 6600 sonde (with copper mesh), and D|wave pressure logger (opposite YSI 6600) ready for deployment at 1027 (CB09) on August 14, 2014. The white paste on Aquadopp transducer face and the copper mesh guard on the YSI 6600 are part of the antifouling controls. The YSI 6600 also had a mechanical wiper to clean sensor faces during the 2- to 3-month-long deployments. 


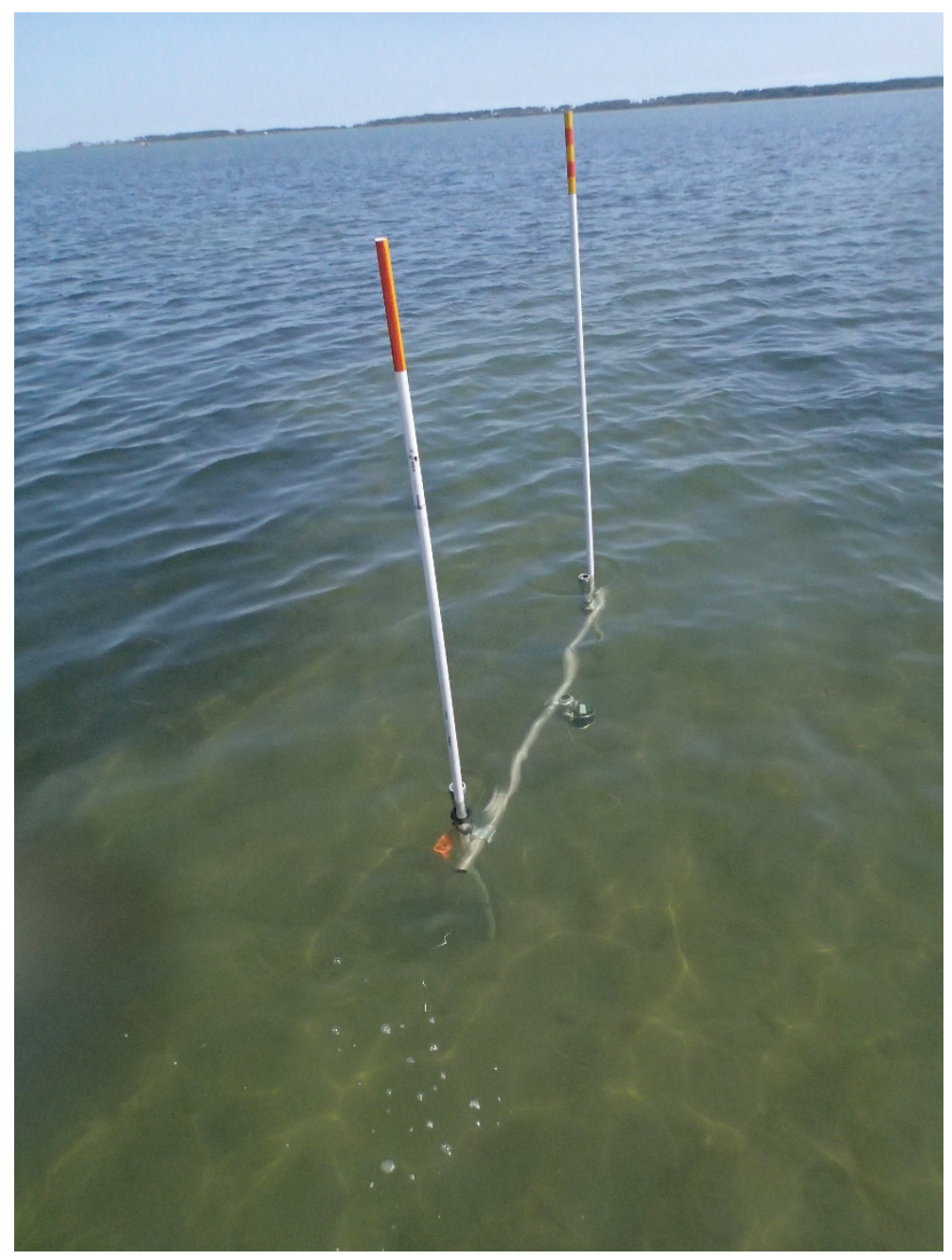

Figure 8. Photograph showing deployment of installed seabed altimeter at mooring 1021 (CB04) on August 15, 2014. An Echologger AA400 altimeter is mounted in the center of the aluminum $\mathrm{H}$-frame cross bar with the transducer pointing straight down toward the seabed, which is nominally 0.50 meter below the altimeter transducer. 


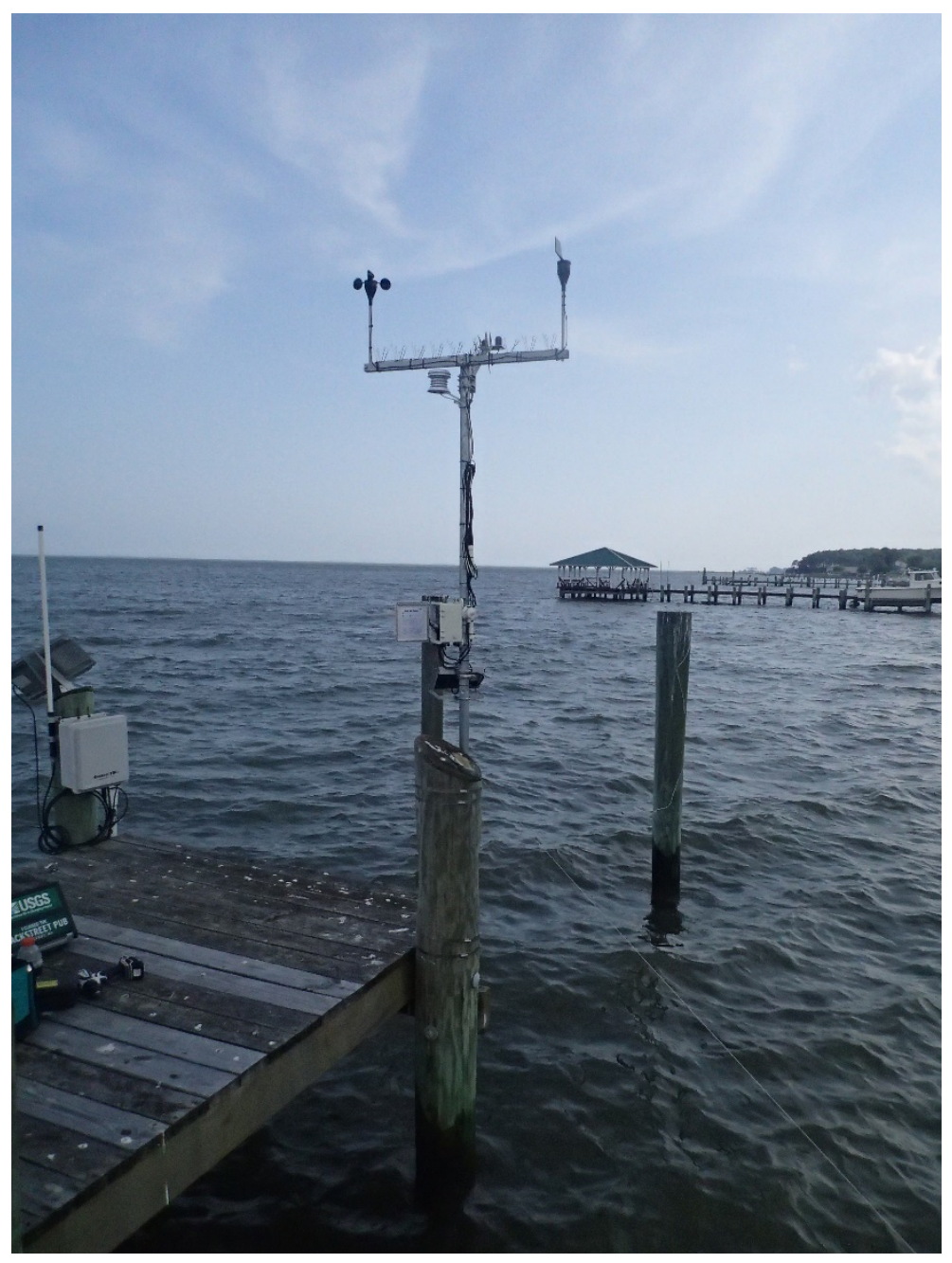

Figure 9. Photograph showing Onset Hobo U30 weather station on private dock at Public Landing, Maryland, mooring 1031 (CBWS), just after installation on August 16, 2014. The weather station measured wind speed and direction, air temperature, relative humidity, barometric pressure, photosynthetically active radiation, and shortwave irradiance. 


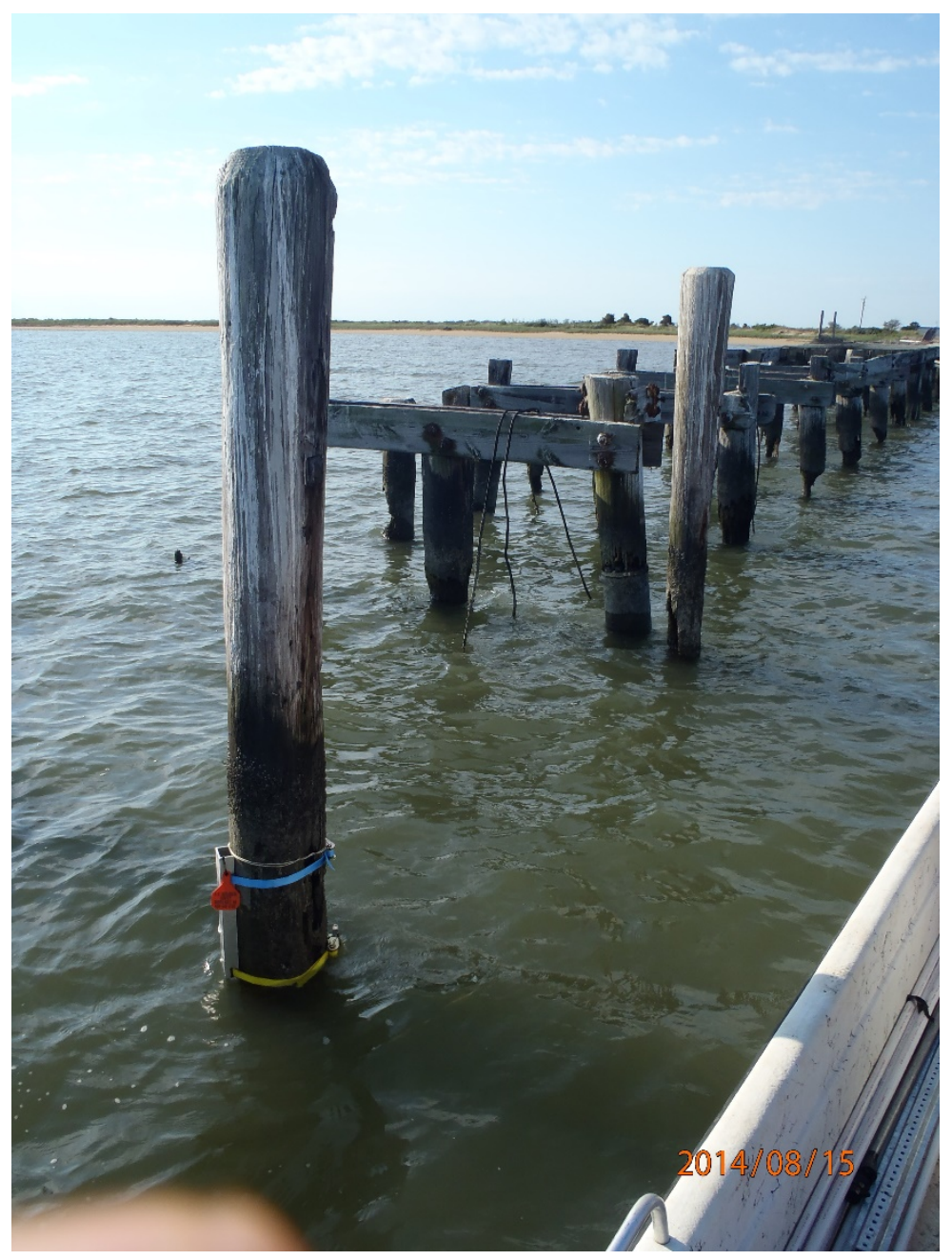

Figure 10. Photograph showing Mooring 1018 (CB01) mounted to an old Coast Guard station piling at Toms Cove near Chincoteague Inlet on August 15, 2014. A YSI 6600 multiparameter water-quality sonde is mounted to the aluminum channel, about 0.5 meter below the water level at time of the photograph. 


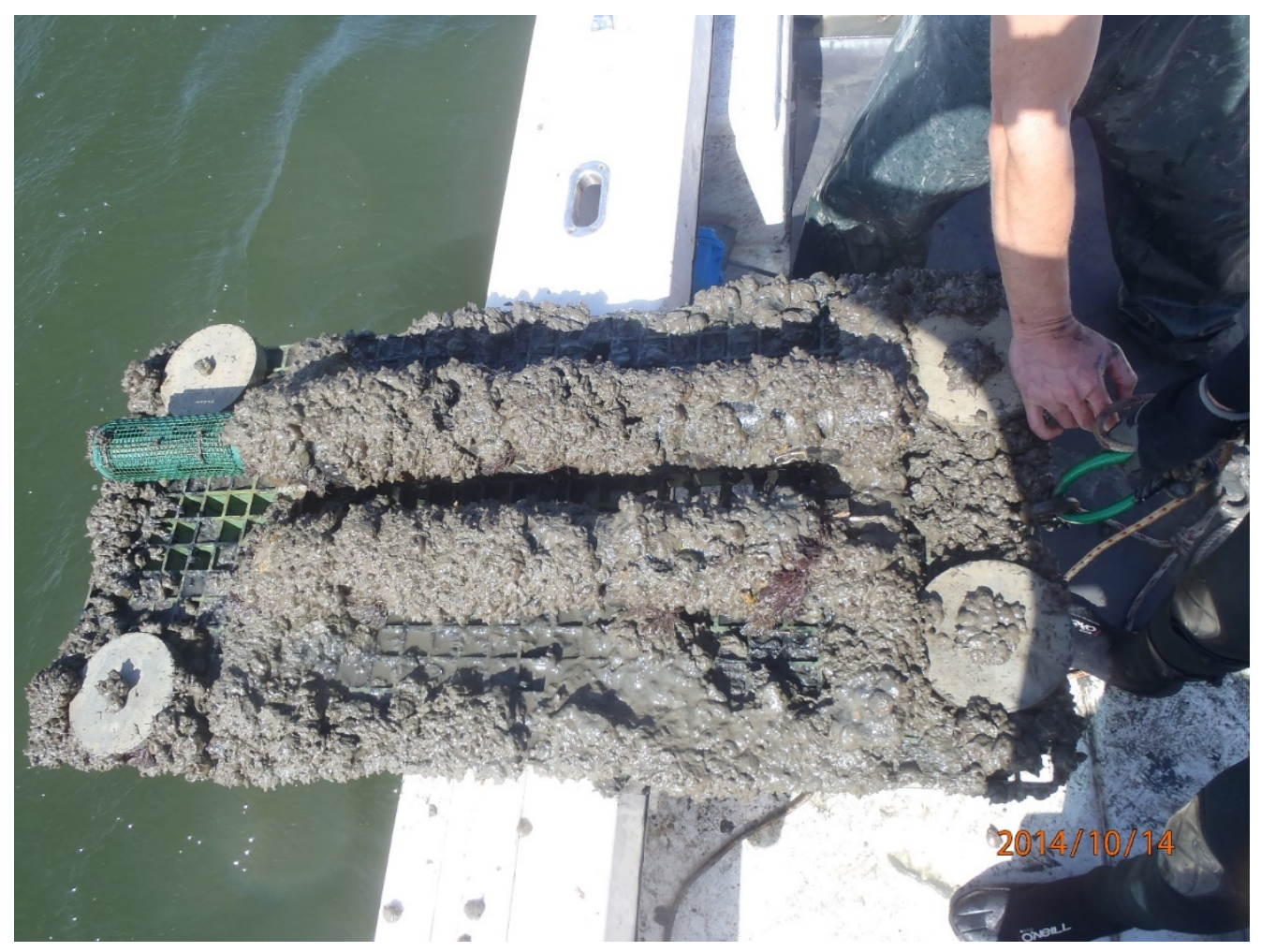

Figure 11. Photograph showing heavy biological and sediment fouling that occurred on a platform recovered at mooring 1029 (CB11) in Newport Bay on October 14, 2014. Copper mesh and guard kept the EXO2 sonde sampling chamber relatively clean. Despite the heavy fouling, the Aquadopp acoustic Doppler current profiler collected usable data for the entire deployment. The EXO2 sonde stopped working 11 days before recovery because of a power issue; however, it collected usable data until that time. 

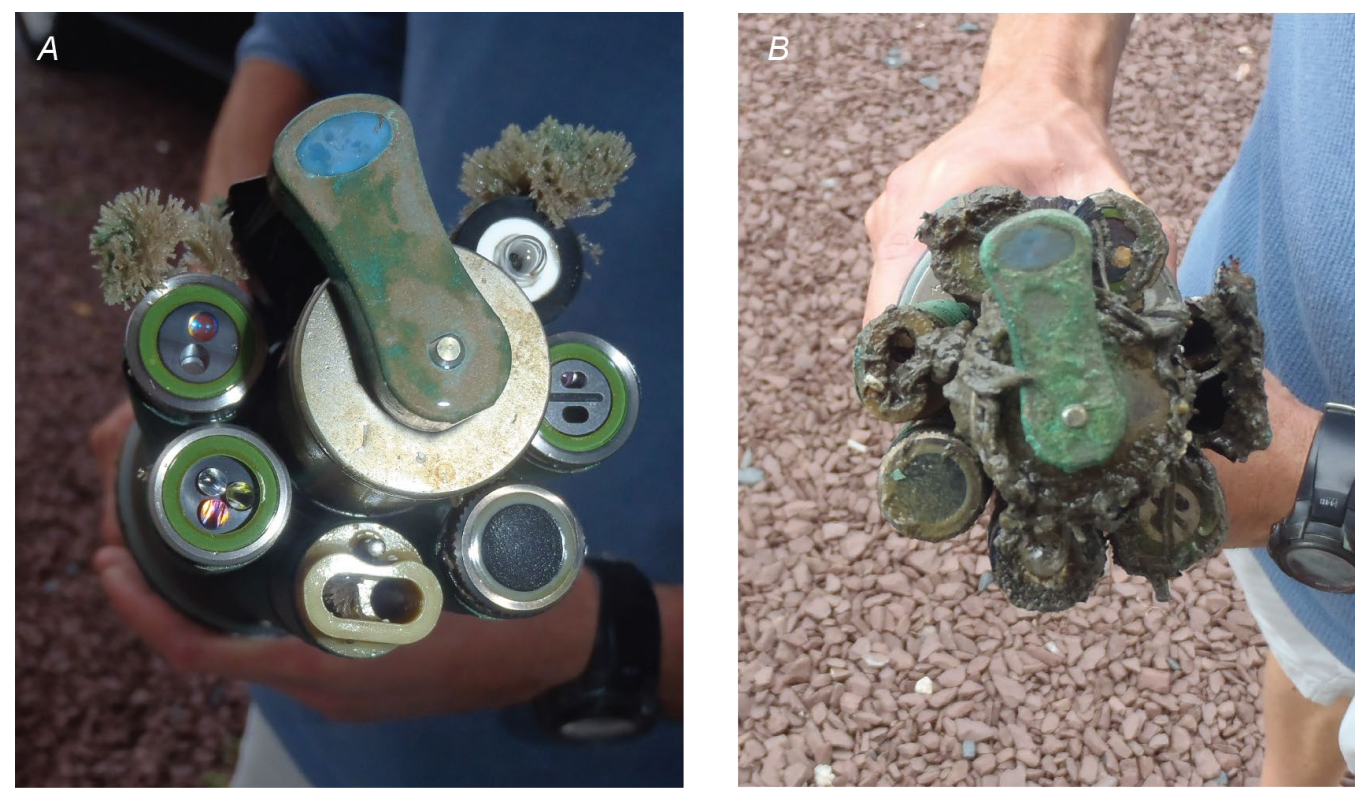

Figure 12. Photographs showing a comparison of fouling on EXO2 sensors from moorings $A, 1028$ and $B, 1029$ upon recovery in October 2014 during the first turnaround of the deployed instruments. Sensor faces are clean on the sensors from mooring 1028 (CB10) with the exception of some fouling on the conductivity cell (third sensor counterclockwise from left, approximately 6 o'clock) where the wiper was not effective. All sensors are heavily fouled from the EXO2 sonde at 1029 (CB11), where the sonde ran out of battery power 11 days prior to recovery, causing the wiper to no longer function.
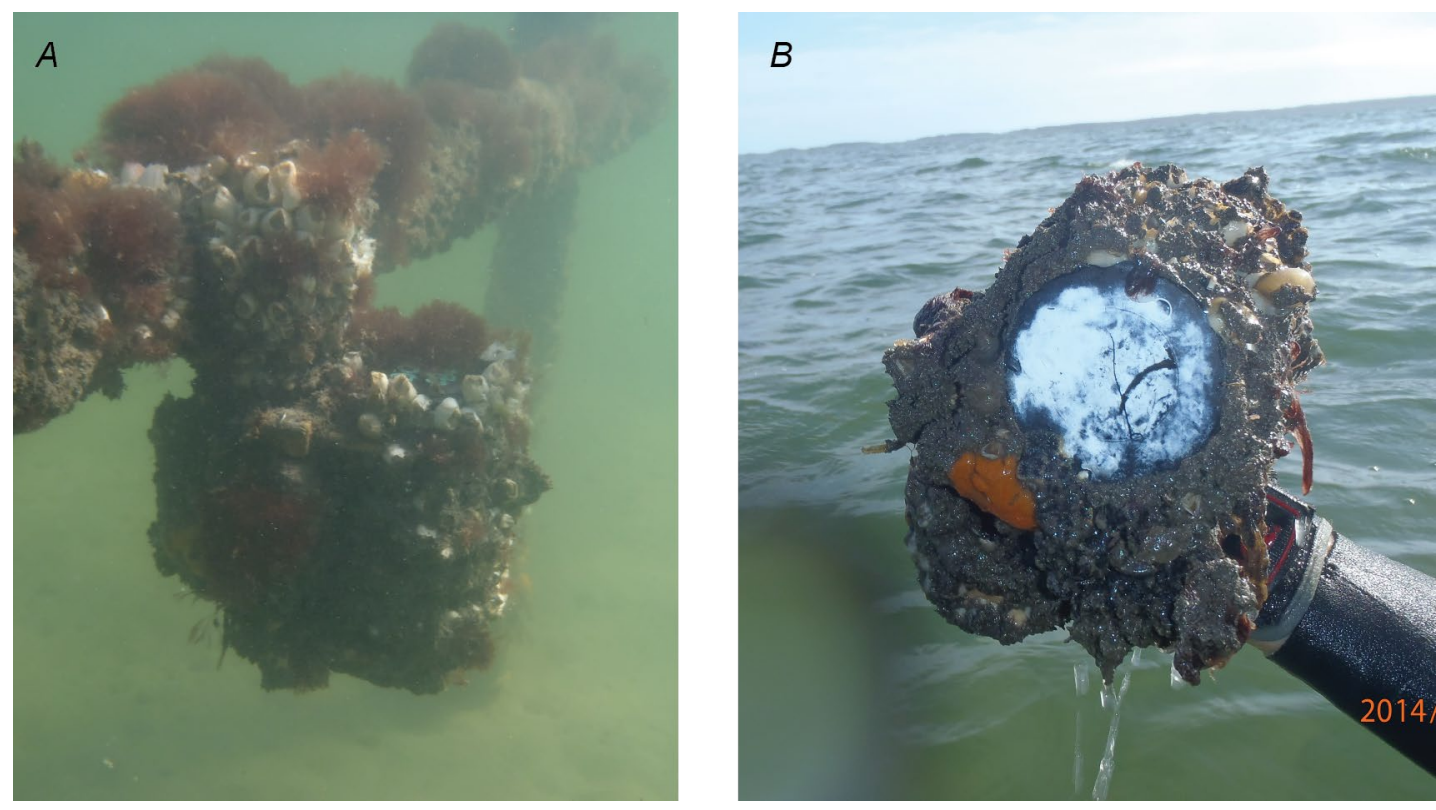

Figure 13. Photographs showing seabed altimeter at mooring 1026 (CB08) heavily encrusted in barnacles at time of recovery in October 2014 on the first instrument turnaround; $A$, the sensor mounted in the $\mathrm{H}$-frame just prior to recovery; $B$, sensor topside just after recovery. Zinc oxide paste kept the transducer face on altimeter clean despite heavy fouling. 


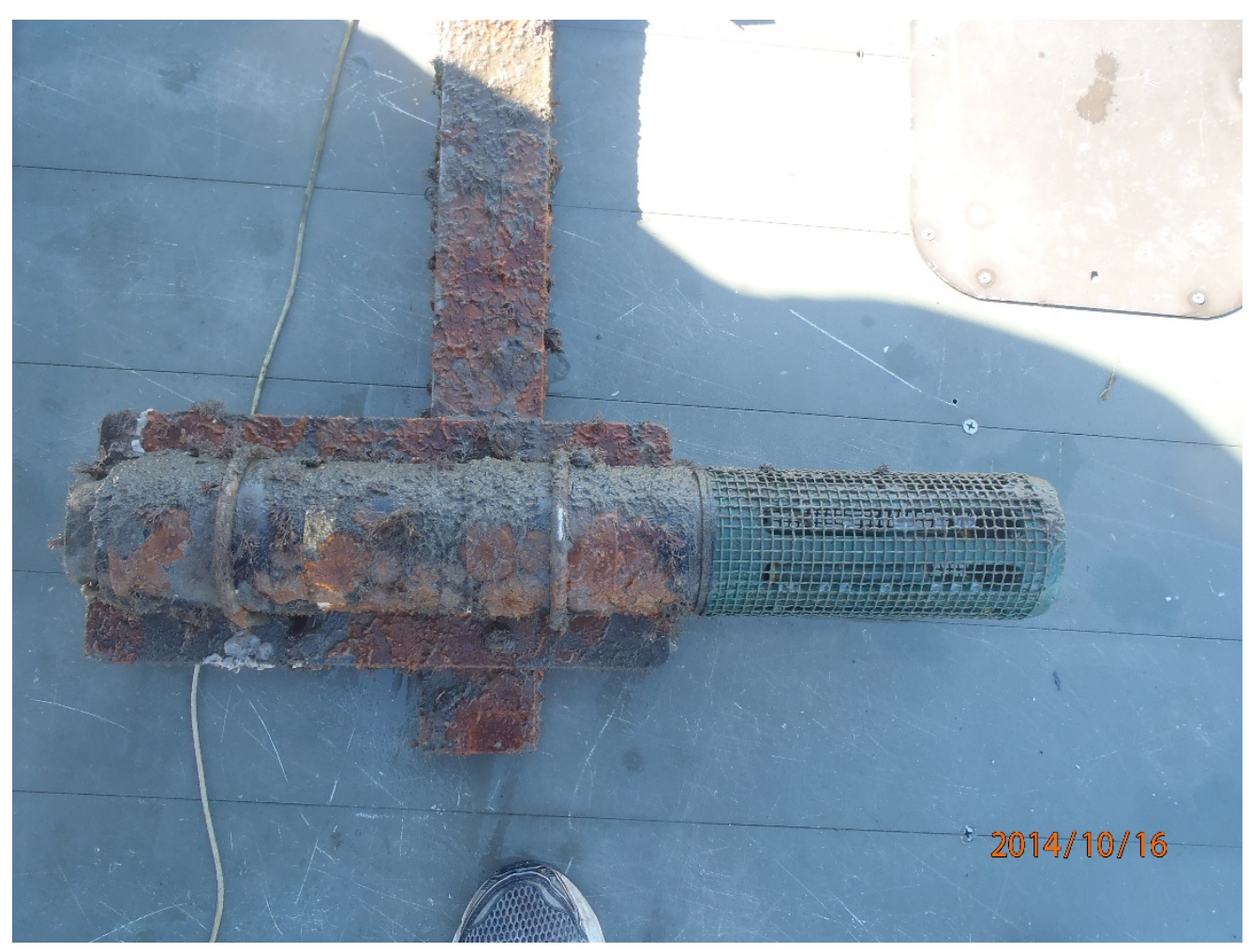

Figure 14. Photograph showing YSI 6600 sonde from mooring 1018 (CB01) just after recovery in October 2014. Some moderate biological fouling was present on the instrument body and mount, but the sampling chamber with copper mesh and copper-taped guard were clean. 


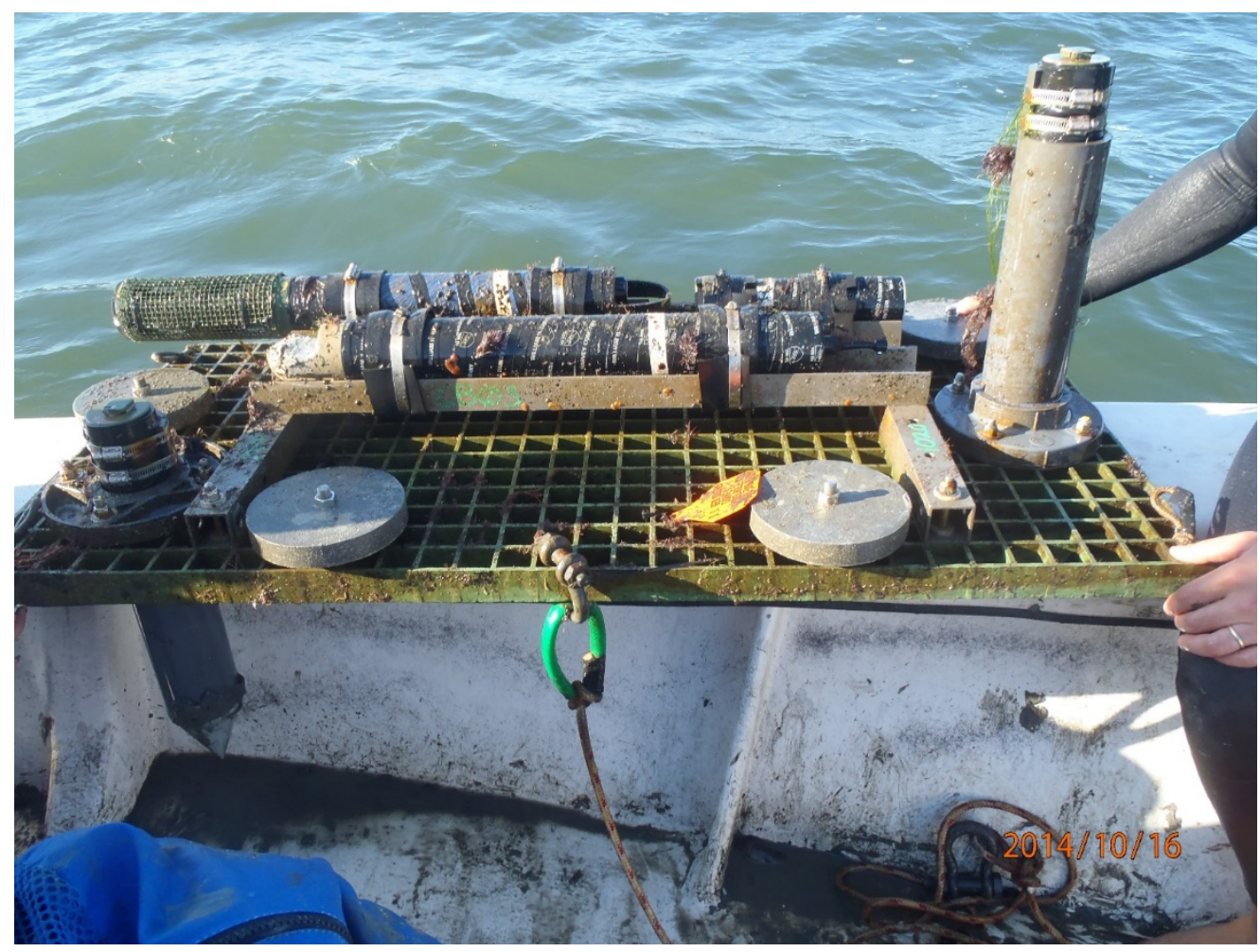

Figure 15. Photograph showing shallow water irradiance platform at mooring 1020 (CB03), a shoal site with dense seagrass coverage, just after recovery on October 16, 2014. Only light fouling was observed on this deployment; some seagrass is attached to the upper photosynthetically active radiation sensor. 


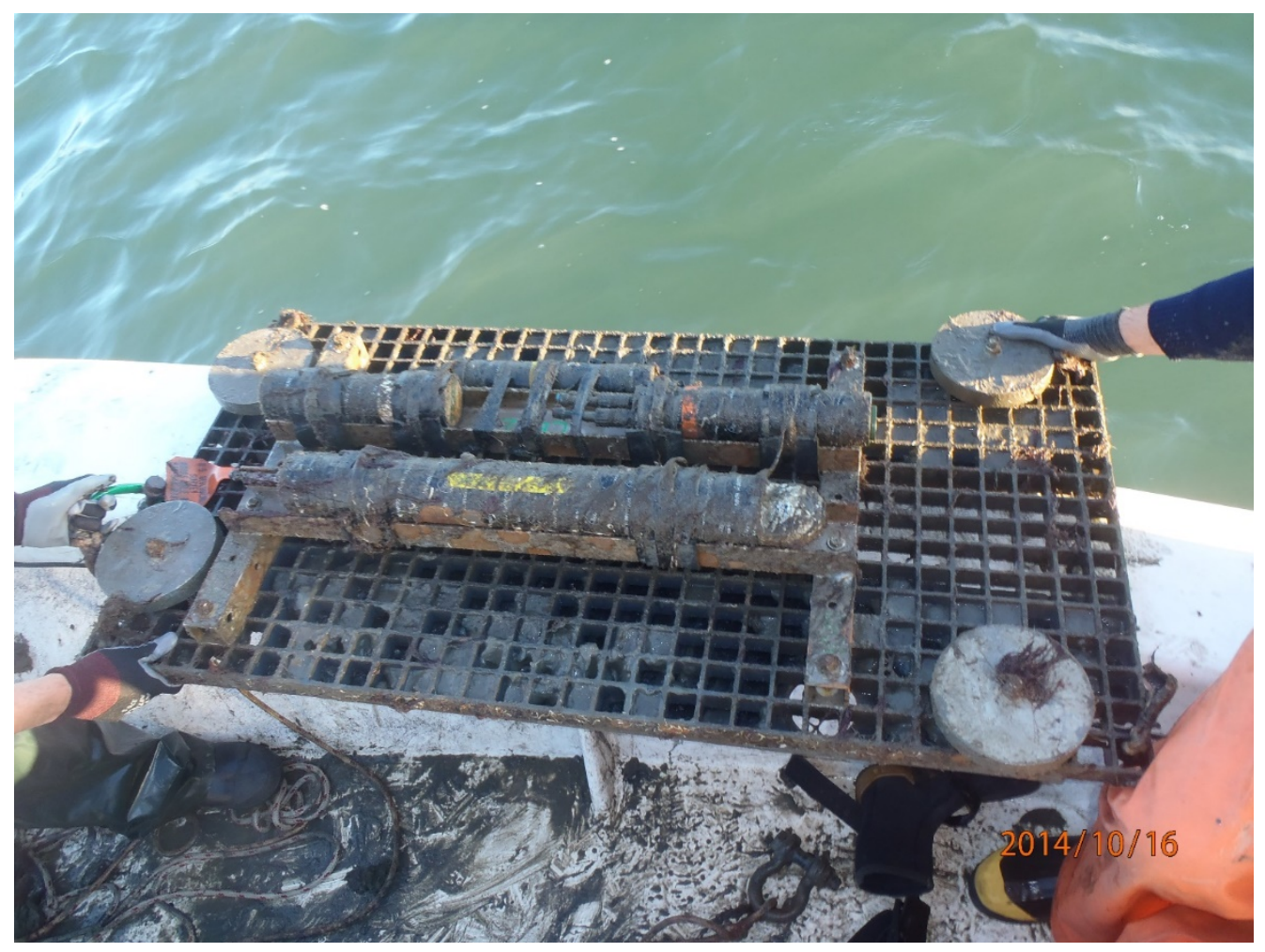

Figure 16. Photograph showing bottom platform at 1019 (CB02) upon recovery on October 16, 2014. Moderate sediment fouling was observed during this deployment. 


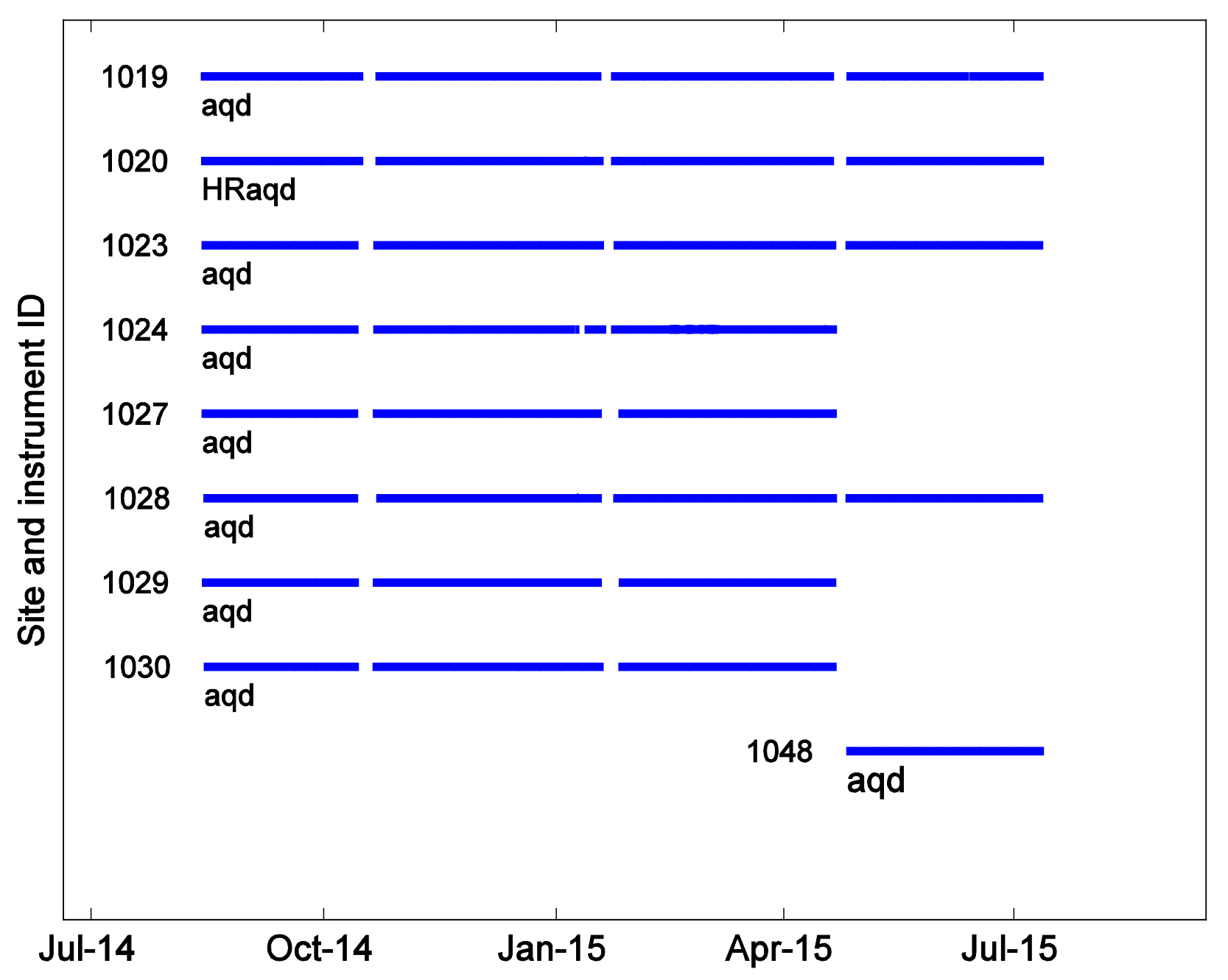

Figure 17. Chart showing the availability of current velocity data for Chincoteague Bay, Maryland and Virginia, for the Estuarine Physical Response to Storms study from August 2014 to July 2015. aqd, Nortek Aquadopp; HRaqd, Nortek Aquadopp high resolution; ID, identification number. 

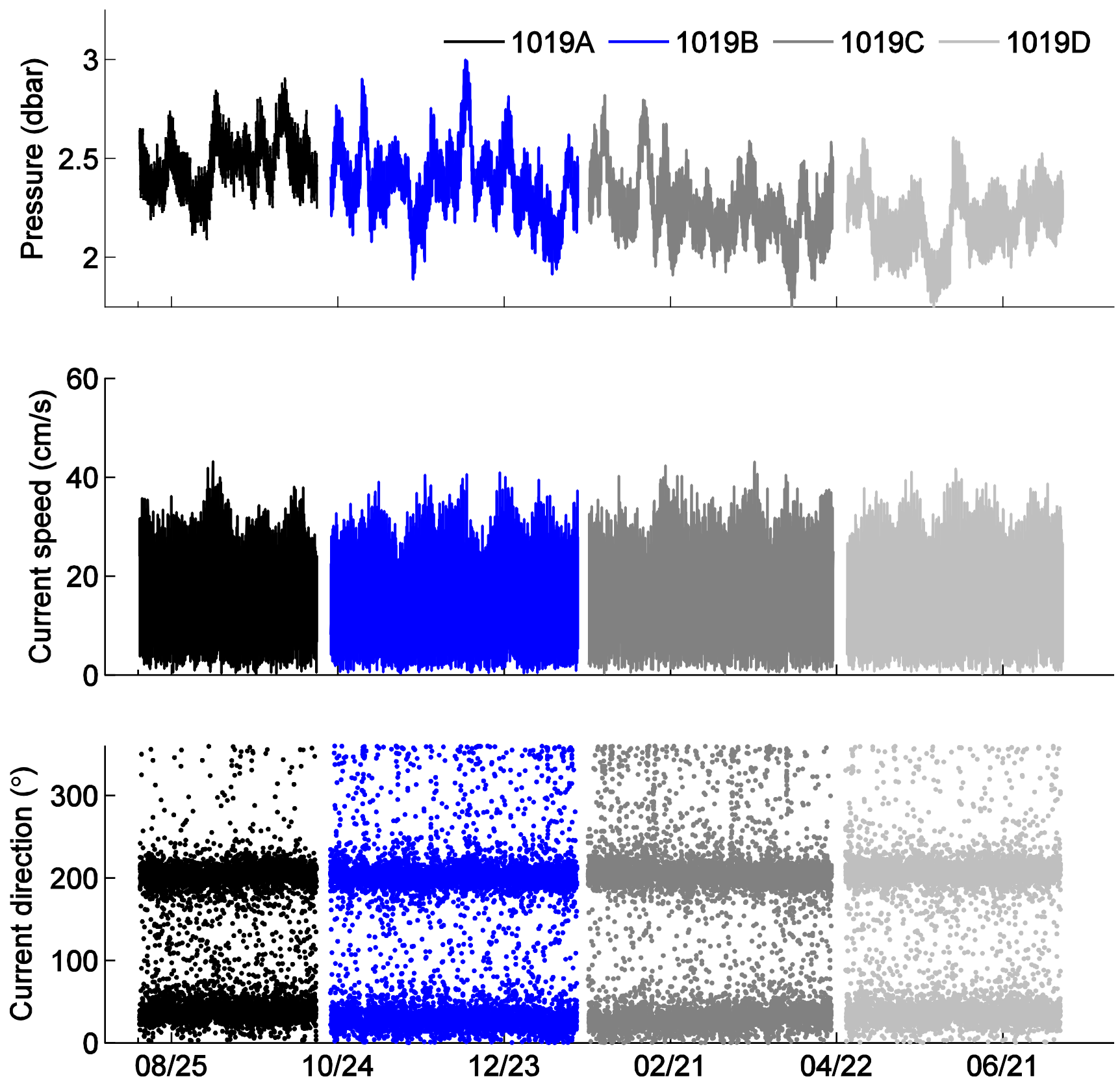

Figure 18. Graphs showing pressure (atmospherically corrected), current speed, and current direction (traveling towards convention) from 1-megahertz Aquadopp acoustic Doppler current profiler, bin 2, at mooring 1019 (CB02) from August 13, 2014, to July 12,2015 . dbar, decibar; $\mathrm{cm} / \mathrm{s}$, centimeter per second; ${ }^{\circ}$, degree true. 

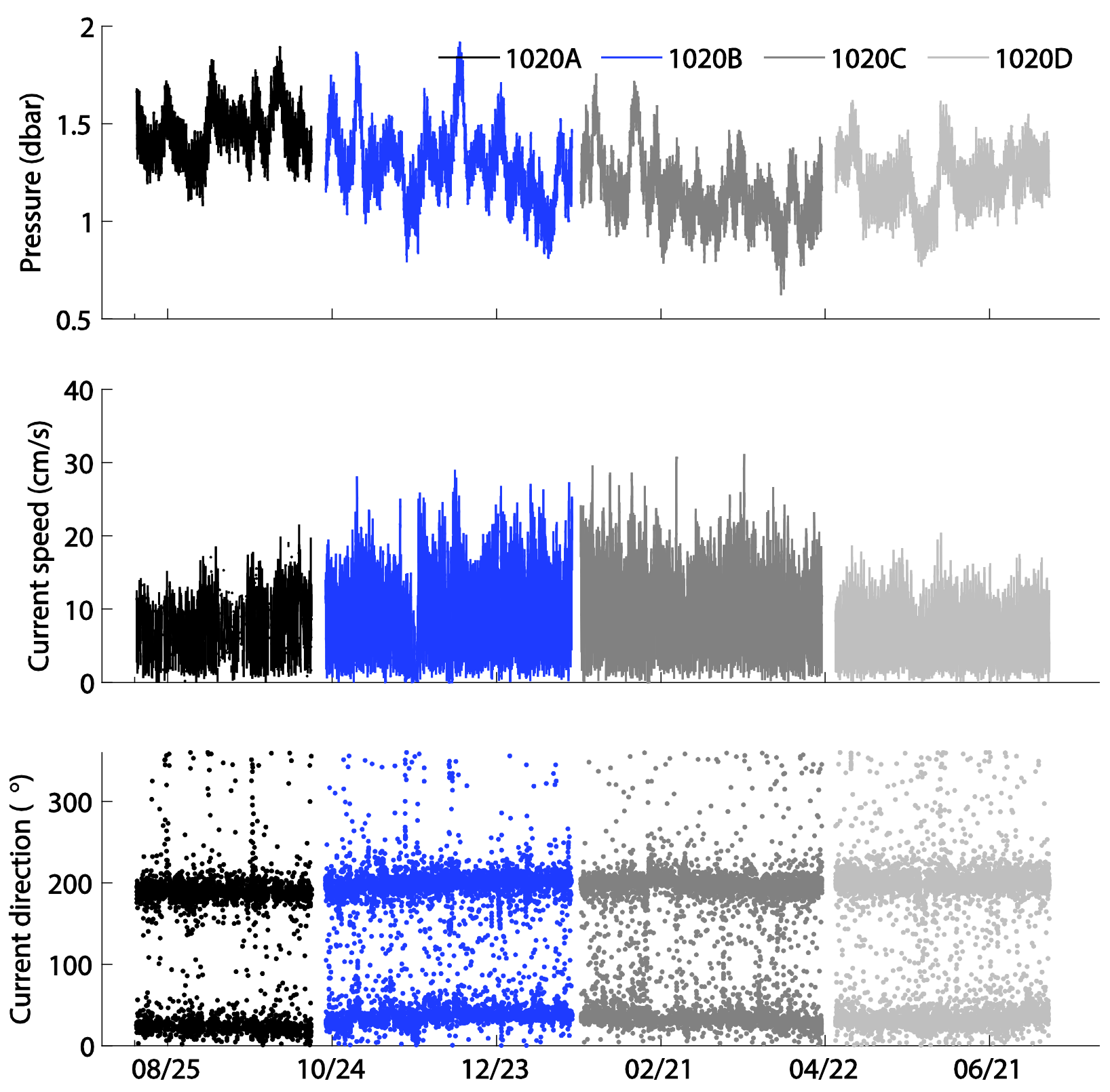

Figure 19. Graphs showing pressure (atmospherically corrected), current speed, and current direction (traveling towards convention) from 1-megahertz Aquadopp high resolution acoustic Doppler current profiler, bin 8, at mooring 1020 (CB03) from August 13, 2014, to July 12, 2015. dbar, decibar; cm/s, centimeter per second; ', degree true. 

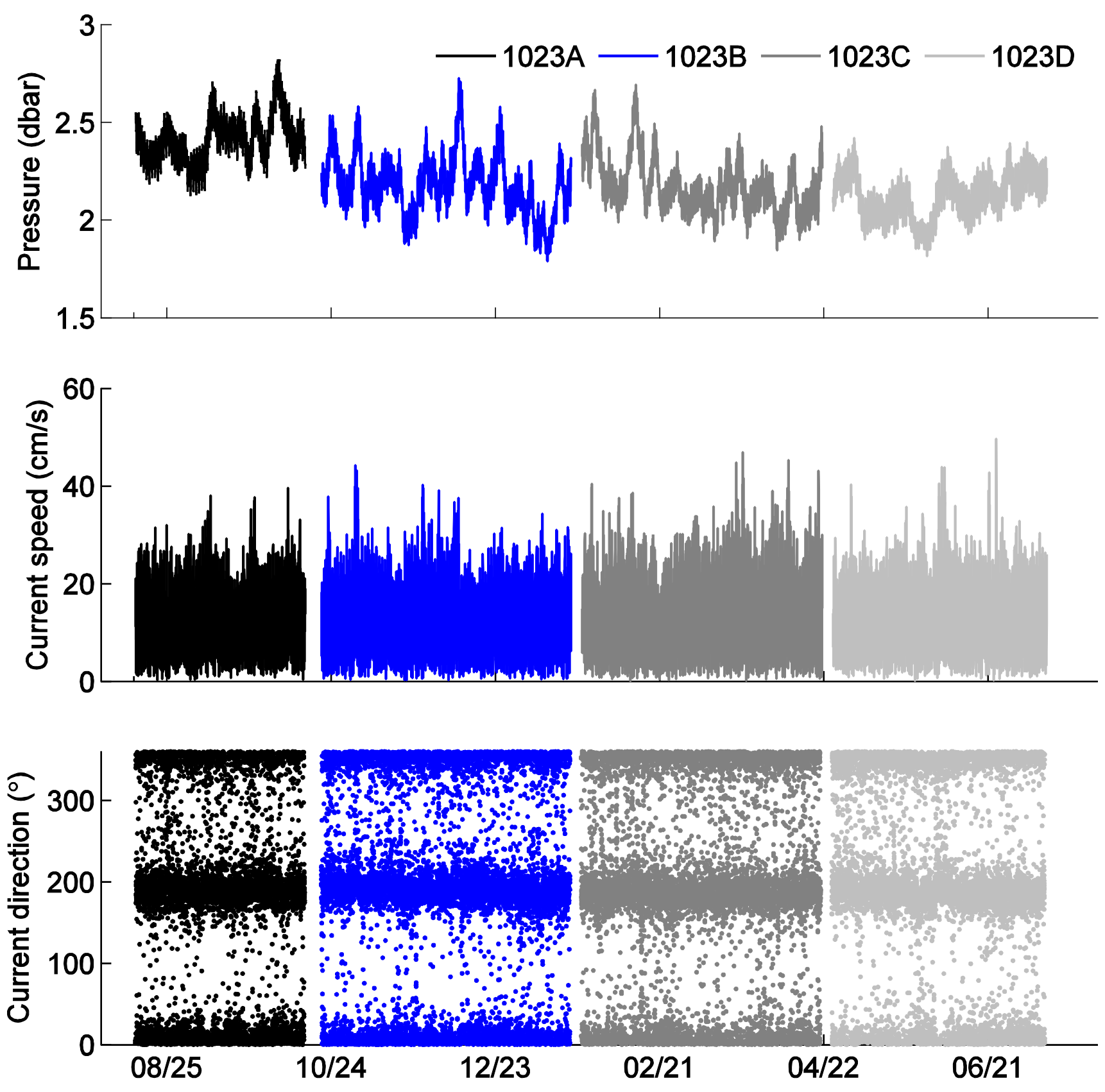

Figure 20. Graphs showing pressure (atmospherically corrected), current speed, and current direction (traveling towards convention) from 1-megahertz Aquadopp acoustic Doppler current profiler, bin 2, at mooring 1023 (CB06) from August 13, 2014, to July 12, 2015. dbar, decibar; $\mathrm{cm} / \mathrm{s}$, centimeter per second; ${ }^{\circ}$, degrees true. 

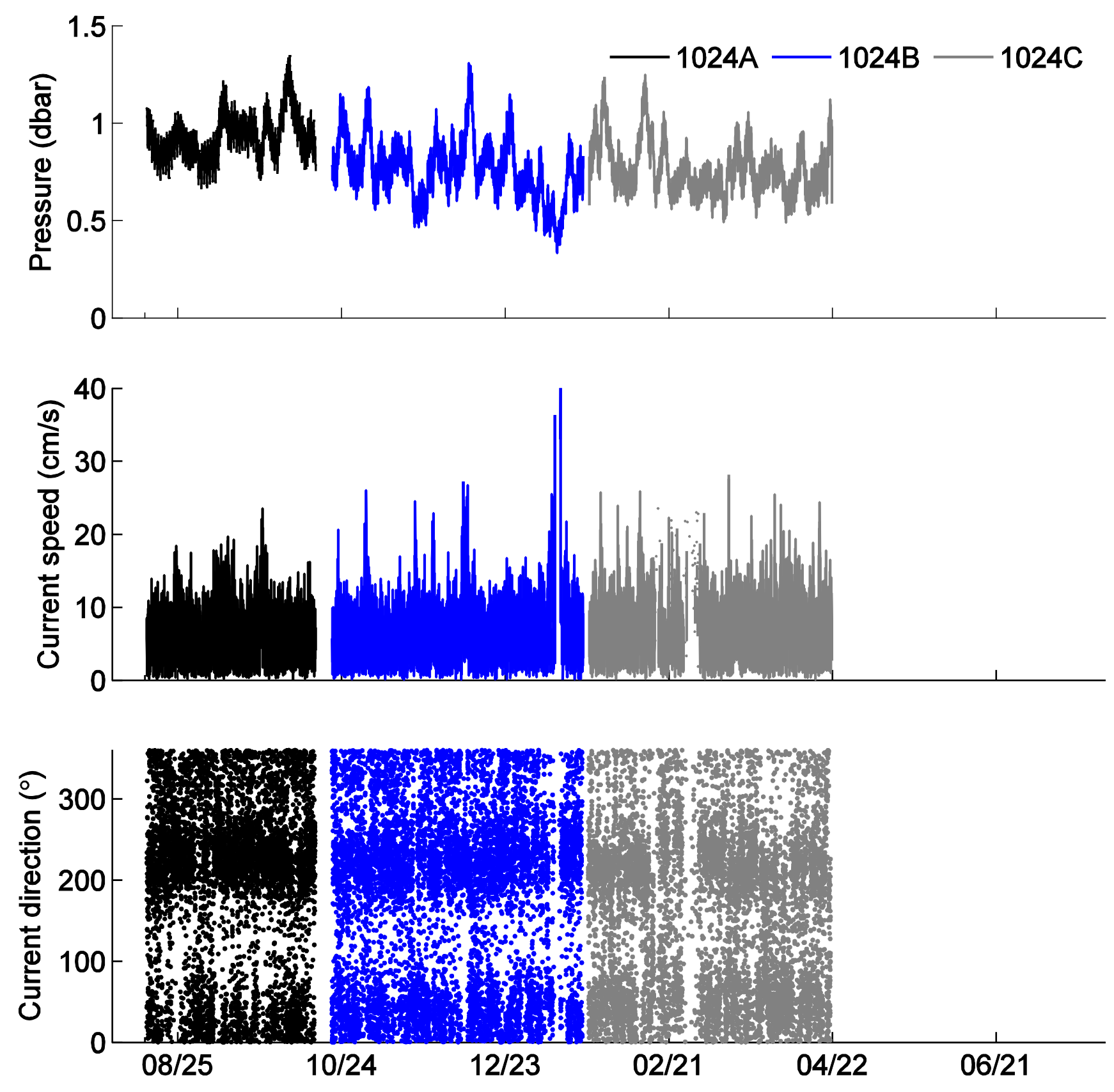

Figure 21. Graphs showing pressure (atmospherically corrected), current speed, and current direction (traveling towards convention) from 2-megahertz Aquadopp acoustic Doppler current profiler, bin 2, at mooring 1024 (CB07) from August 13, 2014, to April 21, 2015. dbar, decibar; $\mathrm{cm} / \mathrm{s}$, centimeter per second; ${ }^{\circ}$, degree true. 

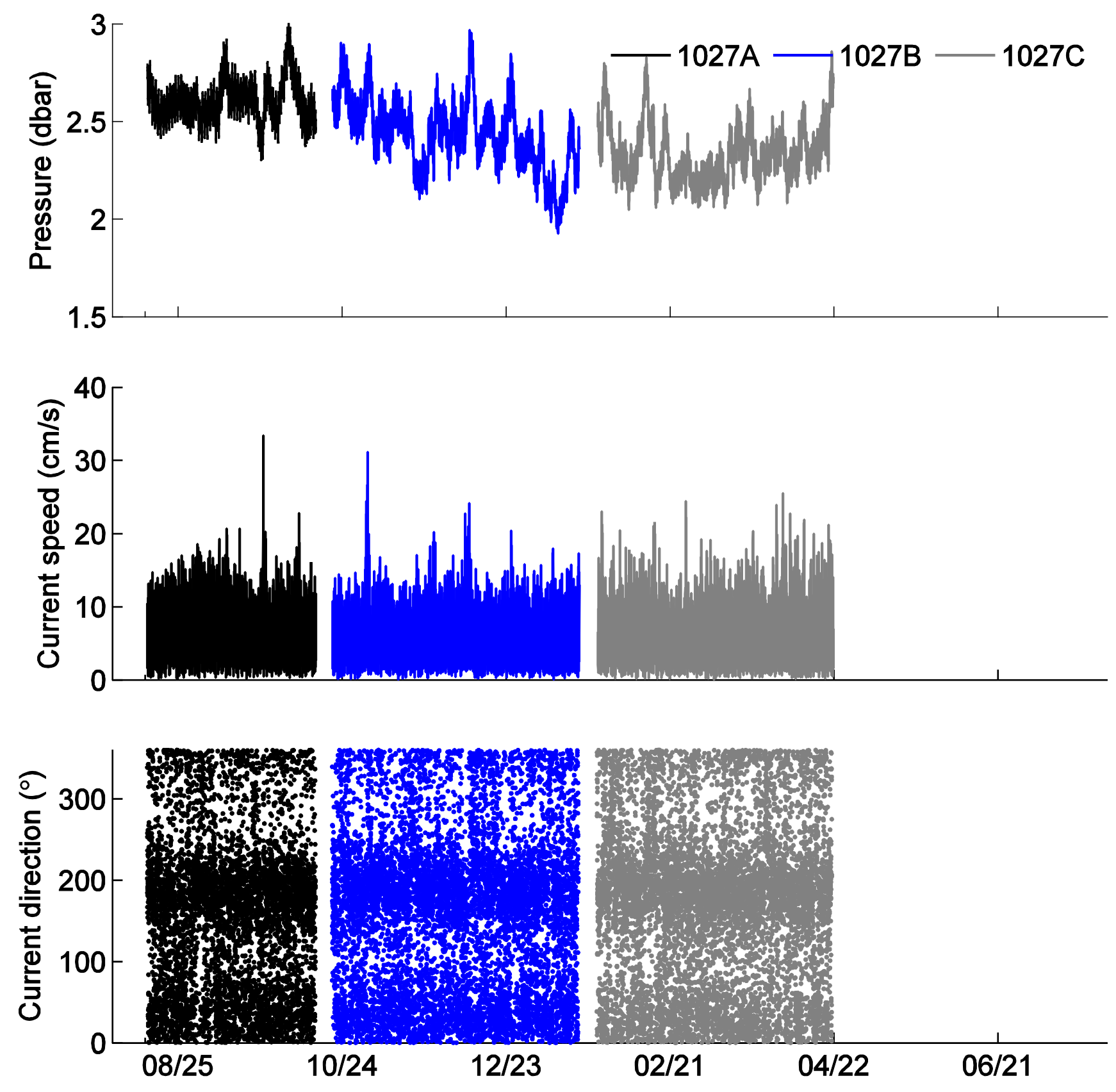

Figure 22. Graphs showing pressure (atmospherically corrected), current speed, and current direction (traveling towards convention) from 2-megahertz Aquadopp acoustic Doppler current profiler, bin 2, at mooring 1027 (CB09) from August 13, 2014, to April 21, 2015. dbar, decibar; $\mathrm{cm} / \mathrm{s}$, centimeter per second; ${ }^{\circ}$, degree true. 

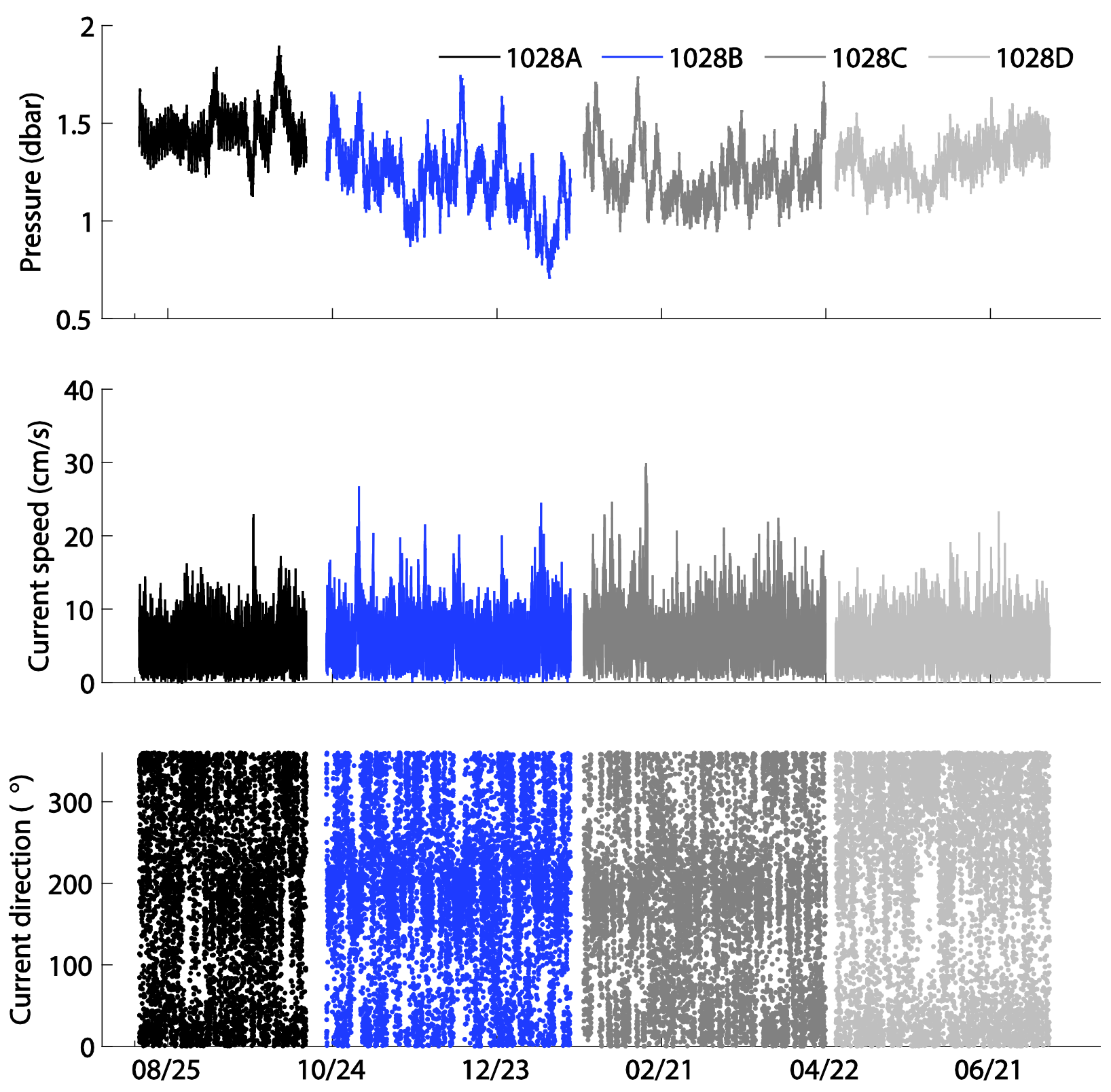

Figure 23. Graphs showing pressure (atmospherically corrected), current speed, and current direction (traveling towards convention) from 2-megahertz Aquadopp acoustic Doppler current profiler, bin 2, at mooring 1028 (CB10) from August 14, 2014, to Jul 12, 2015. dbar, decibar; cm/s, centimeter per second; ${ }^{\circ}$, degree true. 

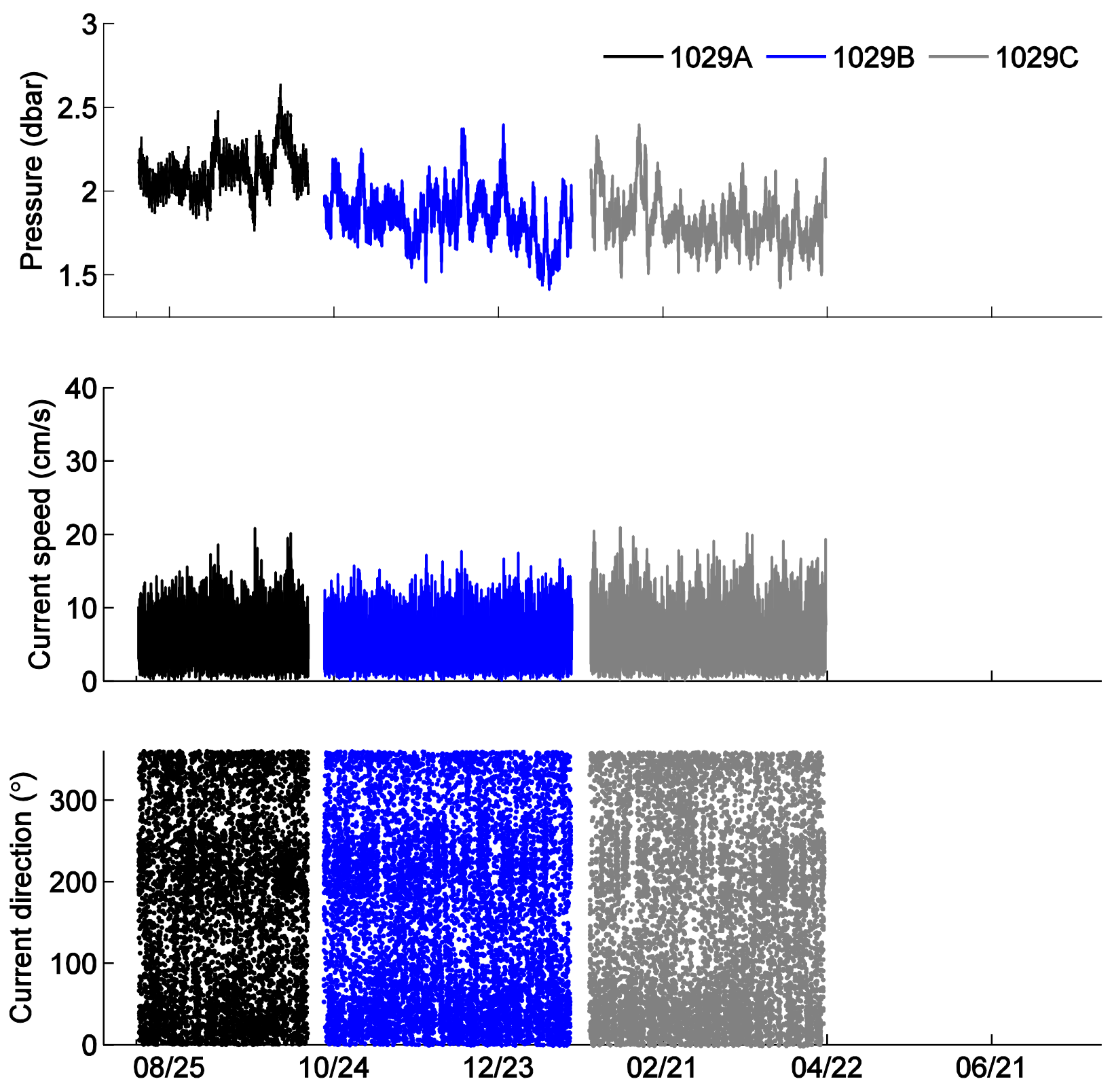

Figure 24. Graphs showing pressure (atmospherically corrected), current speed, and current direction (traveling towards convention) from 2-megahertz Aquadopp acoustic Doppler current profiler, bin 2, at mooring 1029 (CB11) from August 13, 2014, to April 21, 2015. dbar, decibar; $\mathrm{cm} / \mathrm{s}$, centimeter per second; ${ }^{\circ}$, degree true. 

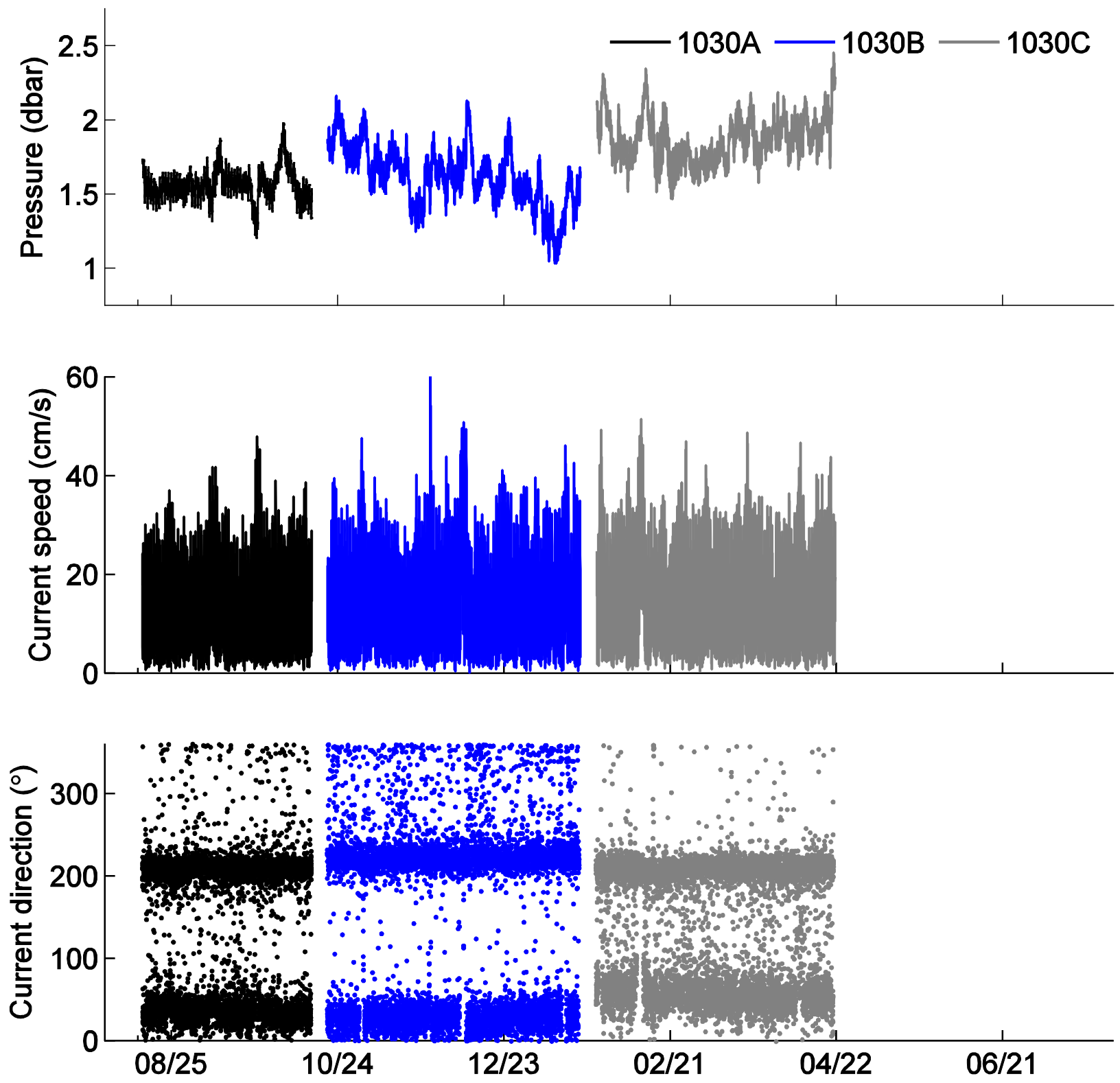

Figure 25. Graphs showing pressure (atmospherically corrected), current speed, and current direction (traveling towards convention) from 2-megahertz Aquadopp acoustic Doppler current profiler, bin 2, at mooring 1030 (CB12) from August 14, 2014, to April 21, 2015. dbar, decibar; $\mathrm{cm} / \mathrm{s}$, centimeter per second; ${ }^{\circ}$, degree true. 

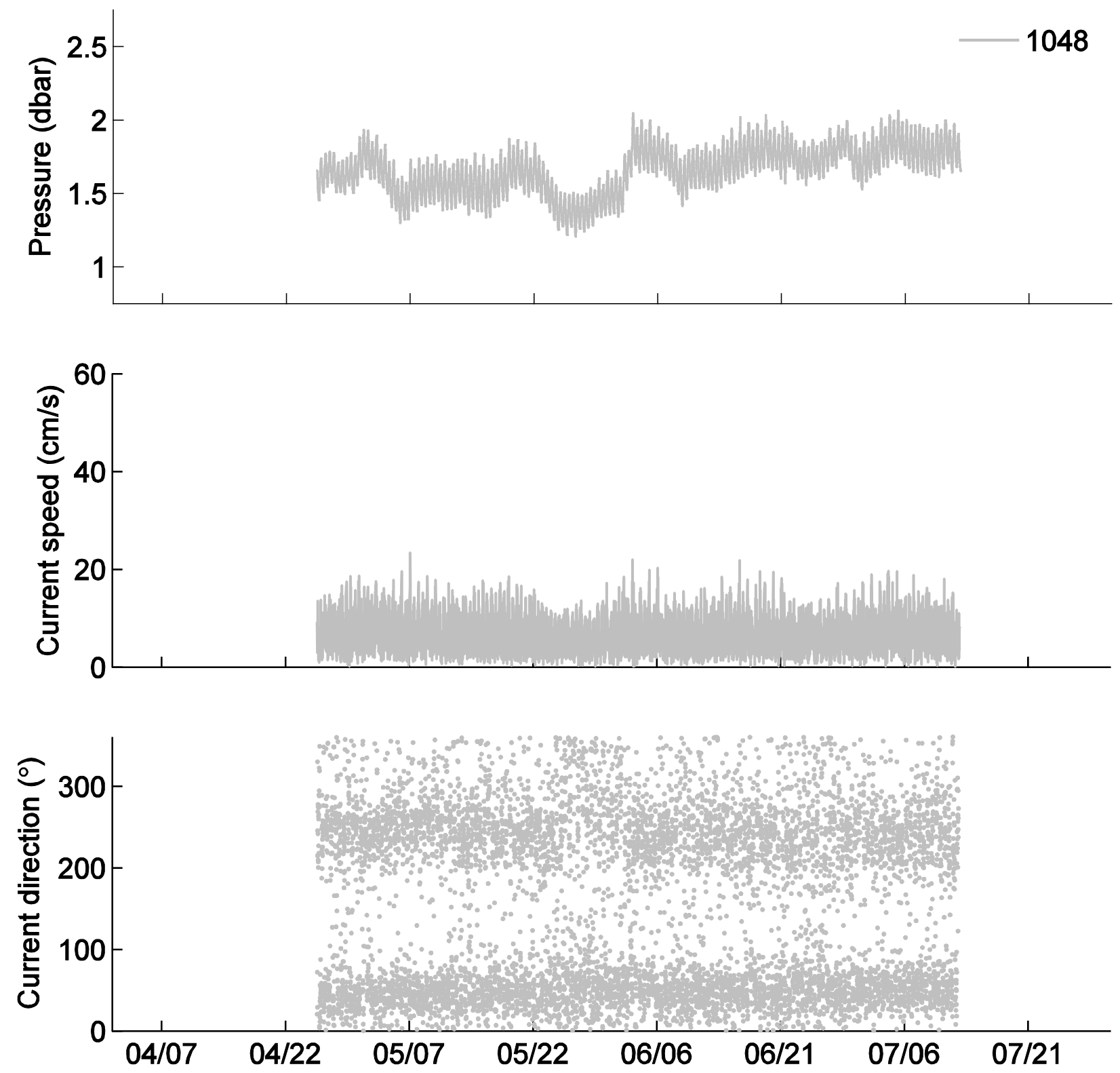

Figure 26. Graphs showing pressure (atmospherically corrected), current speed, and current direction (traveling towards convention) from 2-megahertz Aquadopp acoustic Doppler current profiler, bin 2, at mooring 1048 (V1) from April 25 to July 12, 2015. dbar, decibar; $\mathrm{cm} / \mathrm{s}$, centimeter per second; ${ }^{\circ}$, degree true. 


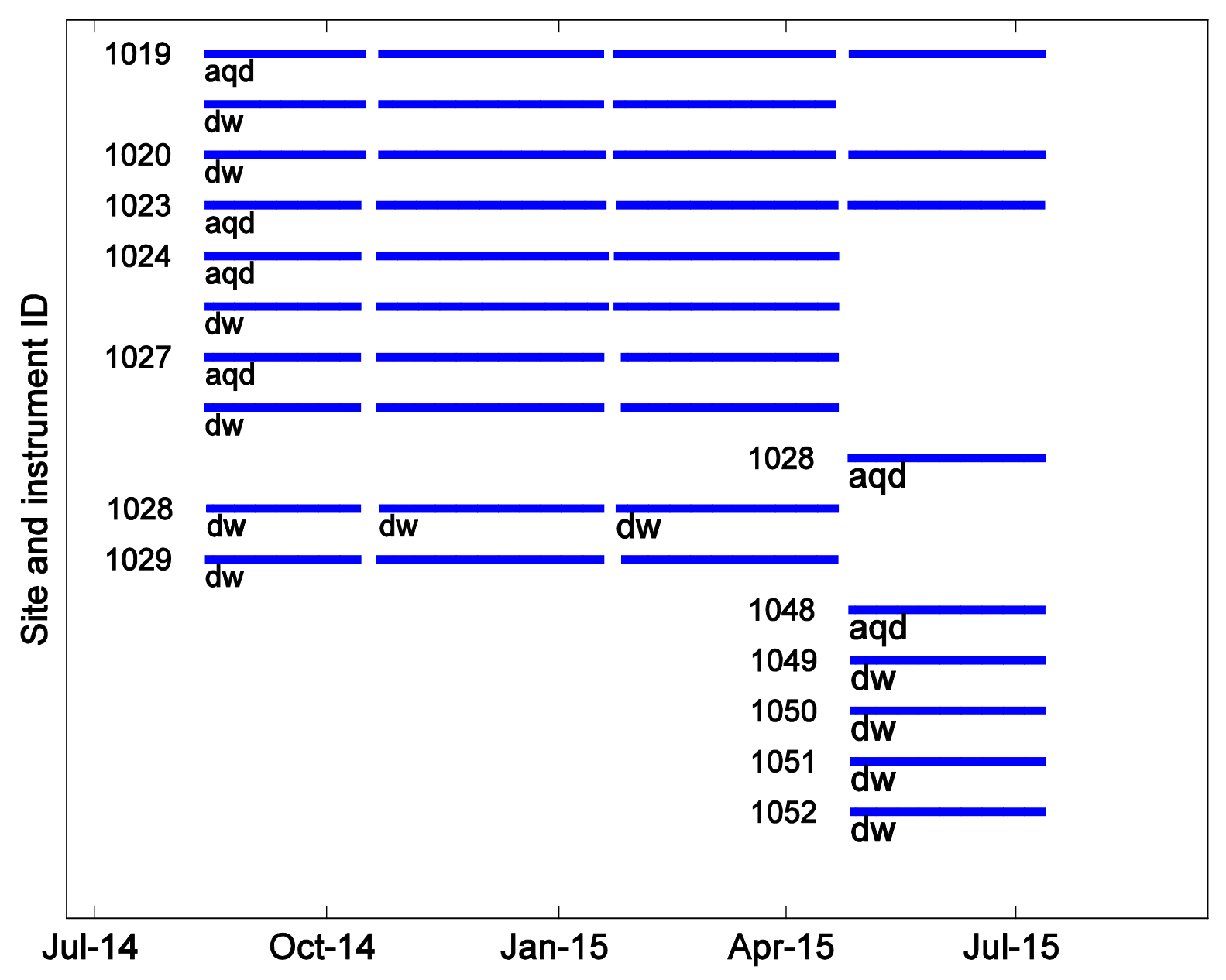

Figure 27. Chart showing the availability of wave data for Chincoteague Bay, Maryland and Virginia, for the estuarine physical response study from August 2014 to July 2015. aqd, Nortek Aquadopp; dw, RBR D|wave; ID, identification number. 

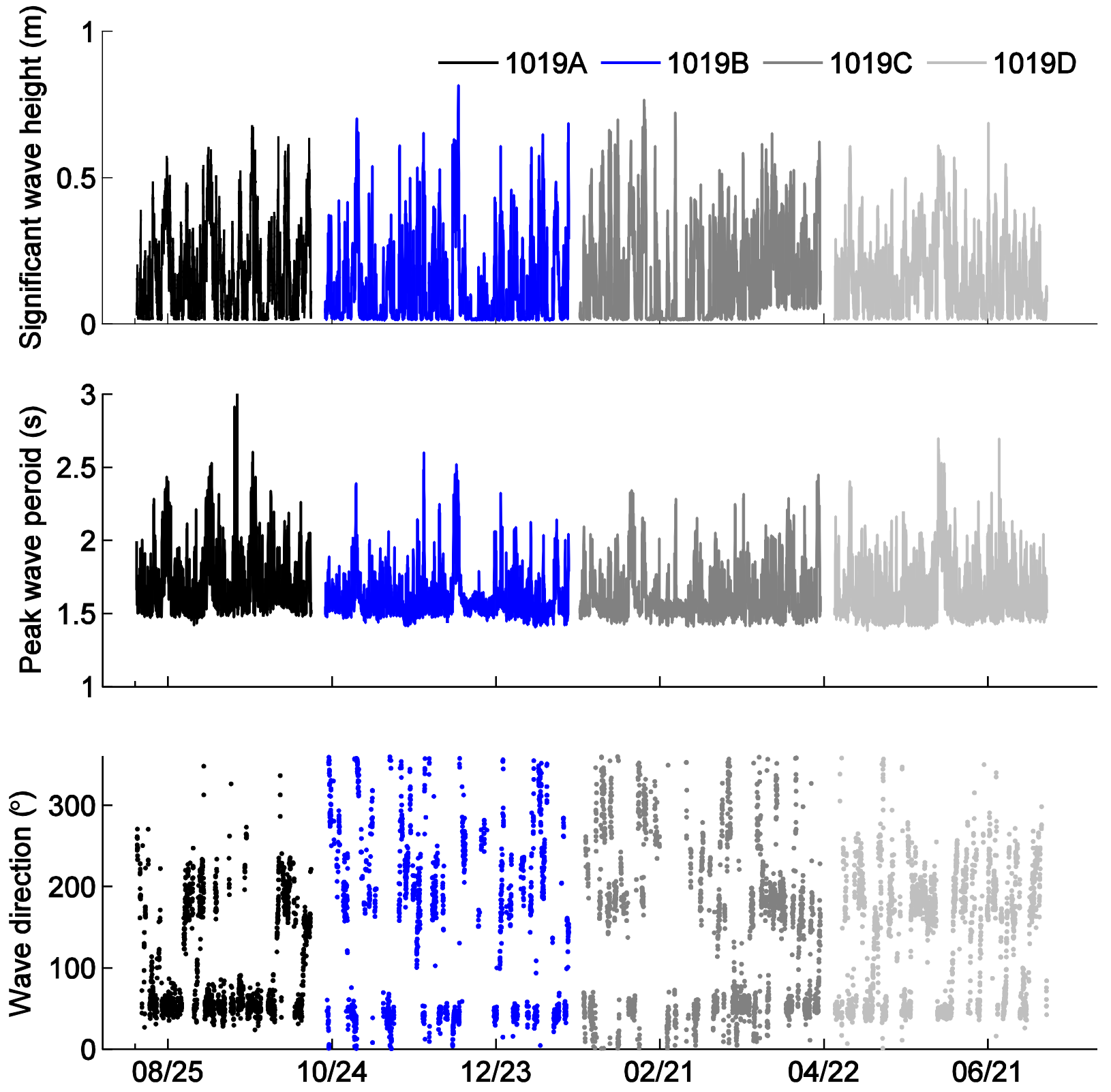

Figure 28. Graphs showing significant wave height, peak wave period, and mean wave direction (traveling from convention) from 1-megahertz Aquadopp acoustic Doppler current profiler wave burst data at mooring 1019 (CB02) from August 13, 2014, to July 12, 2015. Wave directions are shown for significant wave heights greater than or equal to 0.10 meter. m, meter; $\mathrm{s}$, second; ${ }^{\circ}$, degrees true. 

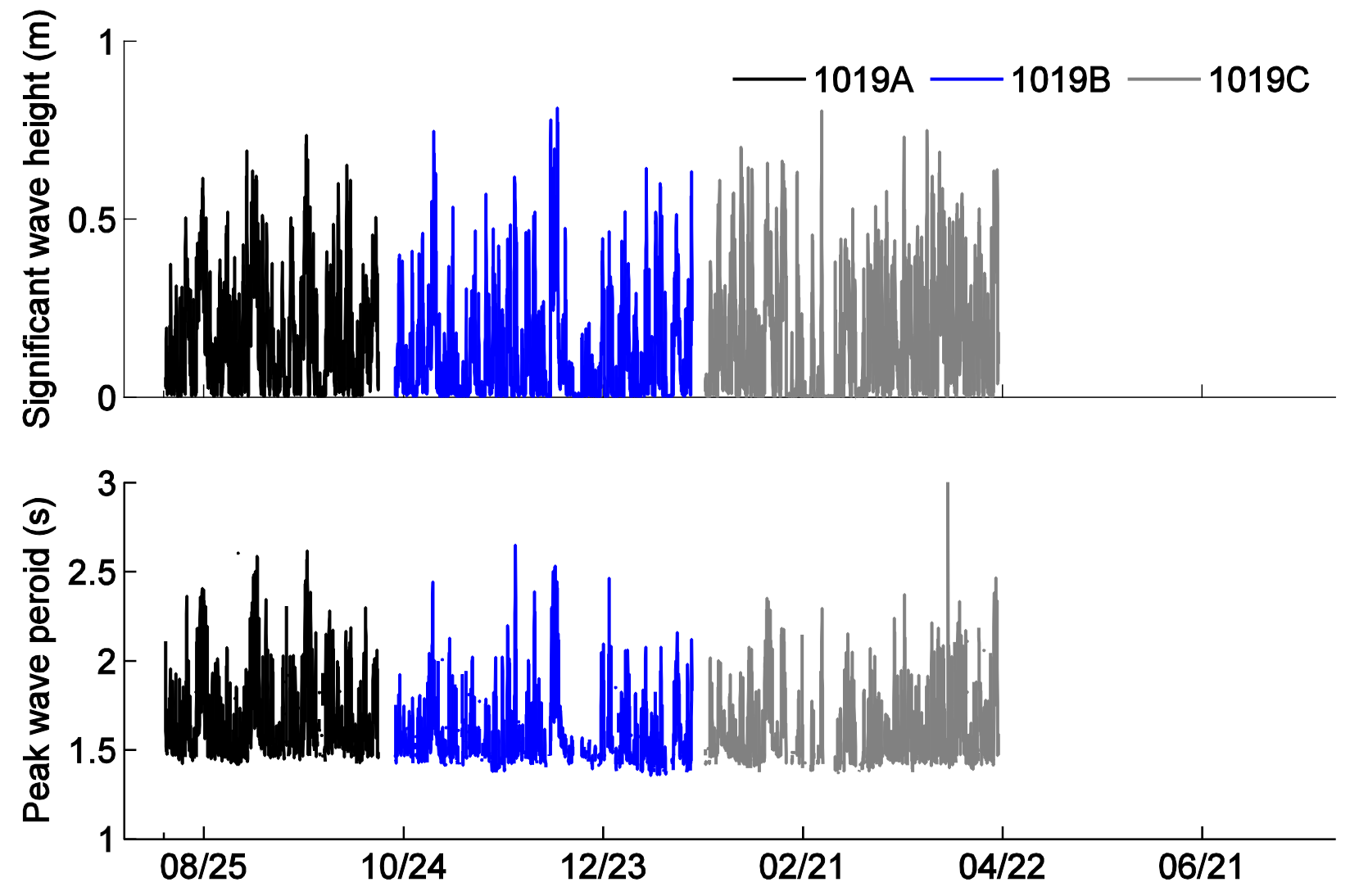

Figure 29. Graphs showing significant wave height and peak wave period from $\mathrm{D} \mid$ wave pressure logger wave burst data at mooring 1019 (CB02) from August 13, 2014, to April 20, 2015. m, meter; s, second. 

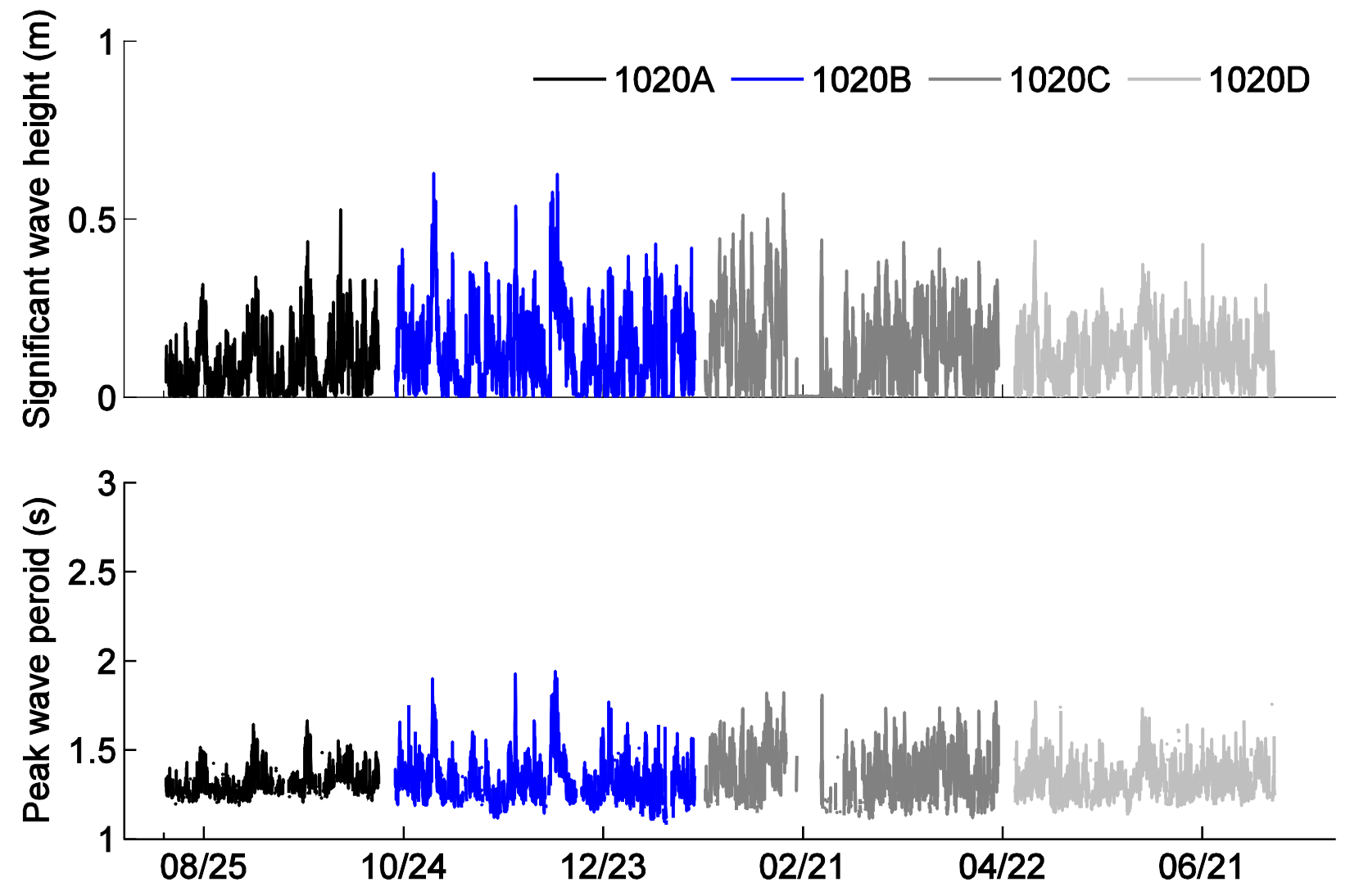

Figure 30. Graphs showing significant wave height and peak wave period from $\mathrm{D} \mid$ wave pressure logger wave burst data at mooring 1020 (CB03) from August 13, 2014, to July 12, 2015. m, meter; s, second. 

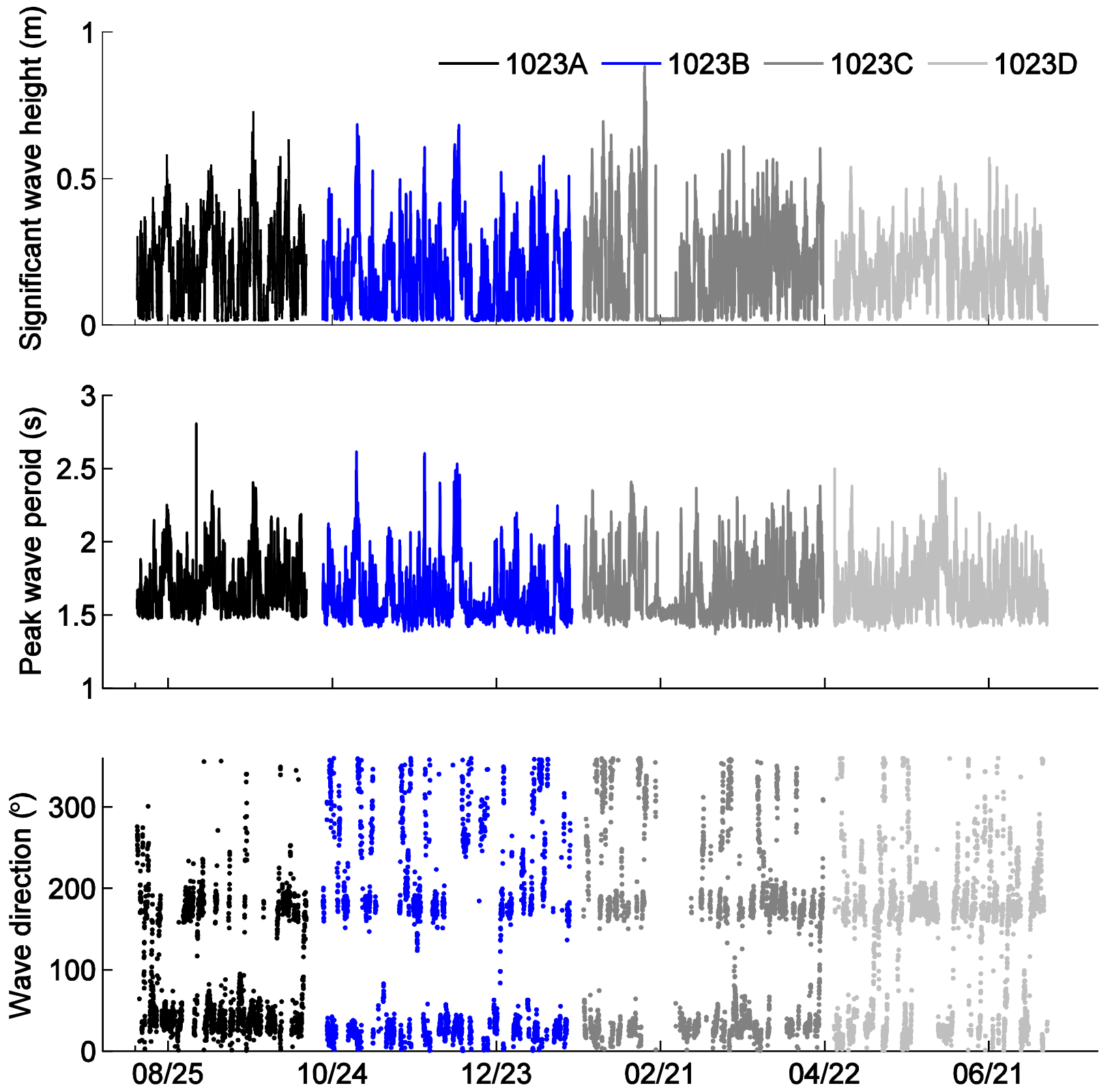

Figure 31. Graphs showing significant wave height, peak wave period, and mean wave direction (traveling from convention) from 1-megahertz Aquadopp acoustic Doppler current profiler wave burst data at mooring 1023 (CB06) from August 13, 2014, to July 12, 2015. Wave directions are shown for significant wave heights greater than or equal to 0.10 meter. m, meter; s, second; ${ }^{\circ}$, degree true. 

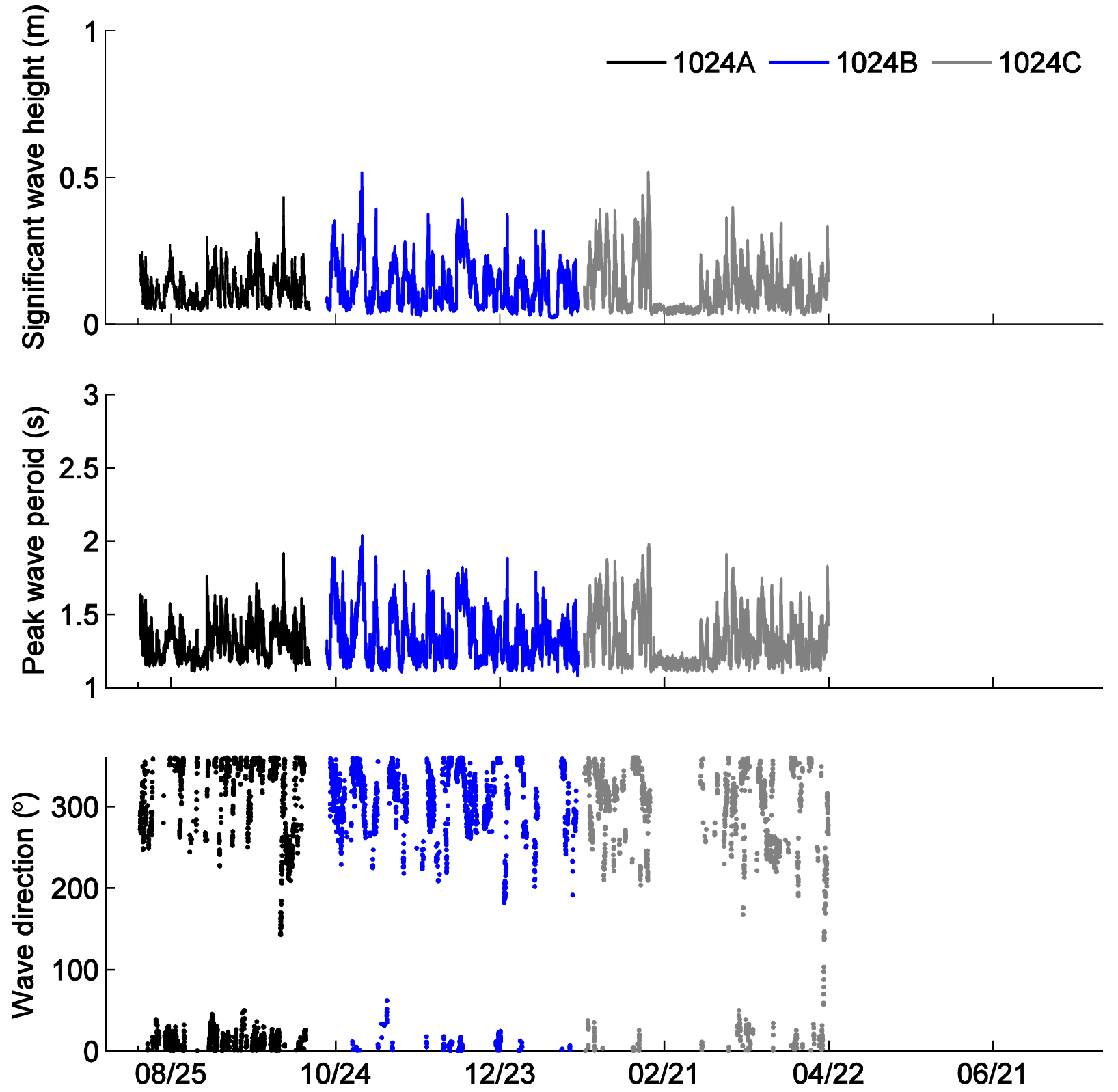

Figure 32. Graphs showing significant wave height, peak wave period, and mean wave direction (traveling from convention) from 2-megahertz Aquadopp acoustic Doppler current profiler wave burst data at mooring 1024 (CB07) from August 13, 2014, to April 21, 2015. Wave directions are shown for significant wave heights greater than or equal to 0.10 meter. m, meter; s, second; ${ }^{\circ}$, degree true. 

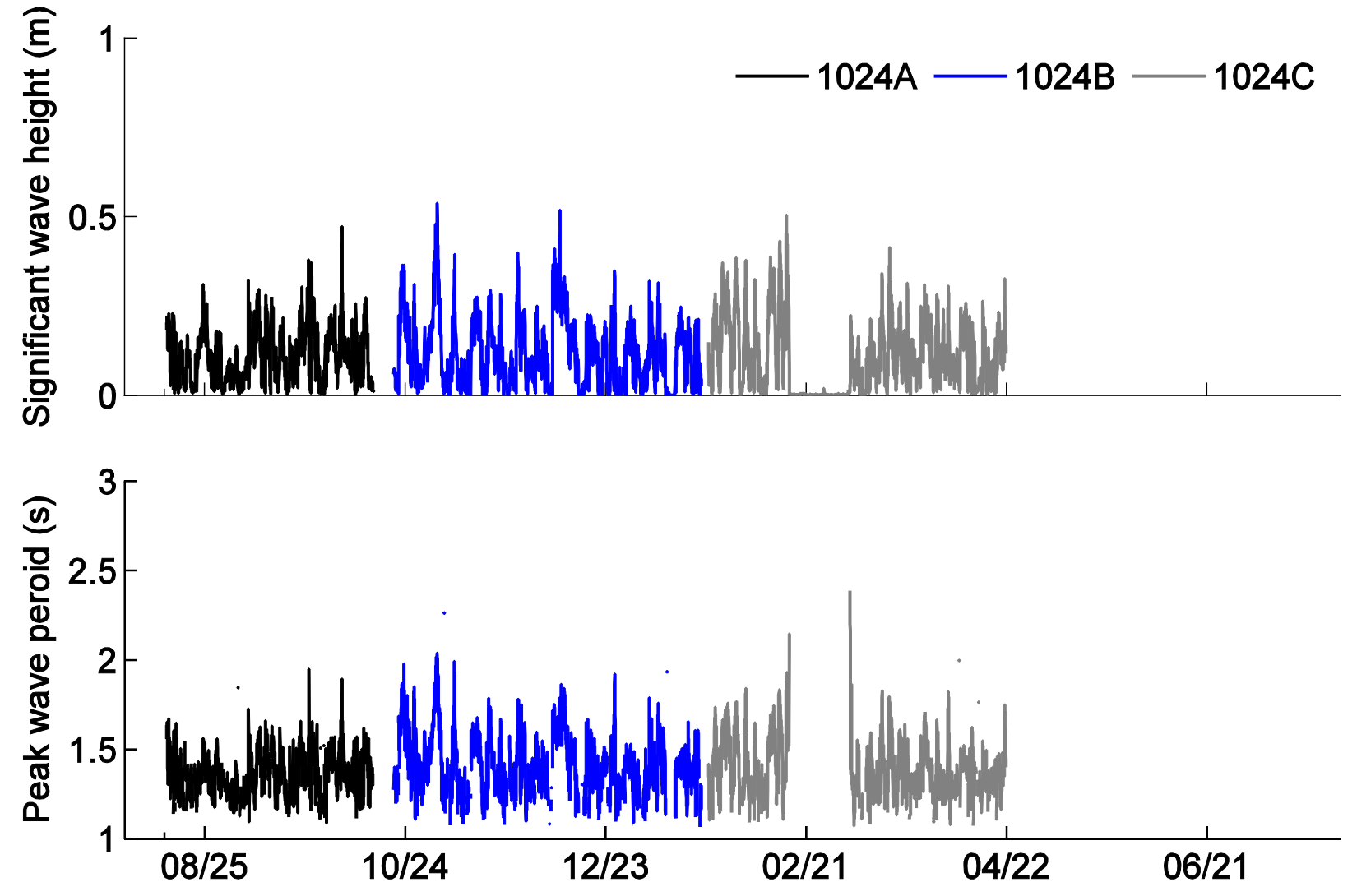

Figure 33. Graphs showing significant wave height and peak wave period from $\mathrm{D} \mid$ wave pressure logger wave burst data at mooring 1024 (CB07) from August 13, 2014, to April 21, 2015. m, meter; s, second. 

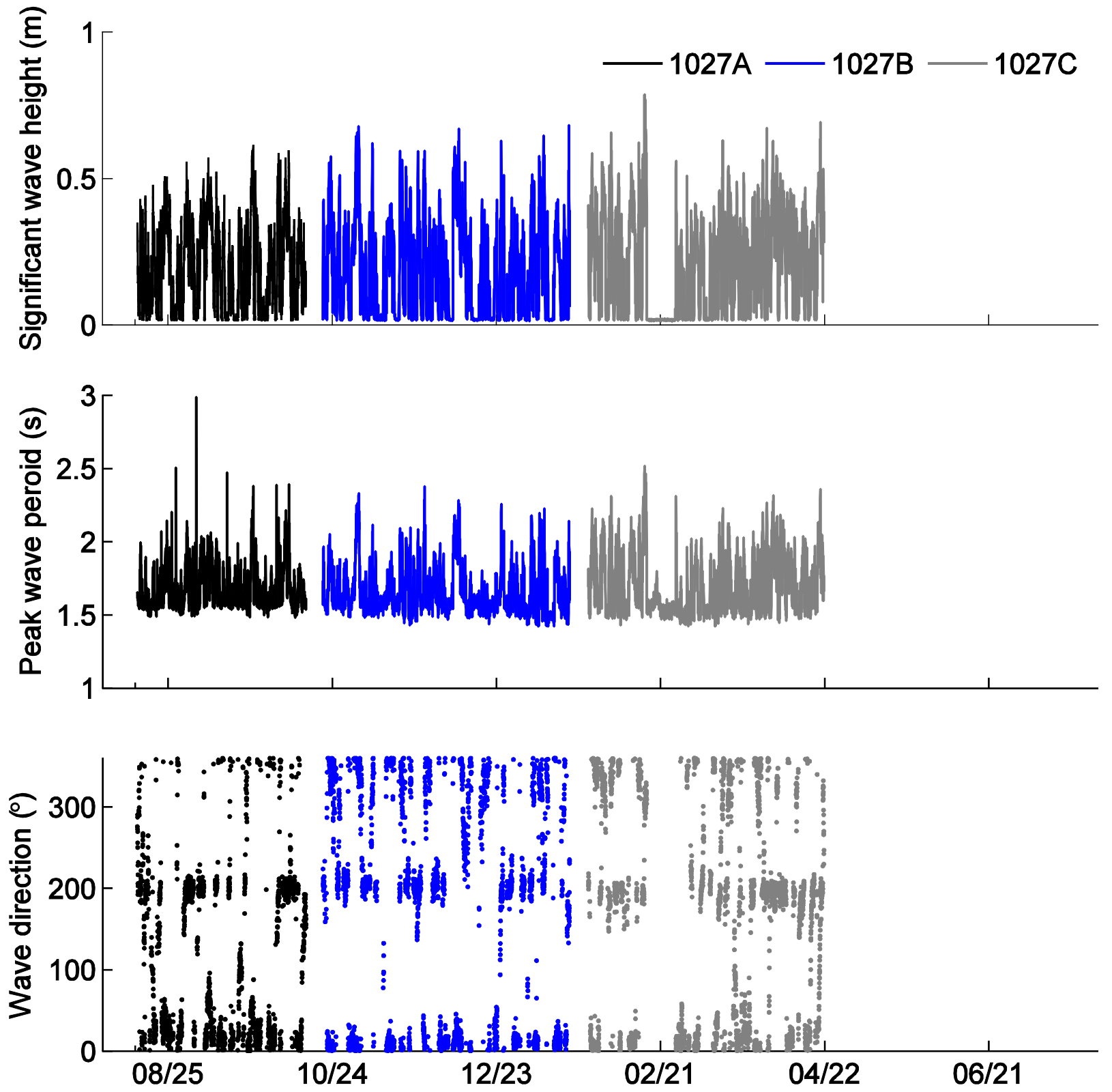

Figure 34. Graphs showing significant wave height, peak wave period, and mean wave direction (traveling from convention) from 1-megahertz Aquadopp acoustic Doppler current profiler wave burst data at mooring 1027 (CB09) from August 13, 2014, to April 21, 2015. Wave directions are shown for significant wave heights greater than or equal to 0.10 meter. m, meter; s, second; ${ }^{\circ}$, degree true. 

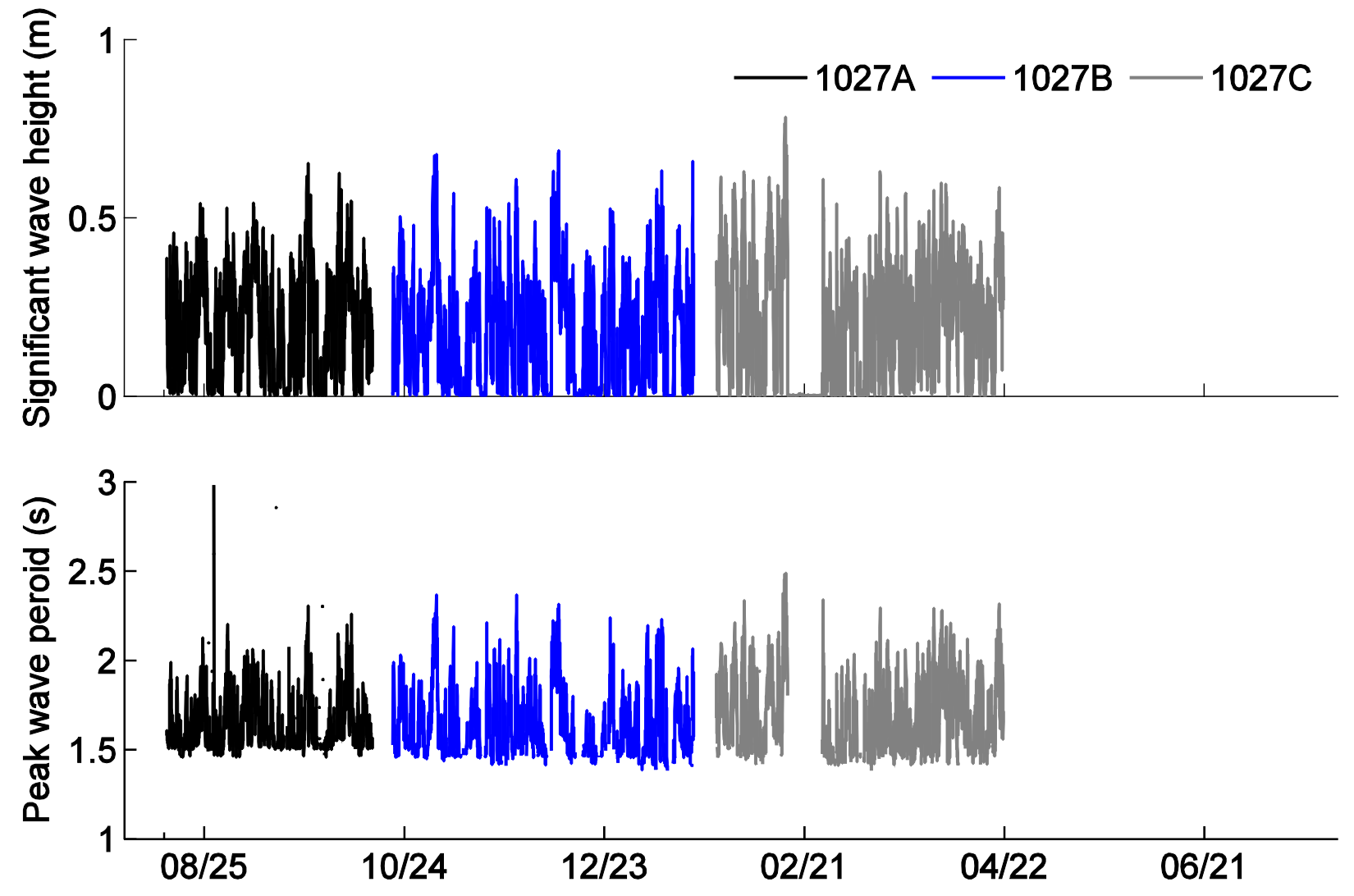

Figure 35. Graphs showing significant wave height and peak wave period from $D \mid$ wave pressure logger wave burst data at mooring 1027 (CB09) from August 13, 2014, to April 21, 2015. m, meter; s, second. 

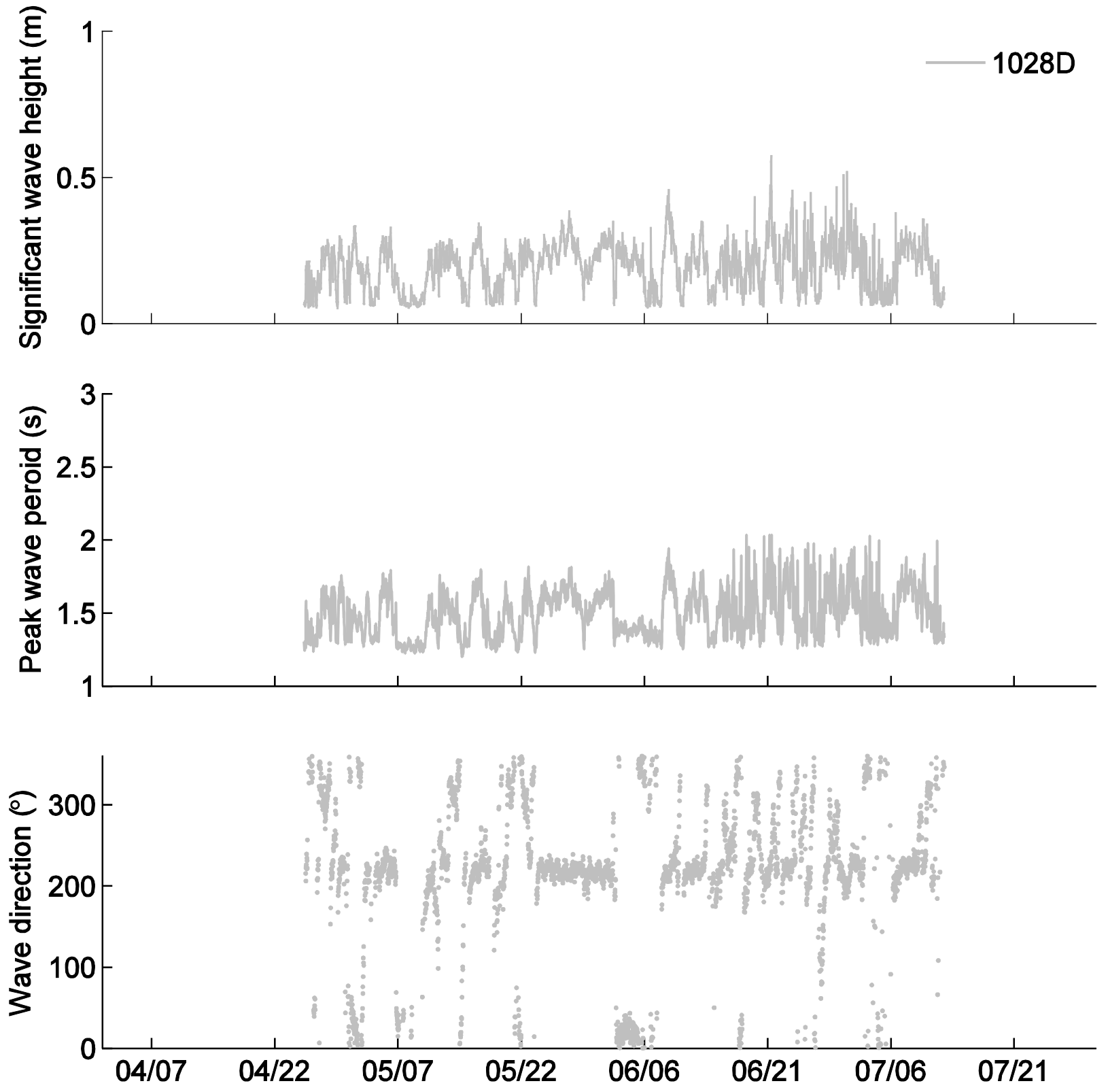

Figure 36. Graphs showing significant wave height, peak wave period, and mean wave direction (traveling from convention) from 2-megahertz Aquadopp acoustic Doppler current profiler wave burst data at mooring 1028 (CB10) from April 25 to July 12, 2015. Wave directions are shown for significant wave heights greater than or equal to 0.10 meter. m, meter; s, second; ${ }^{\circ}$, degree true. 

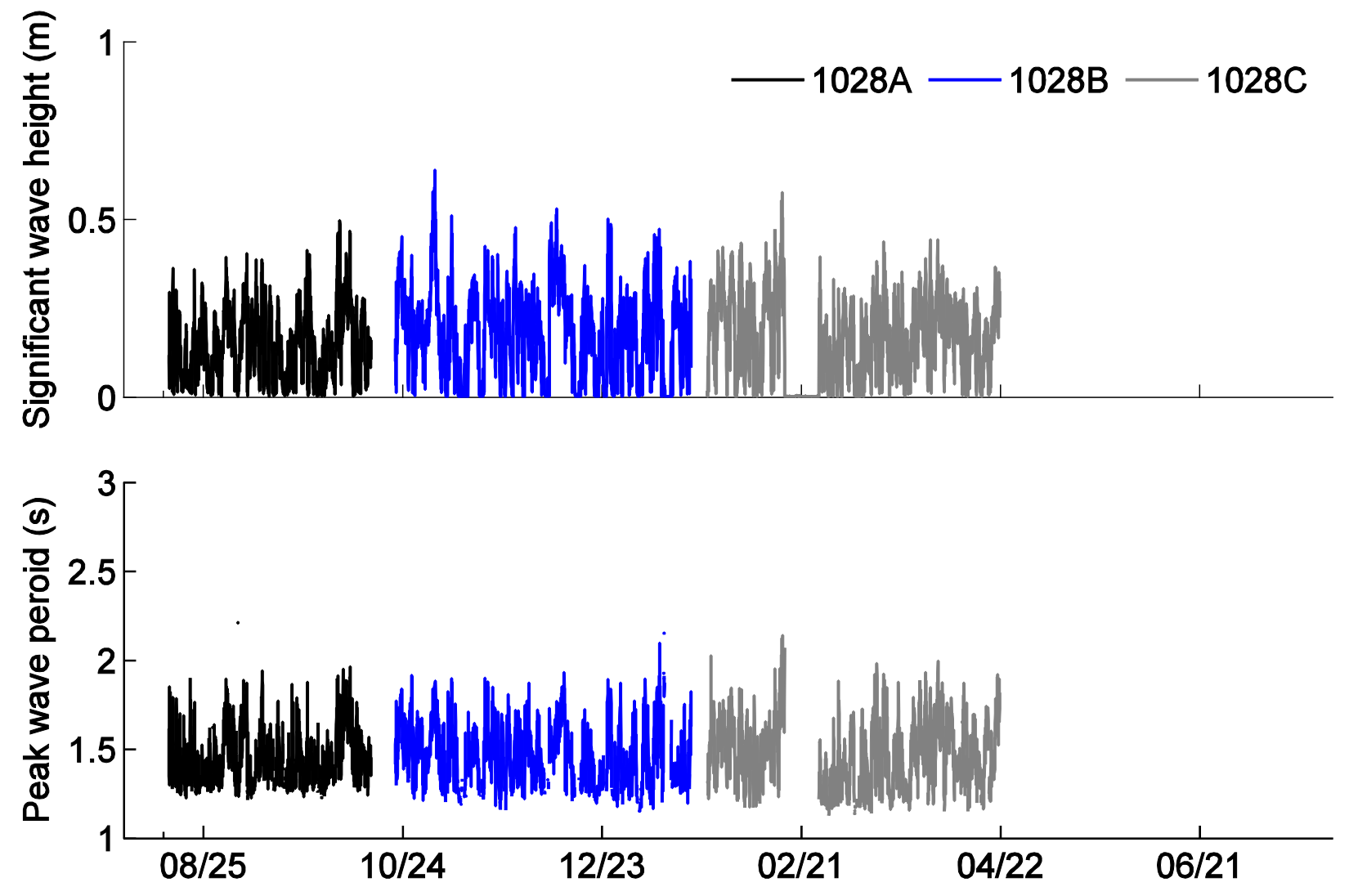

Figure 37. Graphs showing significant wave height and peak wave period from $D \mid$ wave pressure logger wave burst data at mooring 1028 (CB10) from August 14, 2014, to April 21, 2015. m, meter; s, second. 

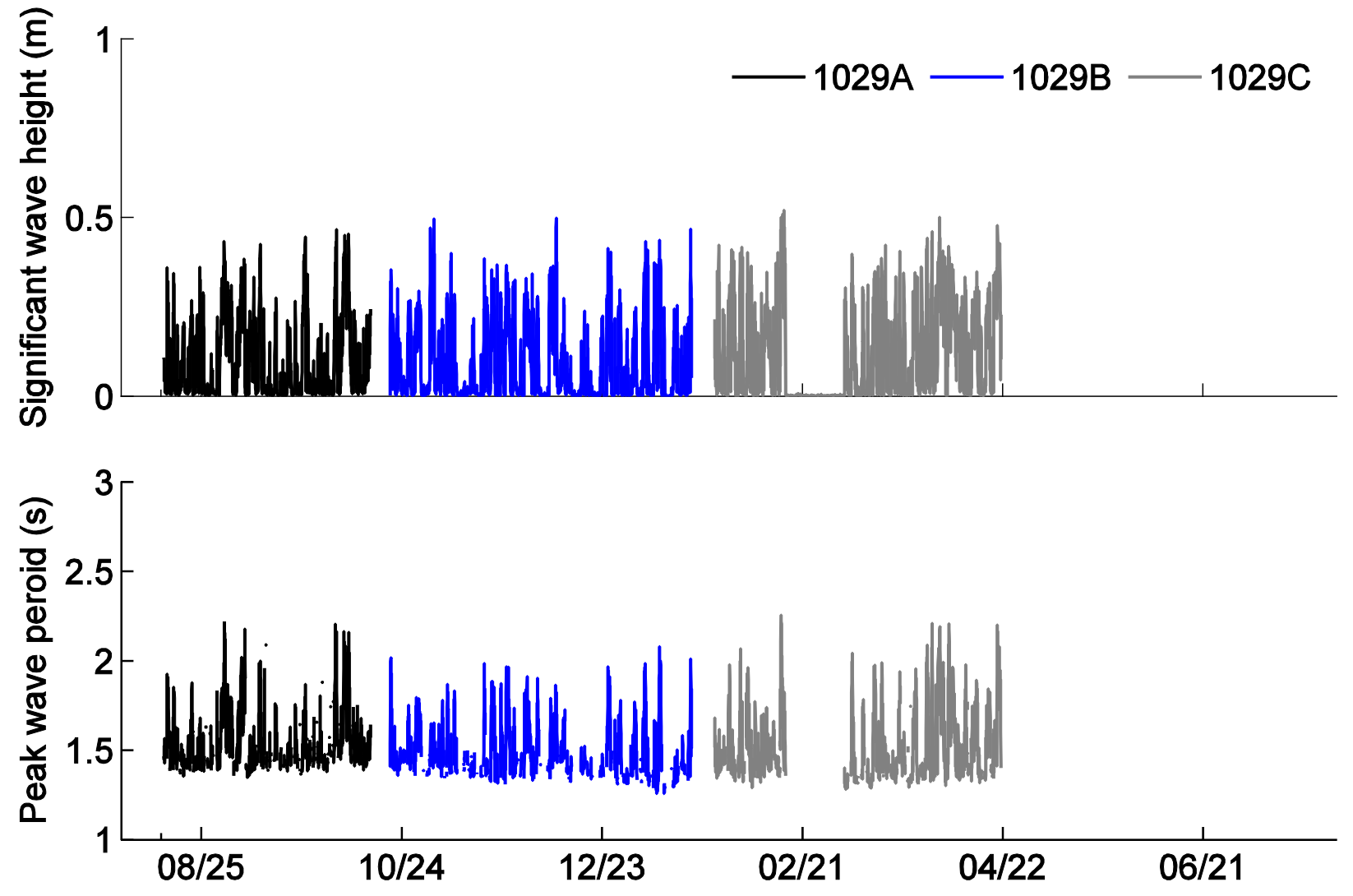

Figure 38. Graphs showing significant wave height and peak wave period from $\mathrm{D} \mid$ wave pressure logger wave burst data at mooring 1029 (CB11) from August 13, 2014, to April 21, 2015. m, meter; s, second. 

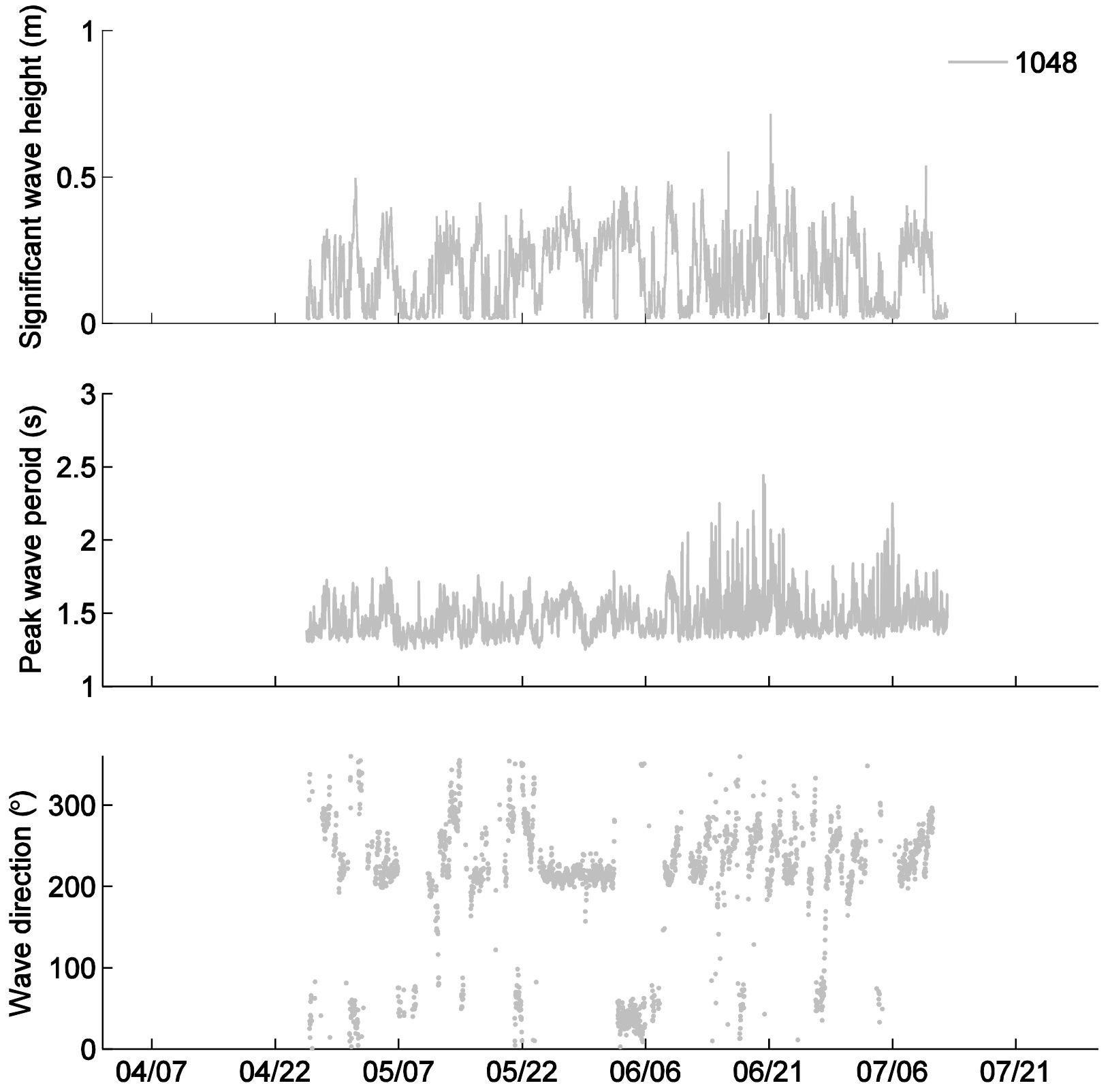

Figure 39. Graphs showing significant wave height, peak wave period, and mean wave direction (traveling from convention) from 2-megahertz Aquadopp acoustic Doppler current profiler wave burst data at mooring 1048 (V1) from April 25 to July 12, 2015. Wave directions are shown for significant wave heights greater than or equal to 0.10 meter. m, meter; s, second; ${ }^{\circ}$, degree true. 

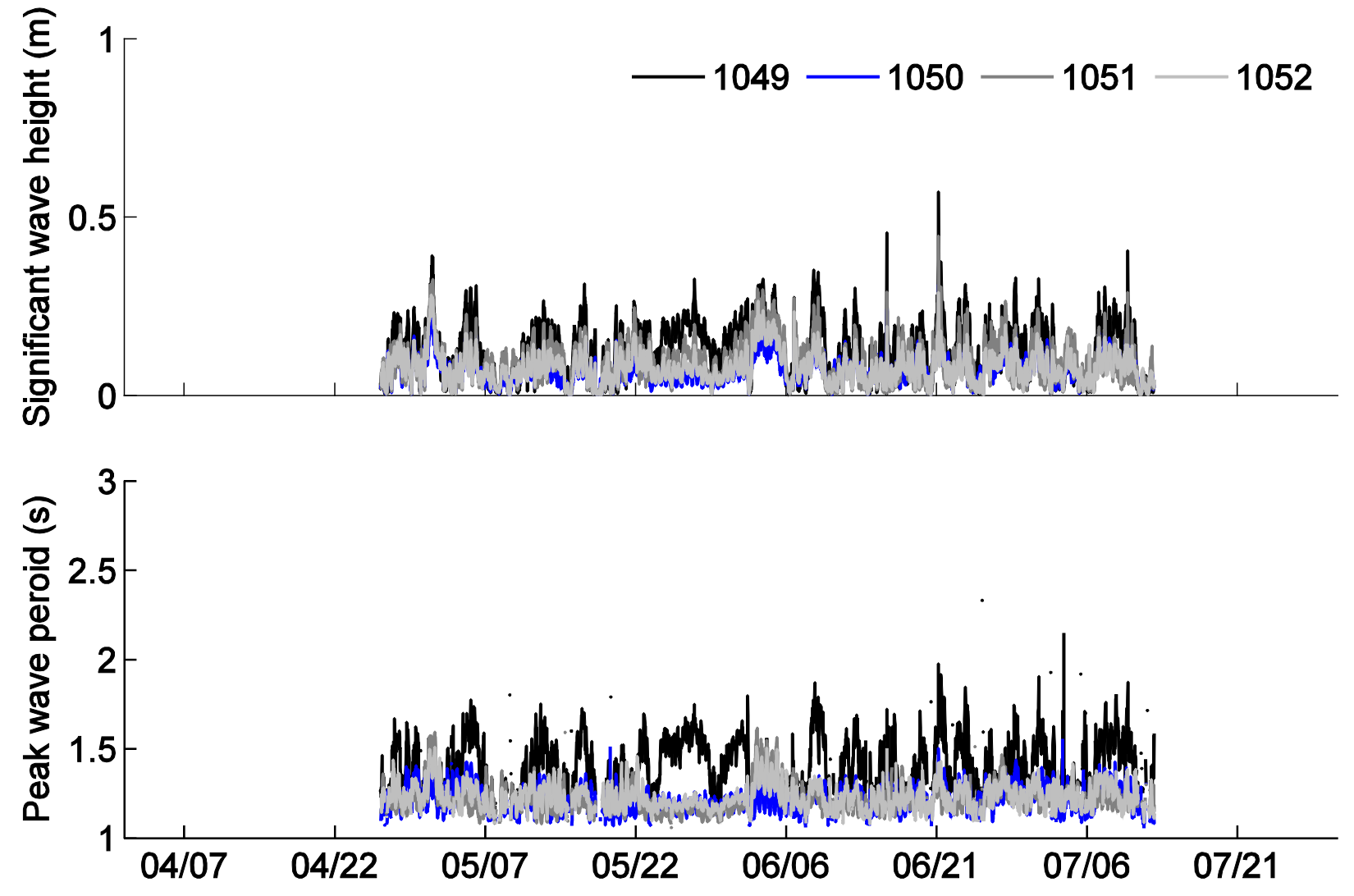

Figure 40. Graphs showing significant wave height and peak wave period from wave burst data collected with D|wave pressure loggers at moorings 1049-1052 (V2-V5) from April 26 to July 12, 2015. m, meter; s, second. 


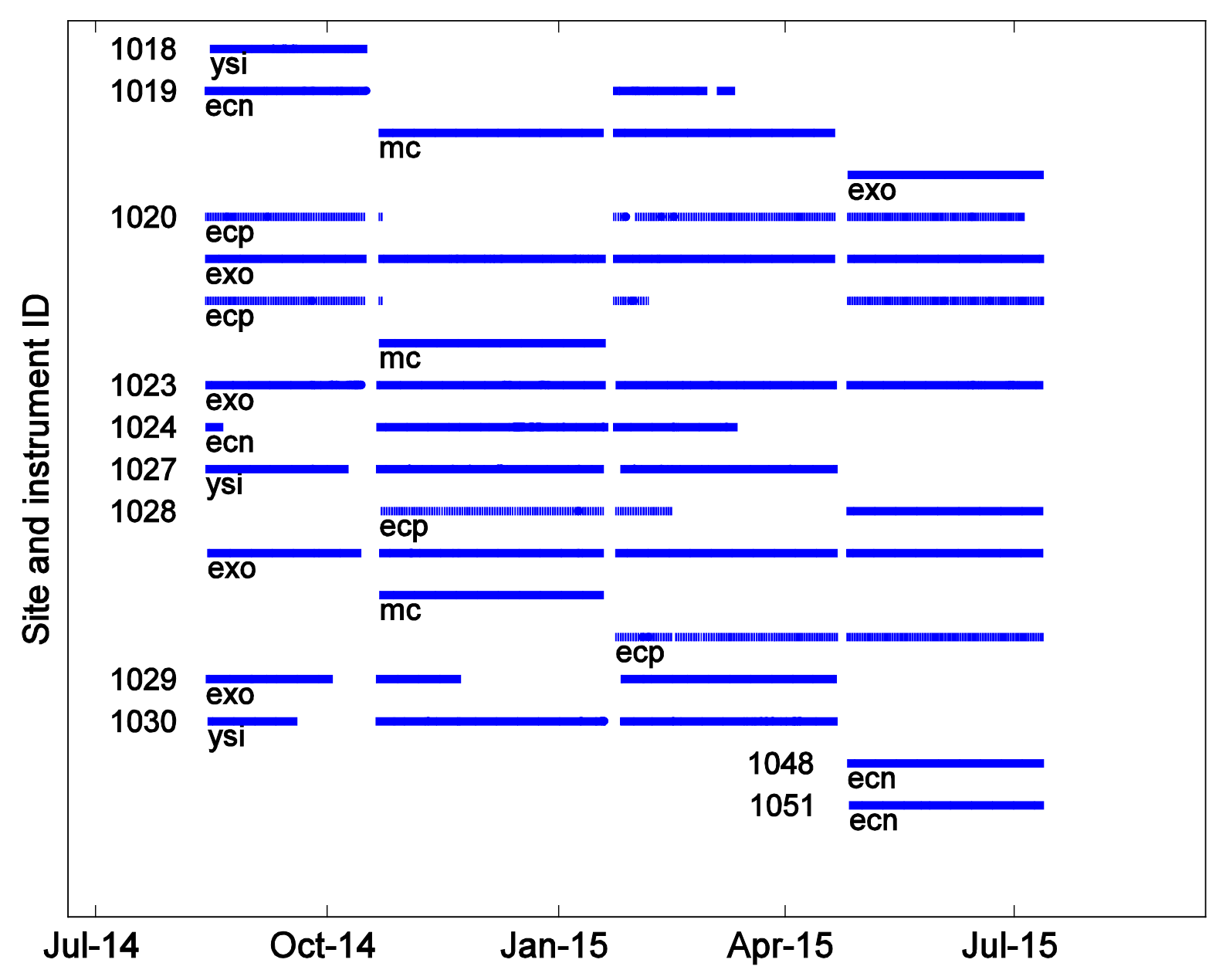

Figure 41. Chart showing the availability of water-quality data for Chincoteague Bay, Maryland and Virginia, for the Estuarine Physical Response to Storms study from August 2014 to July 2015. ysi, YSI 6600 sonde; ecn, WET Labs ECO-NTUSB; ecp, WET Labs ECO-PARSB; exo, YSI EXO2 sonde; mc, Sea-Bird SBE 37-SM MicroCAT; ID, identification number. 

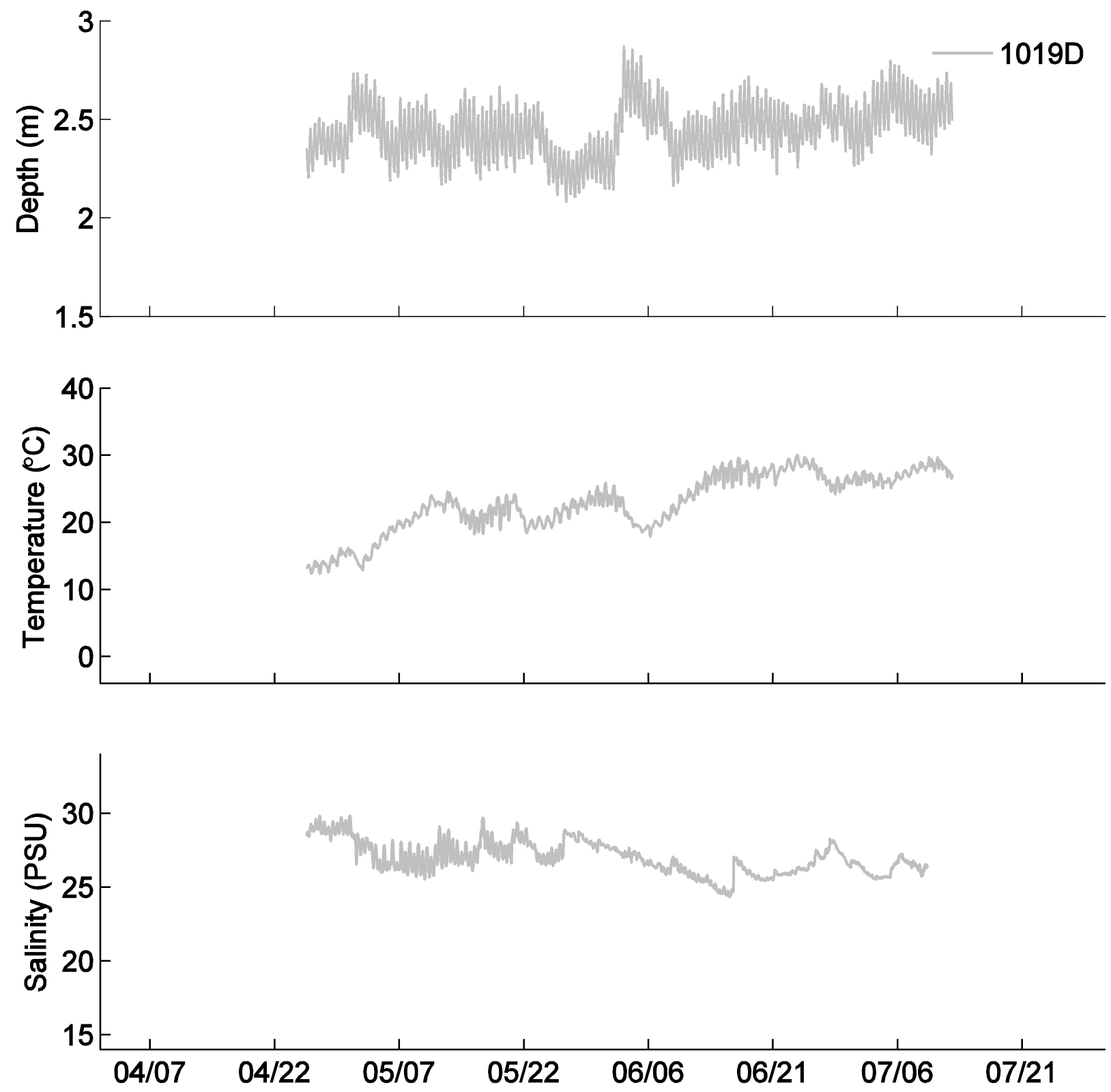

Figure 42. Graphs showing sensor depth, water temperature, and salinity from YSI EXO2 multiparameter sonde data at mooring 1019 (CB02) from April 25 to July 12, 2015. m, meter; ${ }^{\circ} \mathrm{C}$, degree Celsius; PSU, practical salinity unit. 

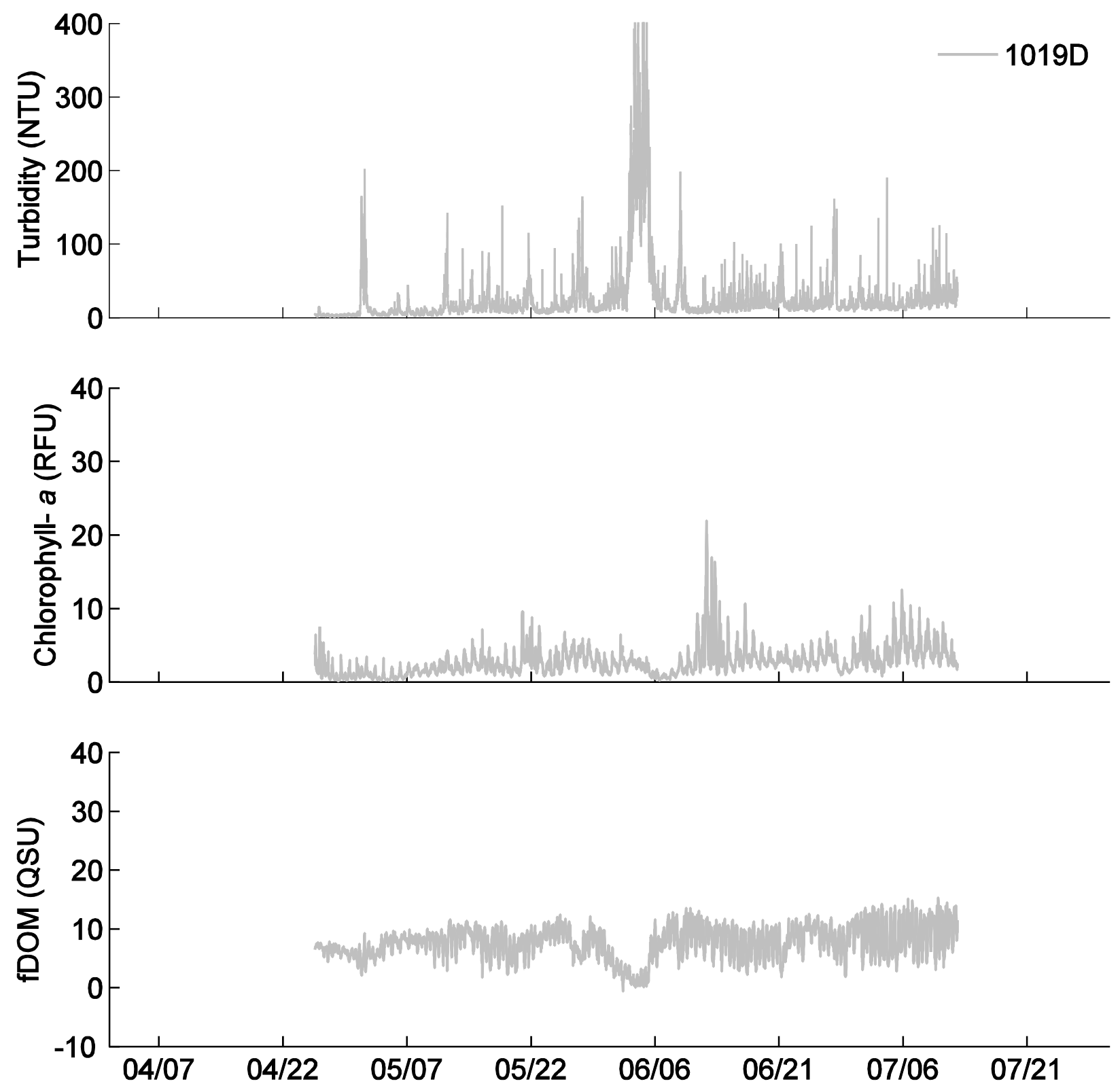

Figure 43. Graphs showing turbidity, chlorophyll-a, and fluorescent dissolved organic matter (fDOM) from YSI EXO2 multiparameter sonde data at mooring 1019 (CB02) from April 25 to July 12, 2015. NTU, nephelometric turbidity unit; RFU, relative fluorescence unit; QSU, quinine sulfate unit. 

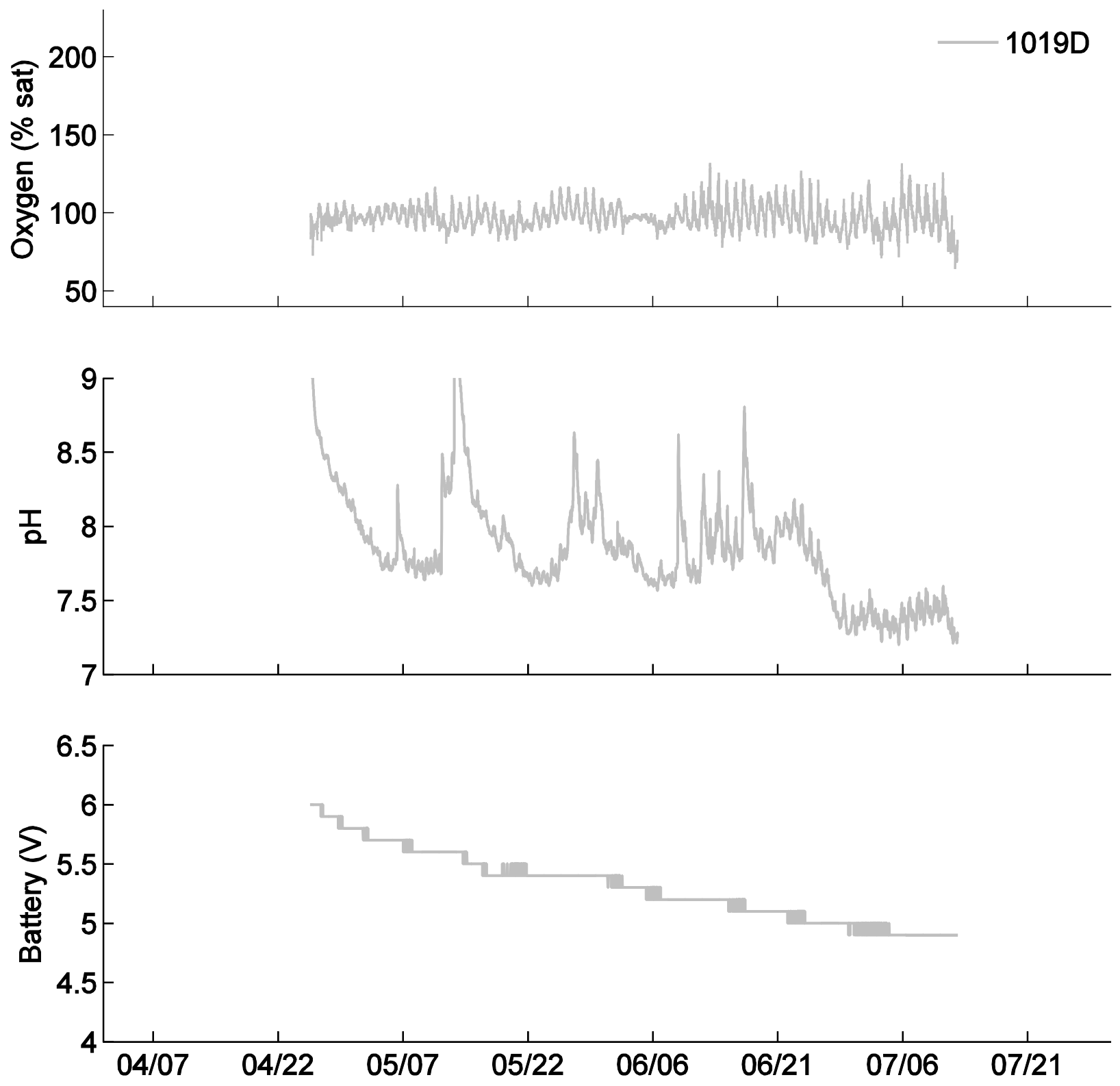

Figure 44. Graphs showing oxygen saturation, $\mathrm{pH}$, and battery power from YSI EXO2 multiparameter sonde data at mooring 1019 (CB02) from April 25 to July 12, 2015. \% sat, percent saturation; pH, pH unit; V, volt. 

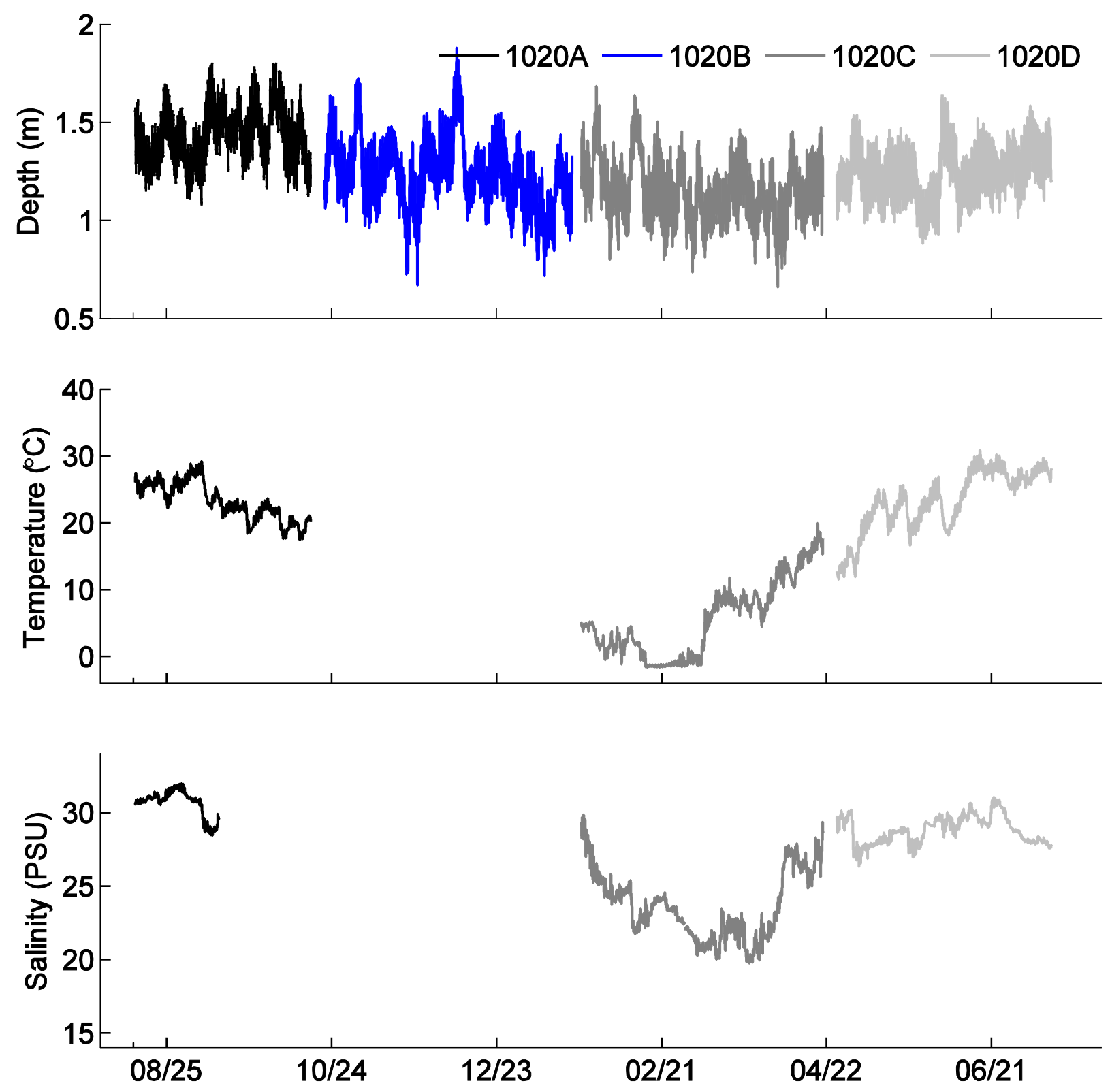

Figure 45. Graphs showing sensor depth, water temperature, and salinity from YSI EXO2 multiparameter sonde data at mooring 1020 (CB03) from August 13, 2014, to July 12, 2015. m, meter; ${ }^{\circ} \mathrm{C}$, degree Celsius; PSU, practical salinity unit. 

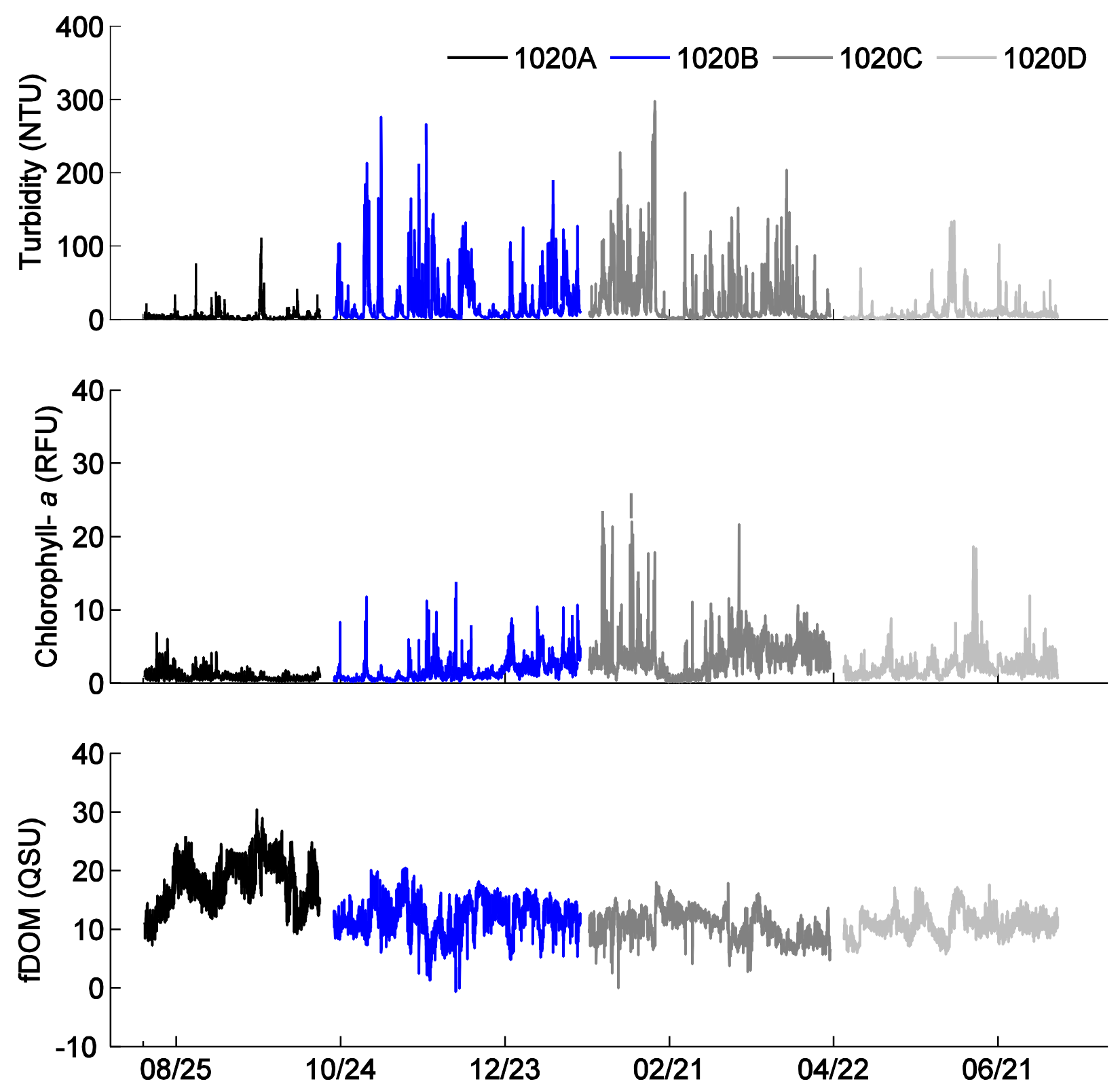

Figure 46. Graphs showing turbidity, chlorophyll-a, and fluorescent dissolved organic matter (fDOM) from YSI EXO2 multiparameter sonde data at mooring 1020 (CB03) from August 13, 2014, to July 12, 2015. NTU, nephelometric turbidity unit; RFU, relative fluorescence unit; QSU, quinine sulfate unit. 

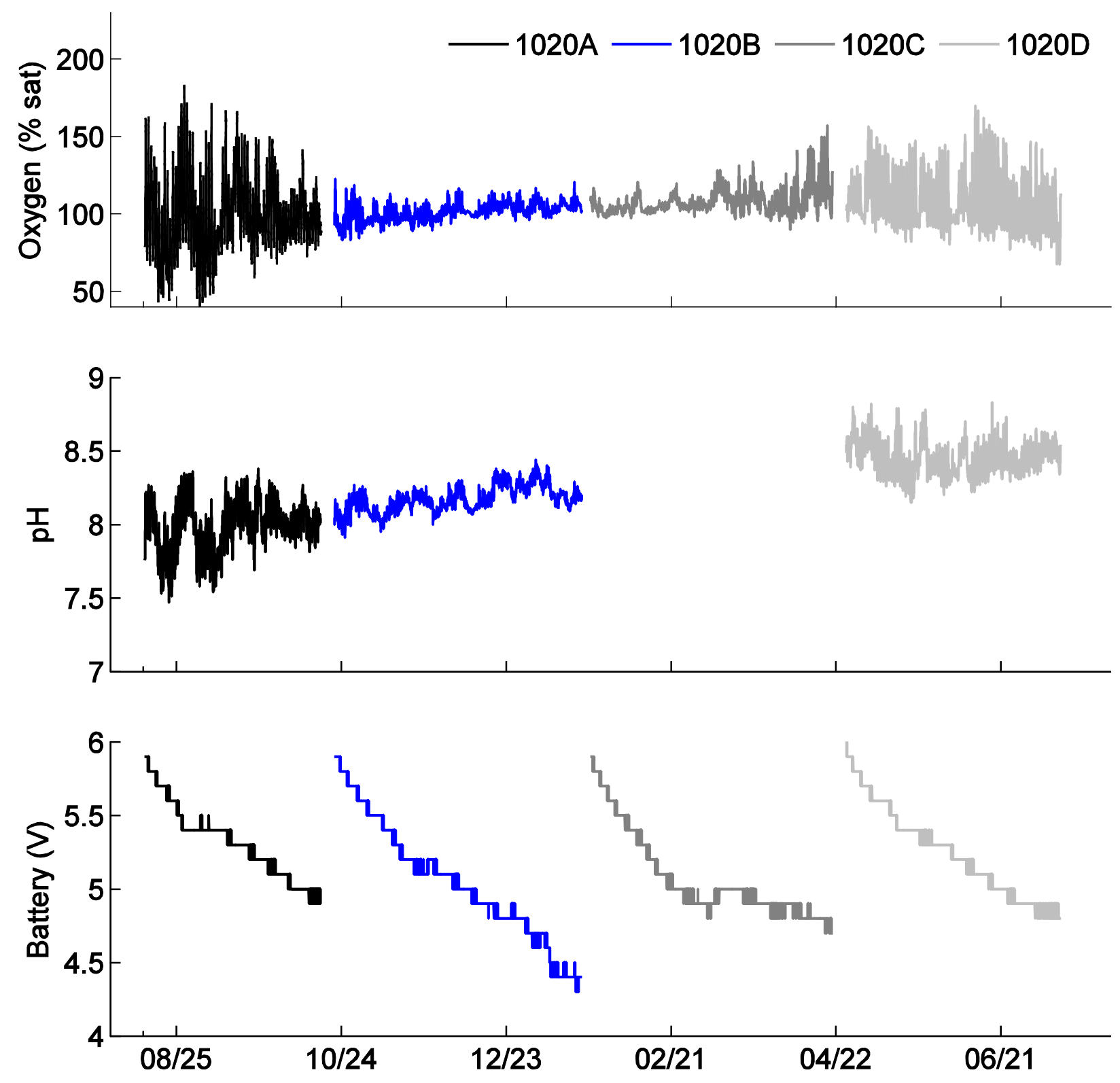

Figure 47. Graphs showing oxygen saturation, $\mathrm{pH}$, and battery power from YSI EXO2 multiparameter sonde data at mooring 1020 (CB03) from August 13, 2014, to July 12, 2015. \% sat, percent saturation; pH, pH unit; V, volt. 

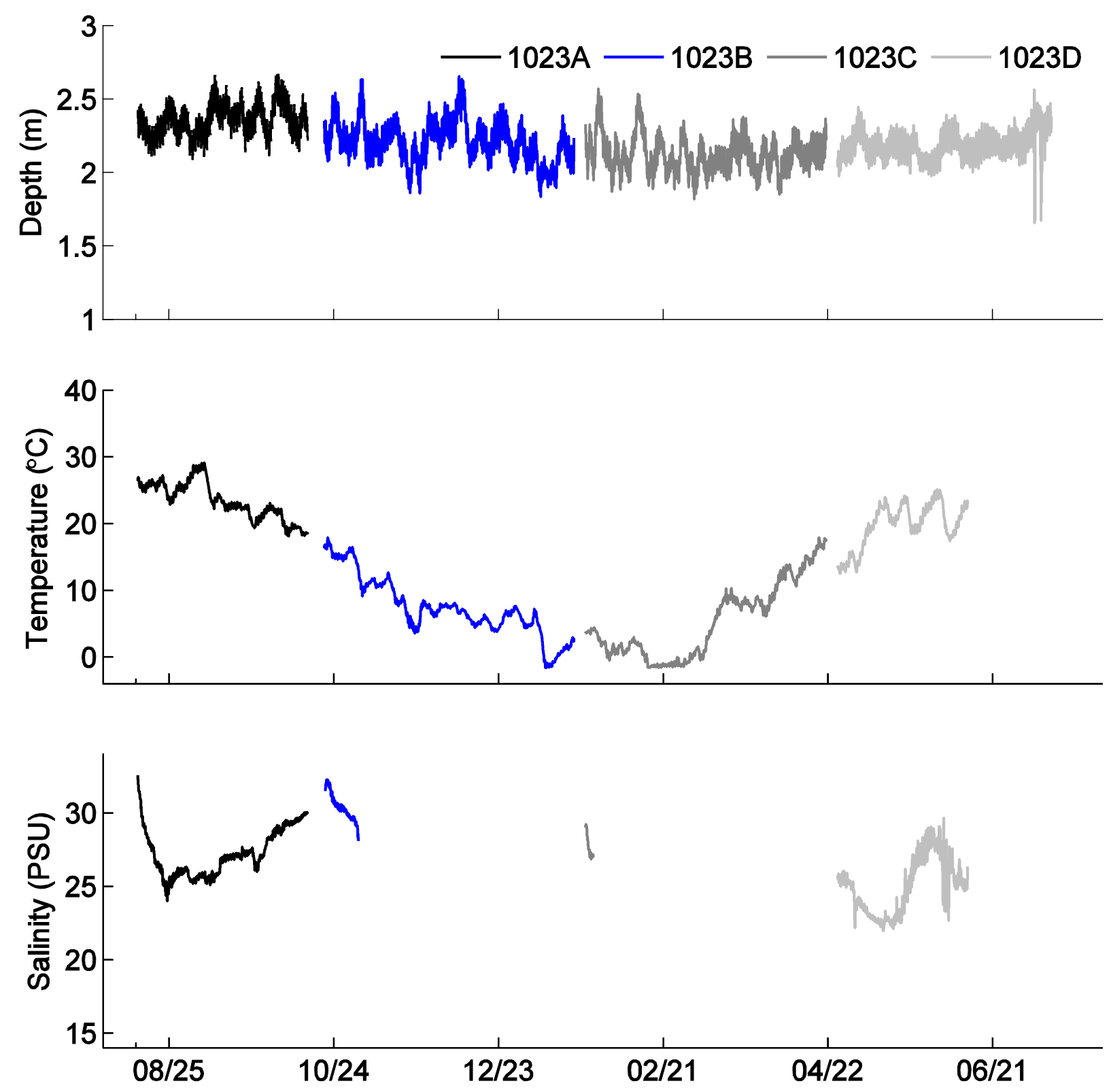

Figure 48. Graphs showing sensor depth, water temperature, and salinity from YSI EXO2 multiparameter sonde data at mooring 1023 (CB06) from August 13, 2014, to July 12, 2015. m, meter; ${ }^{\circ} \mathrm{C}$, degree Celsius; PSU, practical salinity unit. 

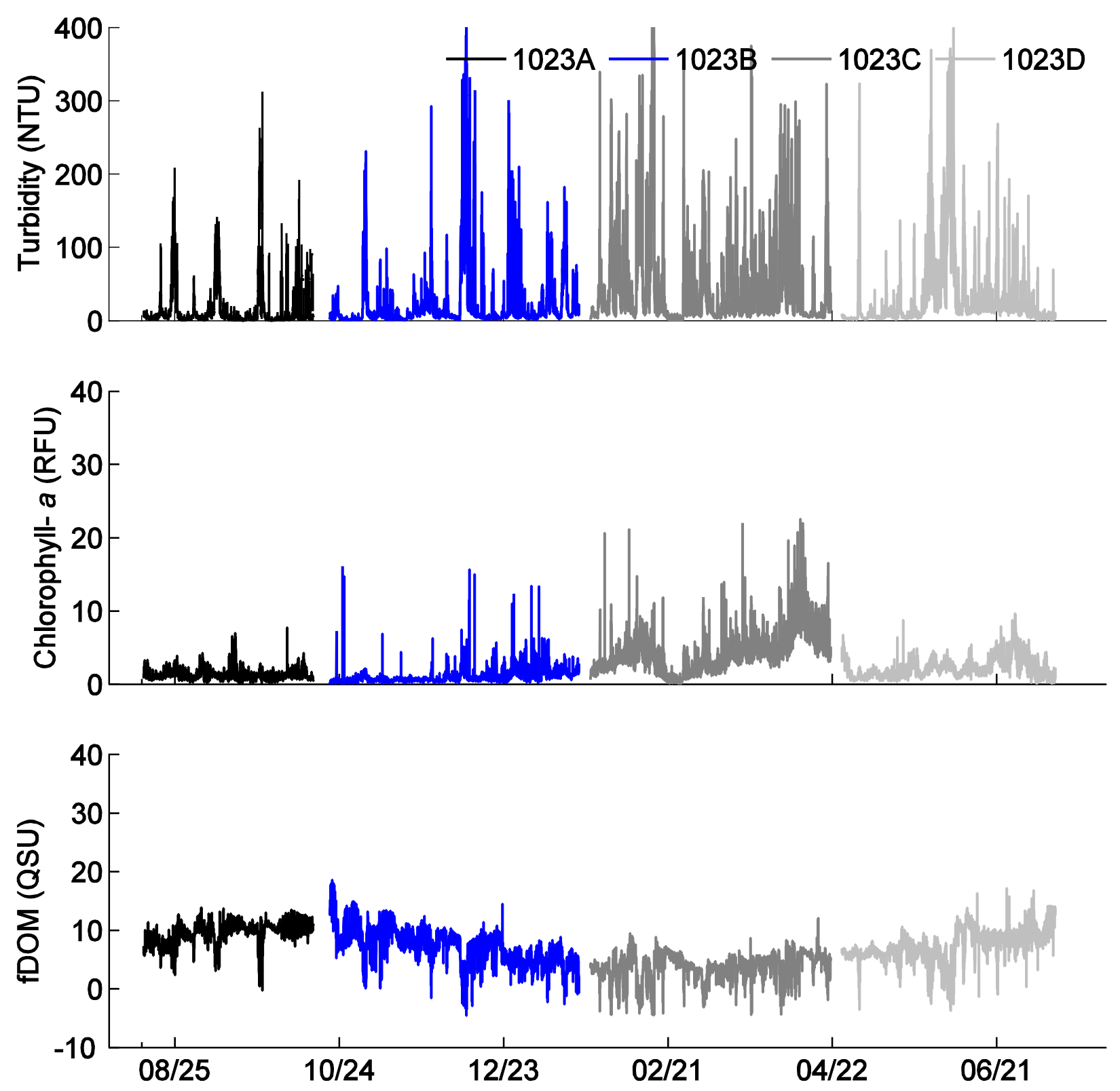

Figure 49. Graphs showing turbidity, chlorophyll-a, and fluorescent dissolved organic matter (fDOM) from YSI EXO2 multiparameter sonde data at mooring 1023 (CB06) from August 13, 2014, to July 12, 2015. NTU, nephelometric turbidity unit; RFU, relative fluorescence unit; QSU, quinine sulfate unit. 

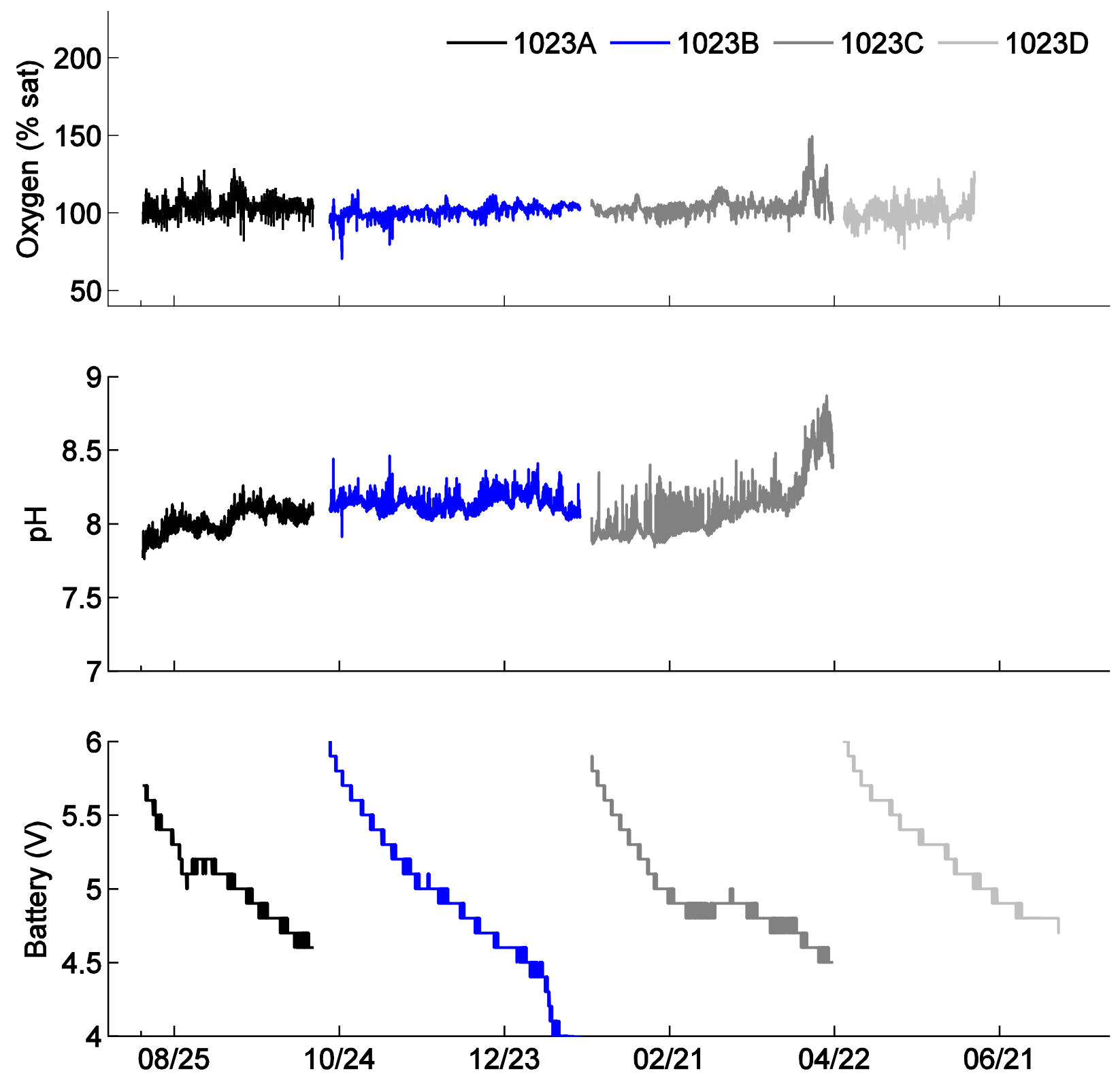

Figure 50. Graphs showing oxygen saturation, $\mathrm{pH}$, and battery power from YSI EXO2 multiparameter sonde data at mooring 1023 (CB06) from August 13, 2014, to July 12, 2015. \% sat, percent saturation; pH, pH unit; V, volt. 

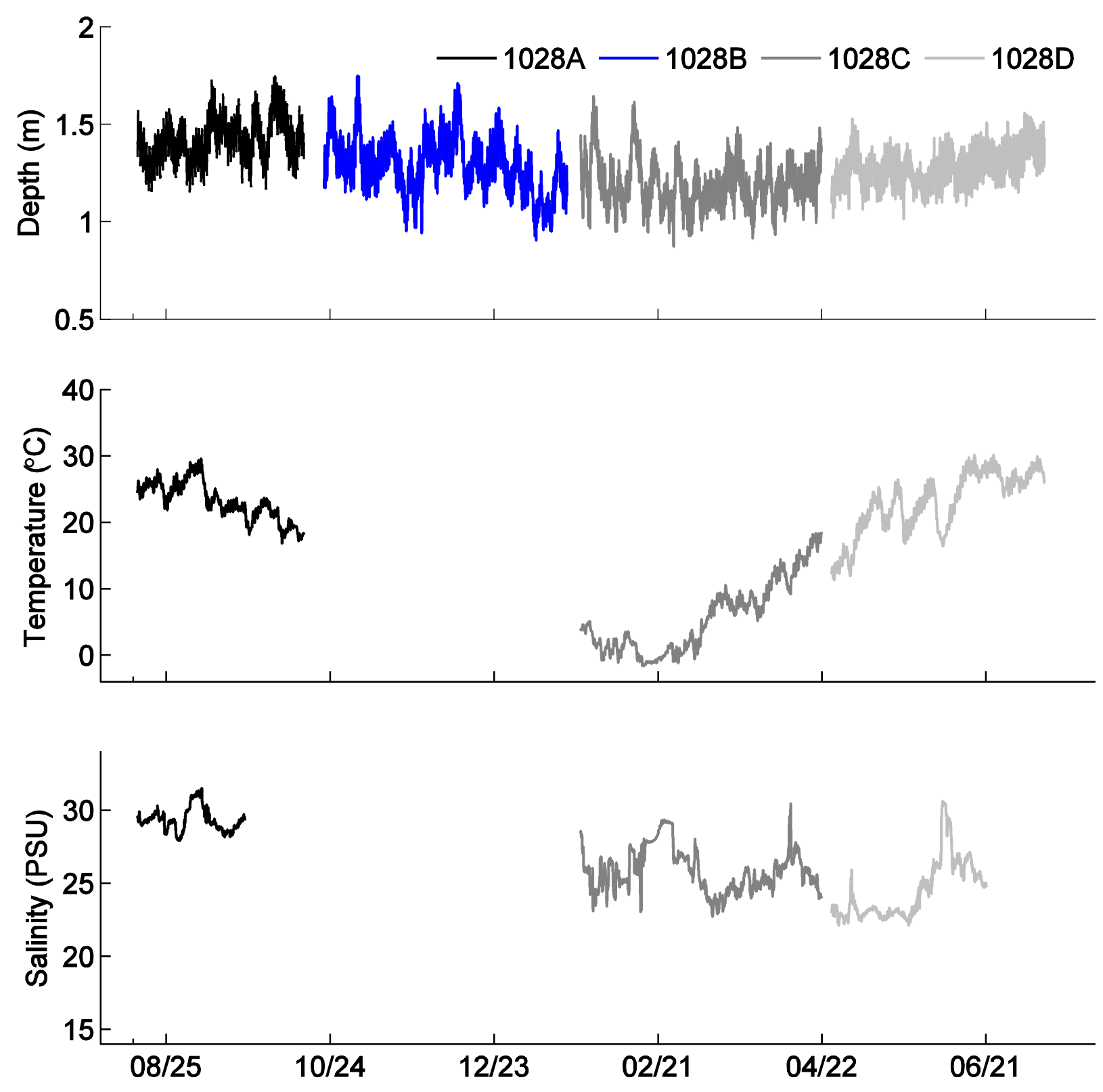

Figure 51. Graphs showing sensor depth, water temperature, and salinity from YSI EXO2 multiparameter sonde data at mooring 1028 (CB10) from August 14, 2014, to July 12, 2015. m, meter; ${ }^{\circ} \mathrm{C}$, degree Celsius; PSU, practical salinity unit. 

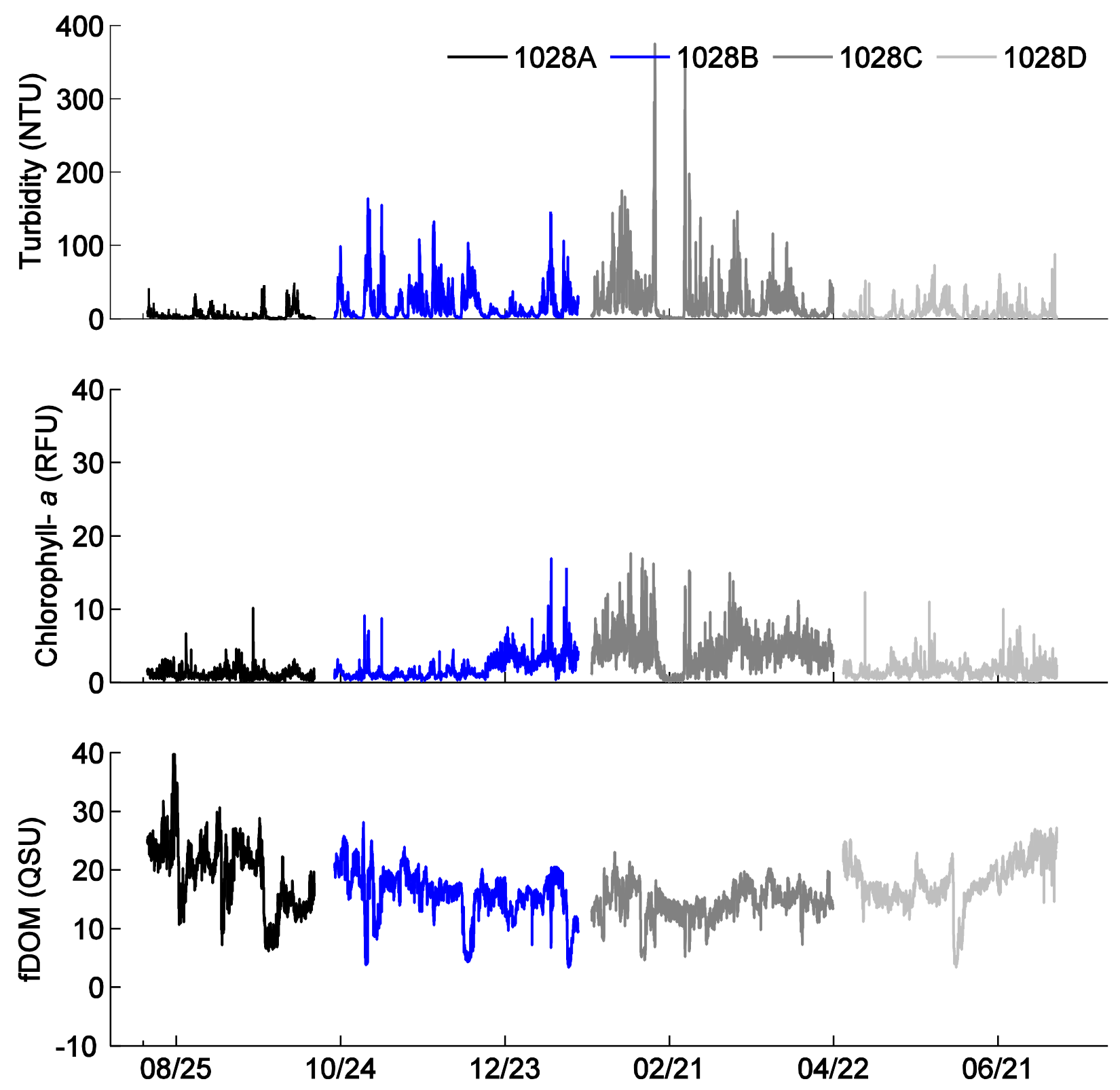

Figure 52. Graphs showing turbidity, chlorophyll-a, and fluorescent dissolved organic matter (fDOM) from YSI EXO2 multiparameter sonde data at mooring 1028 (CB10) from August 14, 2014, to July 12, 2015. NTU, nephelometric turbidity unit; RFU, relative fluorescence unit; QSU, quinine sulfate unit. 

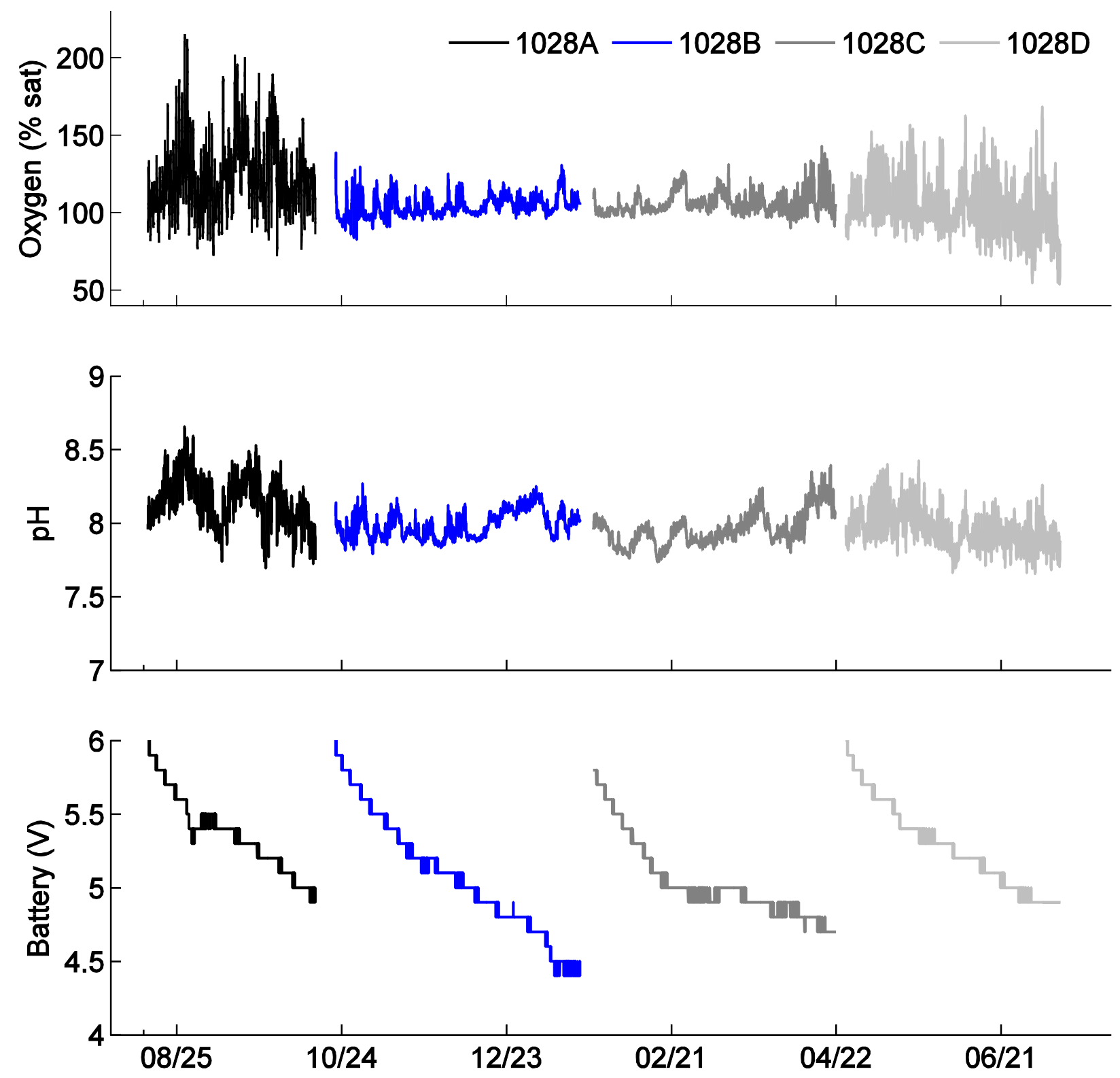

Figure 53. Graphs showing oxygen saturation, $\mathrm{pH}$, and battery power from YSI EXO2 multiparameter sonde data at mooring 1028 (CB10) from August 14, 2014, to July 12, 2015. \% sat, percent saturation; pH, pH unit; V, volt. 

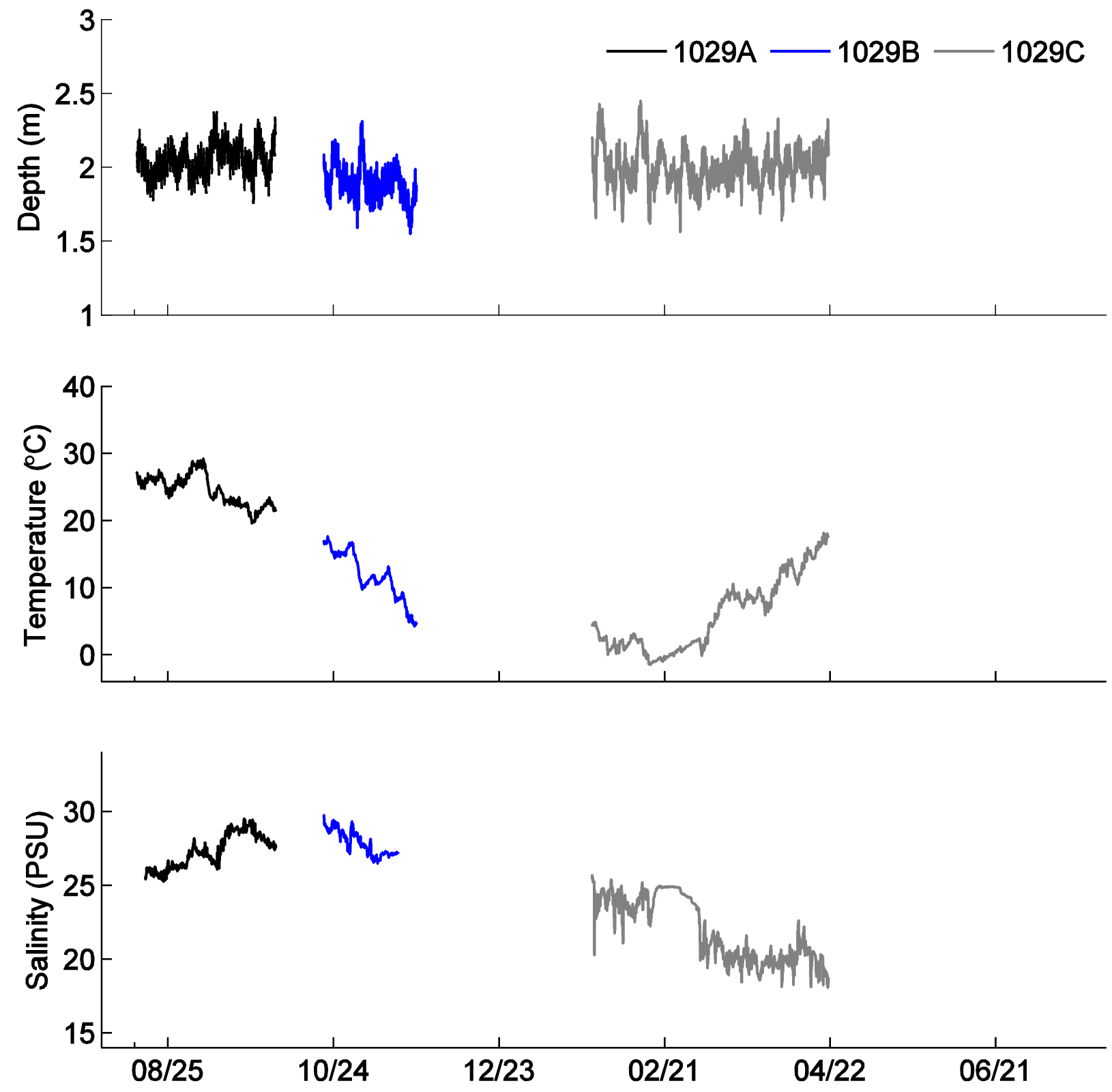

Figure 54. Graphs showing sensor depth, water temperature, and salinity from YSI EXO2 multiparameter sonde data at mooring 1029 (CB11) from August 13, 2014, to April 21, 2015. m, meter; ${ }^{\circ} \mathrm{C}$, degree Celsius; PSU, practical salinity unit. 

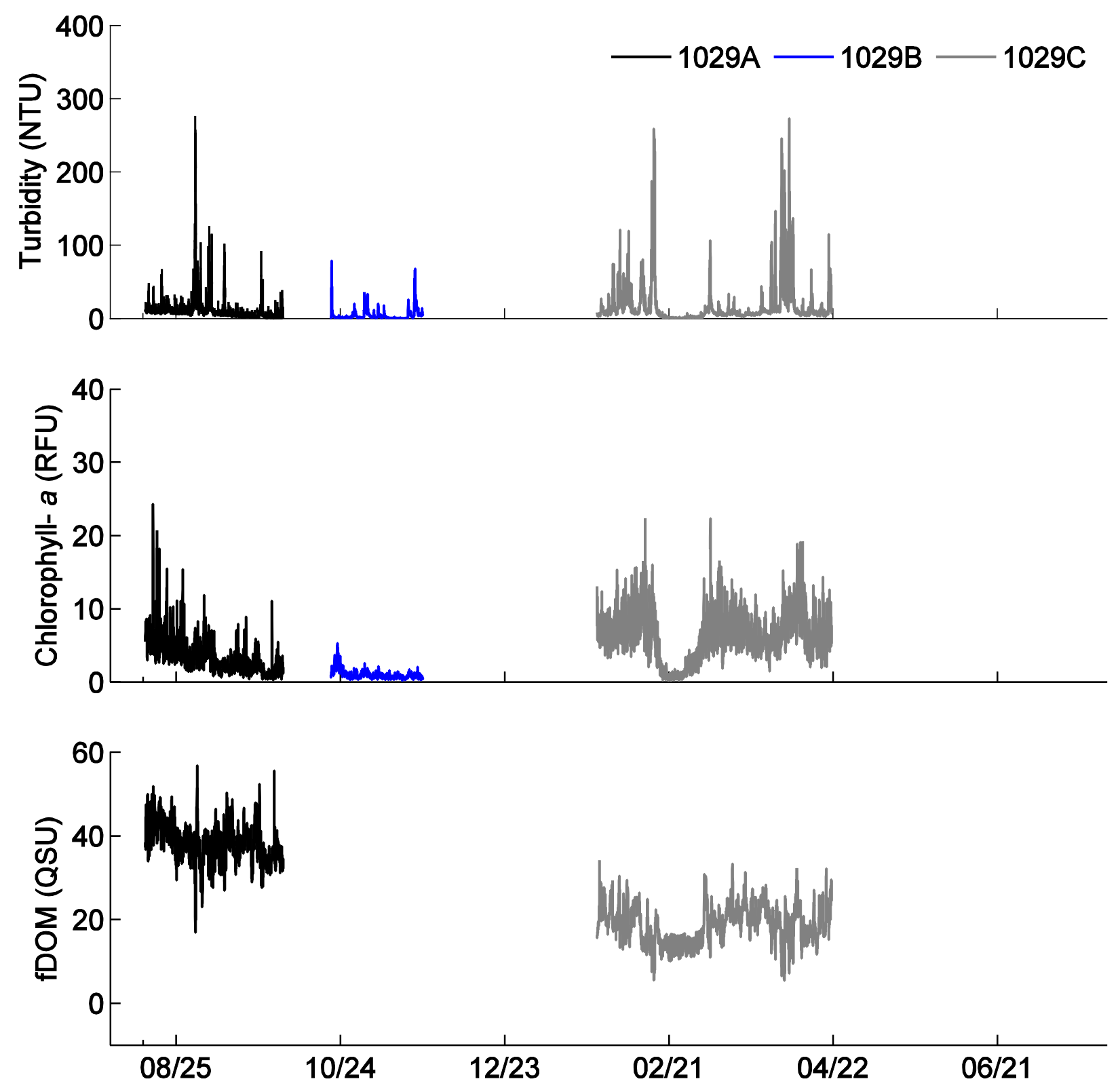

Figure 55. Graphs showing turbidity, chlorophyll-a, and fluorescent dissolved organic matter (fDOM) from YSI EXO2 multiparameter sonde data at mooring 1029 (CB11) from August 14, 2014, to April 21, 2015. NTU, nephelometric turbidity unit; RFU, relative fluorescence unit; QSU, quinine sulfate unit. 

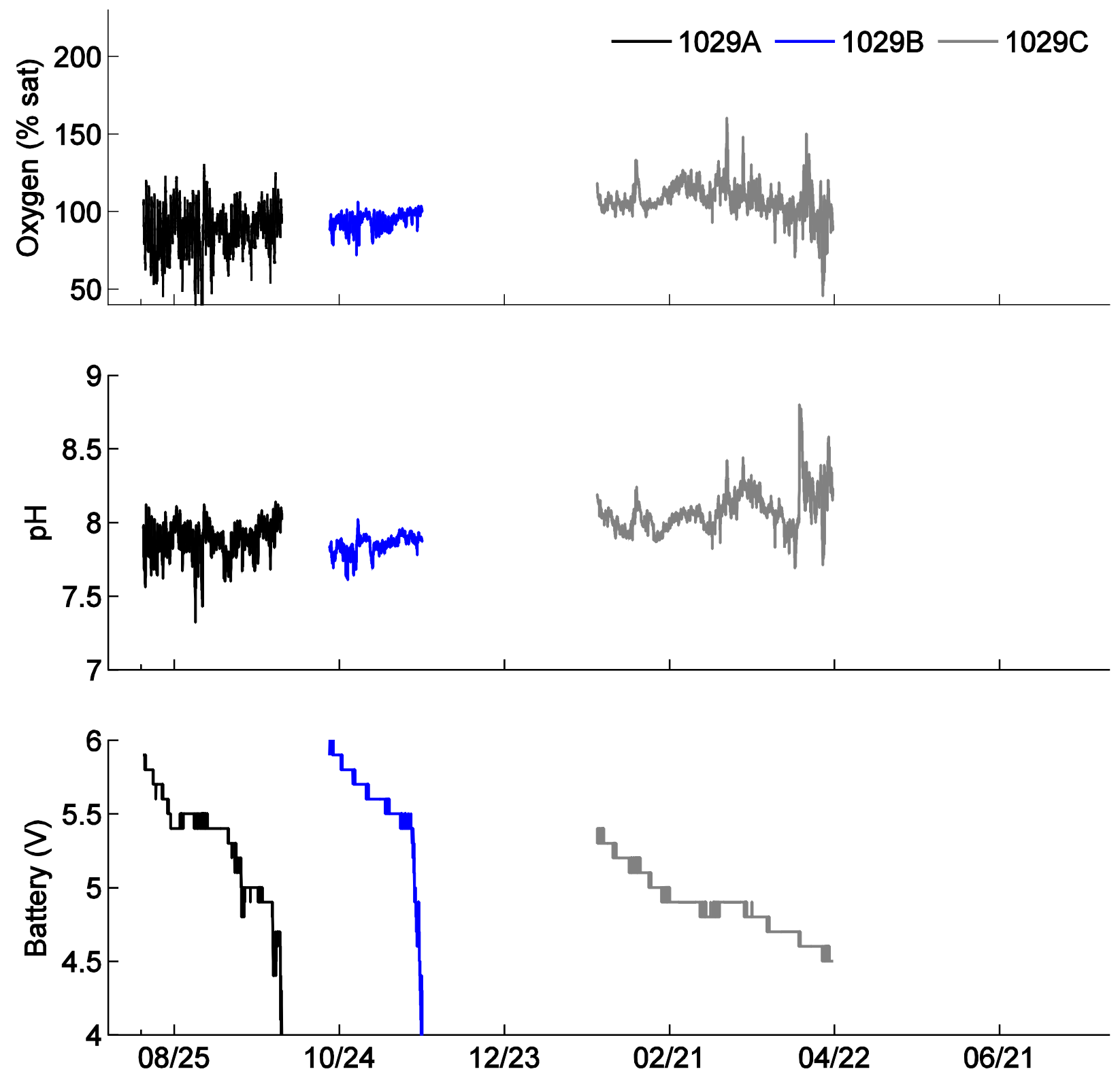

Figure 56. Graphs showing oxygen saturation, $\mathrm{pH}$, and battery power from YSI EXO2 multiparameter sonde data at mooring 1029 (CB11) from August 13, 2014, to April 21, 2015. \% sat, percent saturation; pH, pH unit; V, volt. 

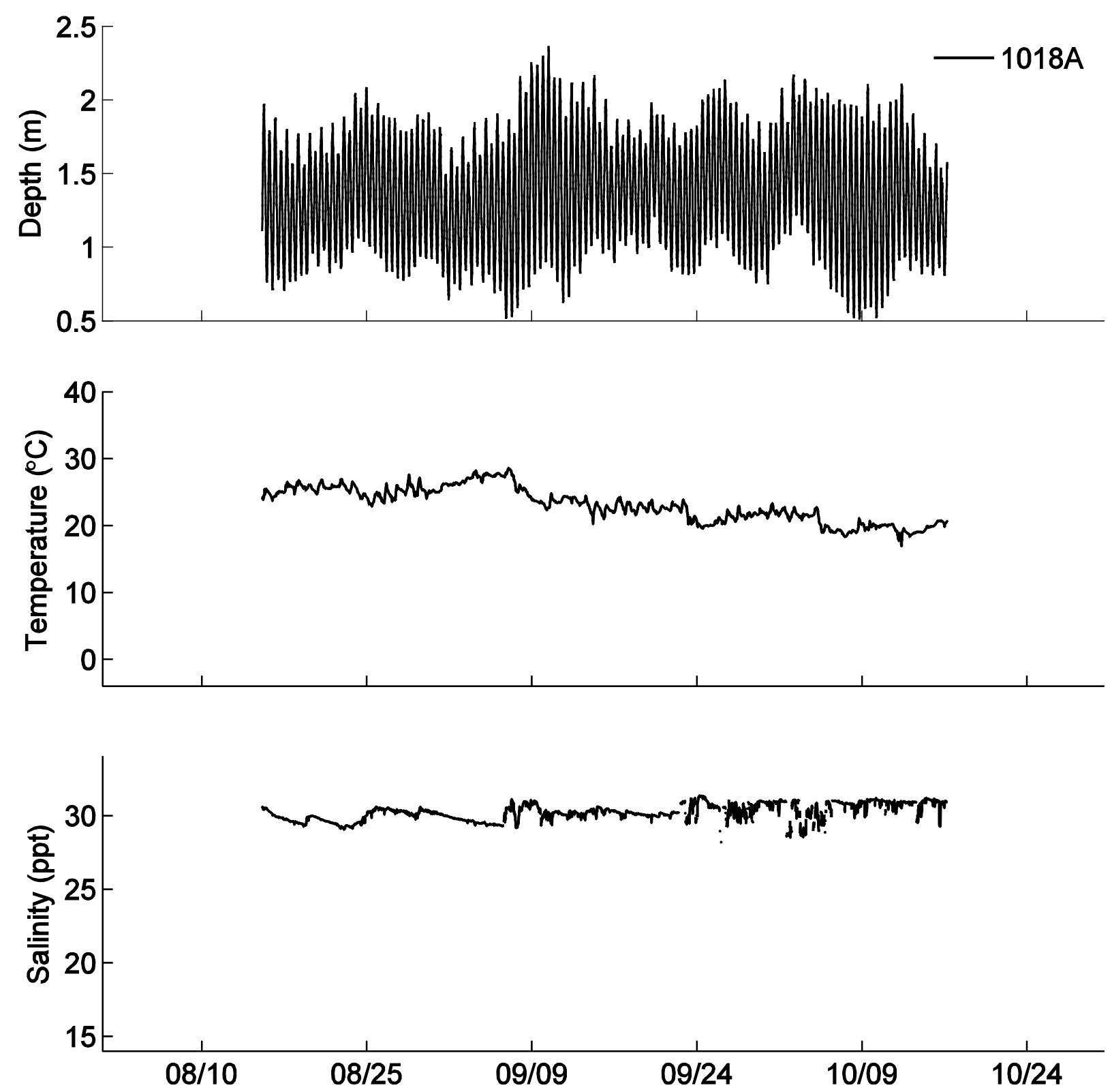

Figure 57. Graphs showing sensor depth, water temperature, and salinity from YSI 6600 multiparameter sonde data at mooring 1018 (CB01) from August 15, 2014, to October 16, 2014. m, meter; ${ }^{\circ} \mathrm{C}$, degree Celsius; ppt, part per thousand. 

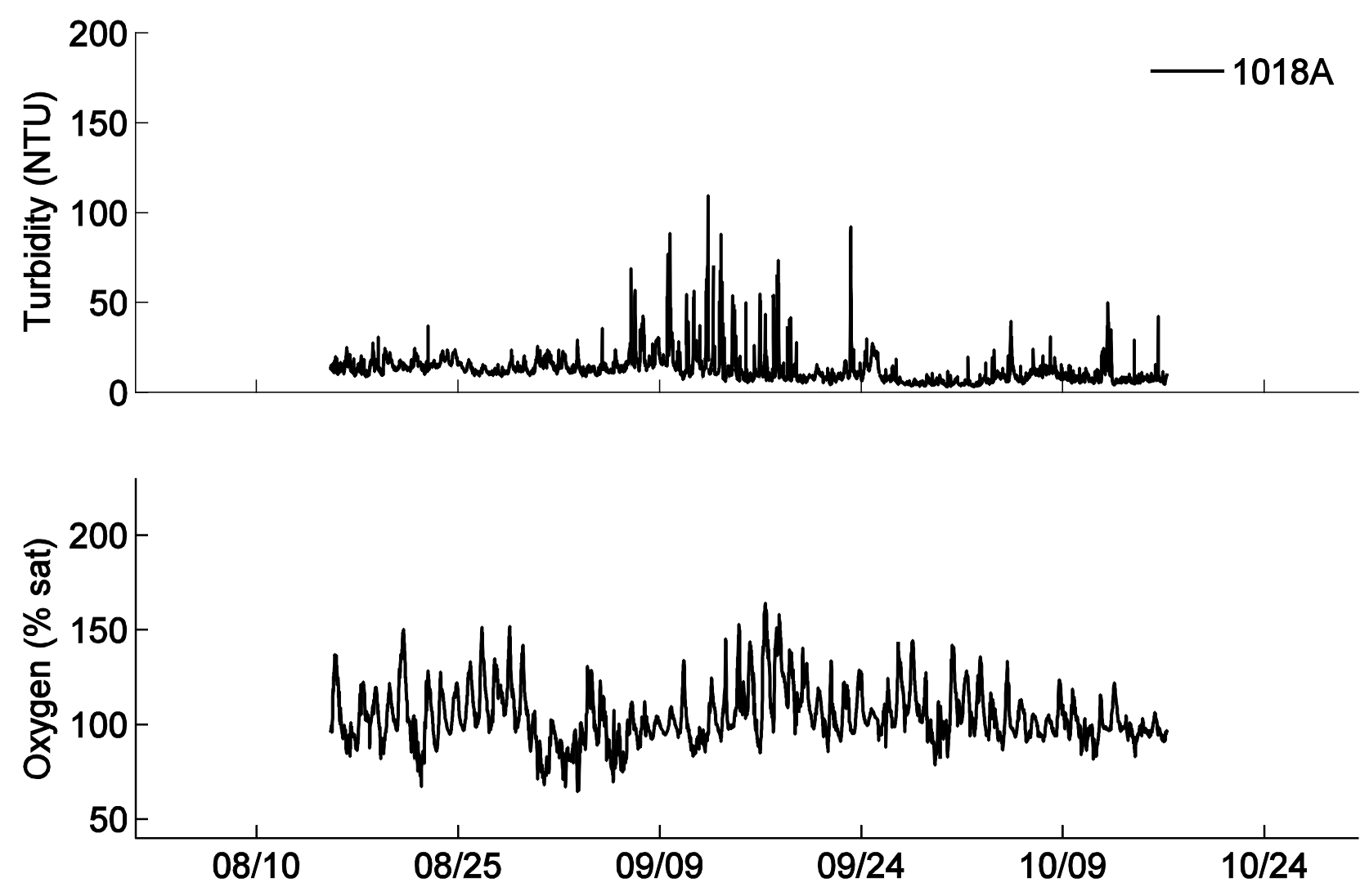

Figure 58. Graphs showing turbidity and oxygen saturation from YSI 6600 multiparameter sonde data at mooring 1018 (CB01) from August 15, 2014, to October 16, 2014. NTU, nephelometric turbidity unit; \% sat, percent saturation. 

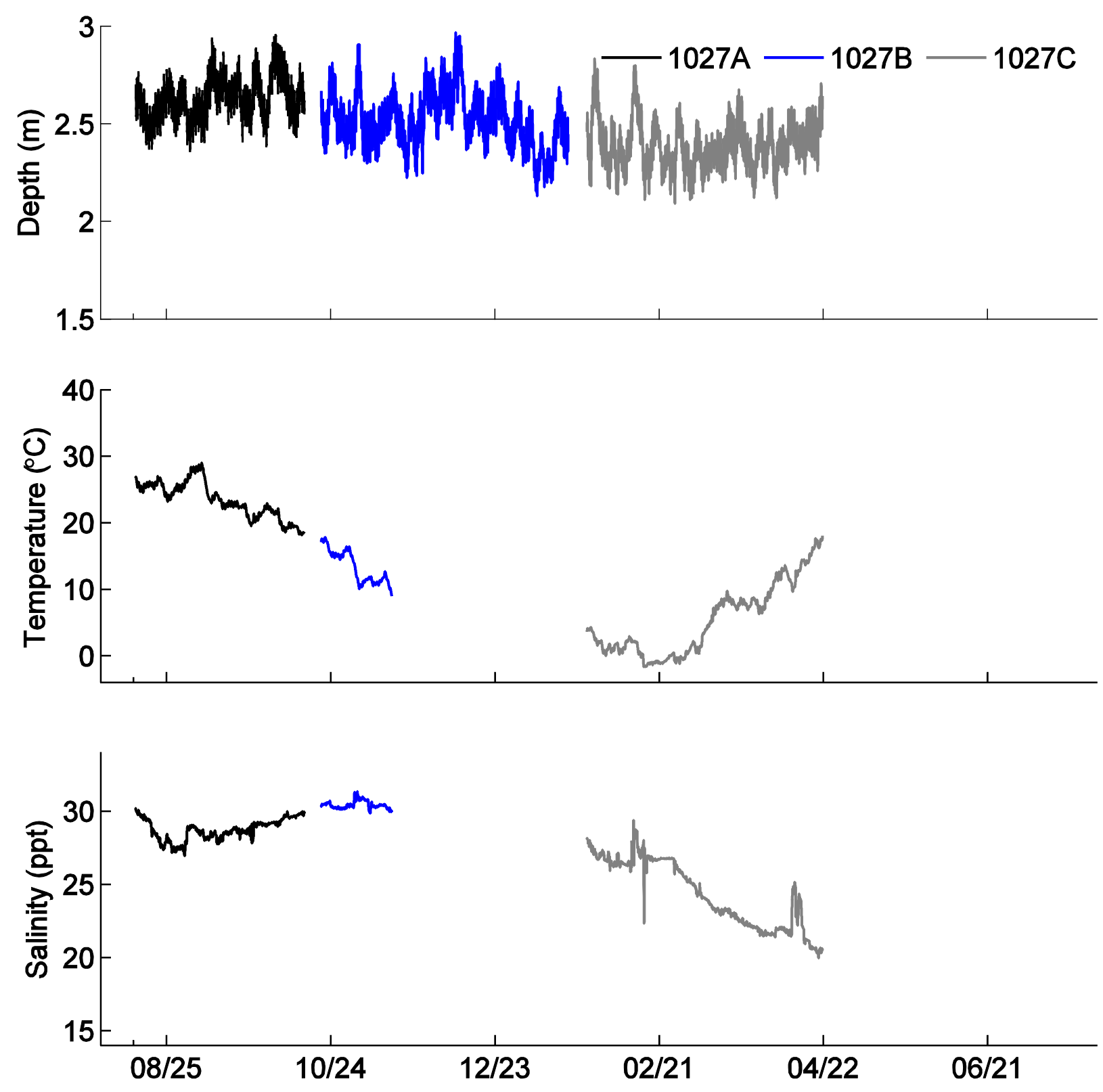

Figure 59. Graphs showing sensor depth, water temperature, and salinity from YSI 6600 multiparameter sonde data at mooring 1027 (CB09) from August 13, 2014, to April 21, 2015. m, meter; ${ }^{\circ} \mathrm{C}$, degree Celsius; ppt, part per thousand. 

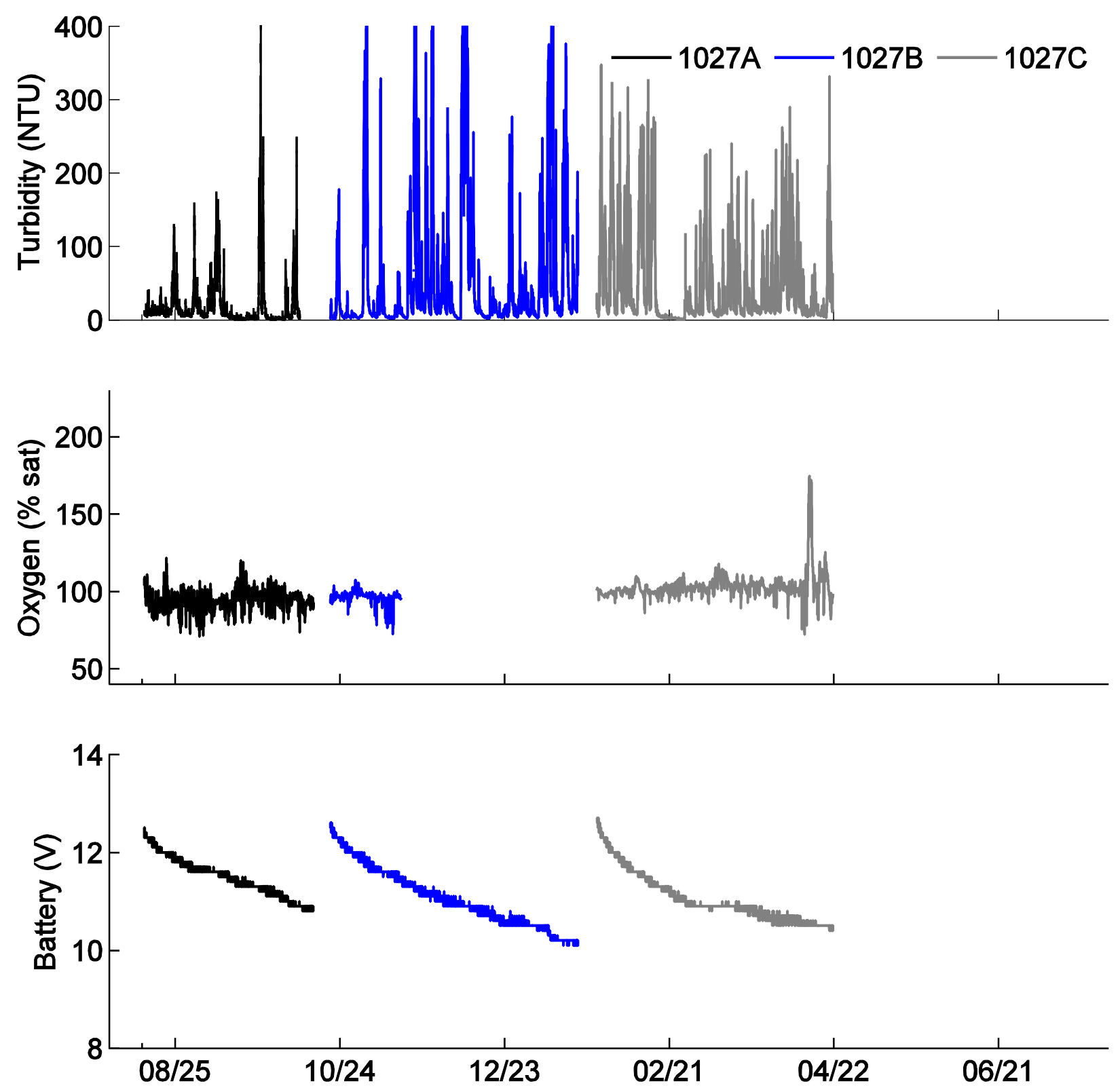

Figure 60. Graphs showing turbidity, oxygen saturation, and battery voltage from YSI 6600 multiparameter sonde data at mooring 1027 (CB09) from August 13, 2014, to April 21, 2015. NTU, nephelometric turbidity unit; \% sat, percent saturation; $\mathrm{V}$, volt. 

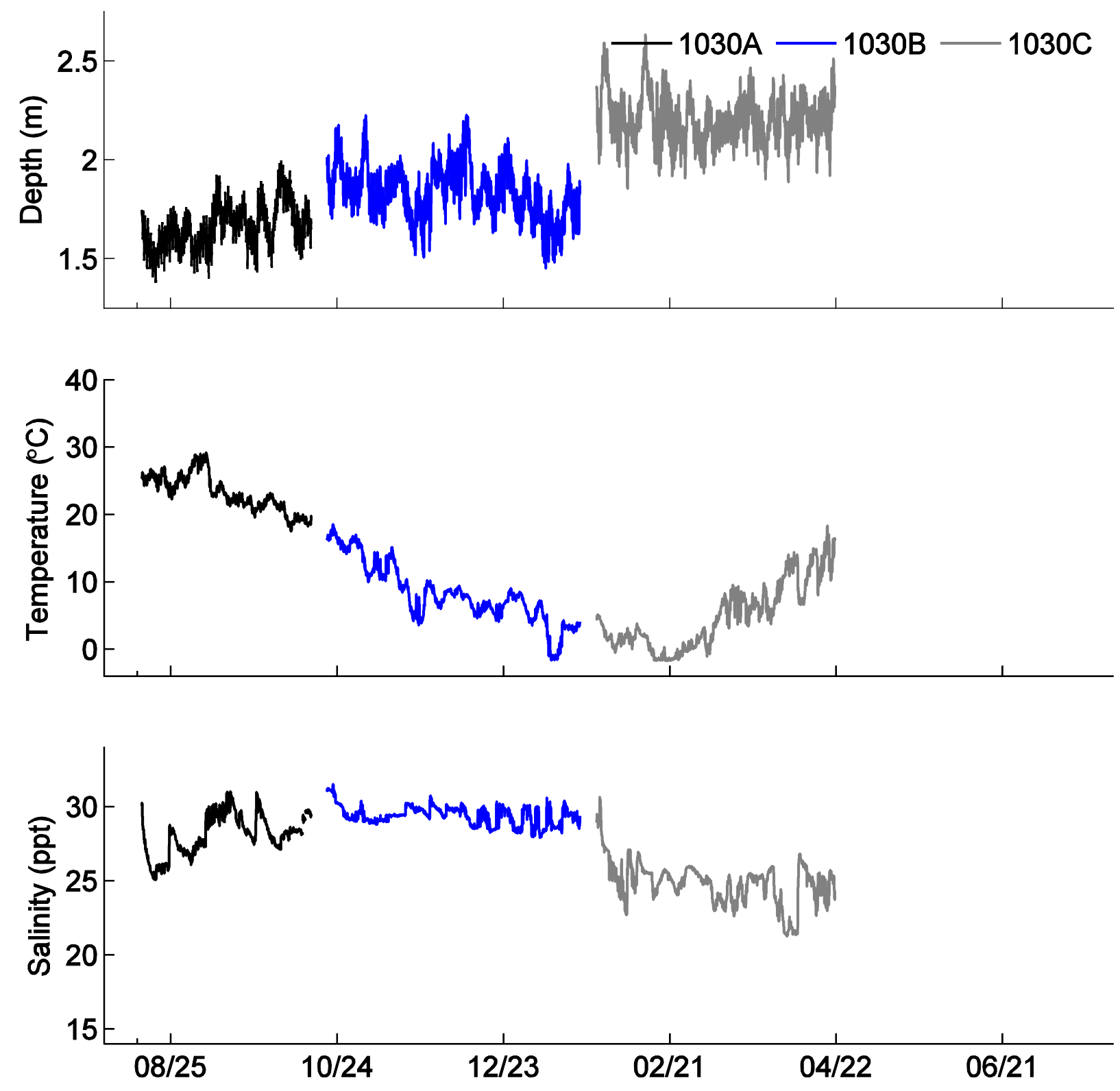

Figure 61. Graphs showing sensor depth, water temperature, and salinity from YSI 6600 multiparameter sonde data at mooring 1030 (CB12) from August 14, 2014, to April 21, 2015. m, meter; ${ }^{\circ} \mathrm{C}$, degree Celsius; ppt, part per thousand. 

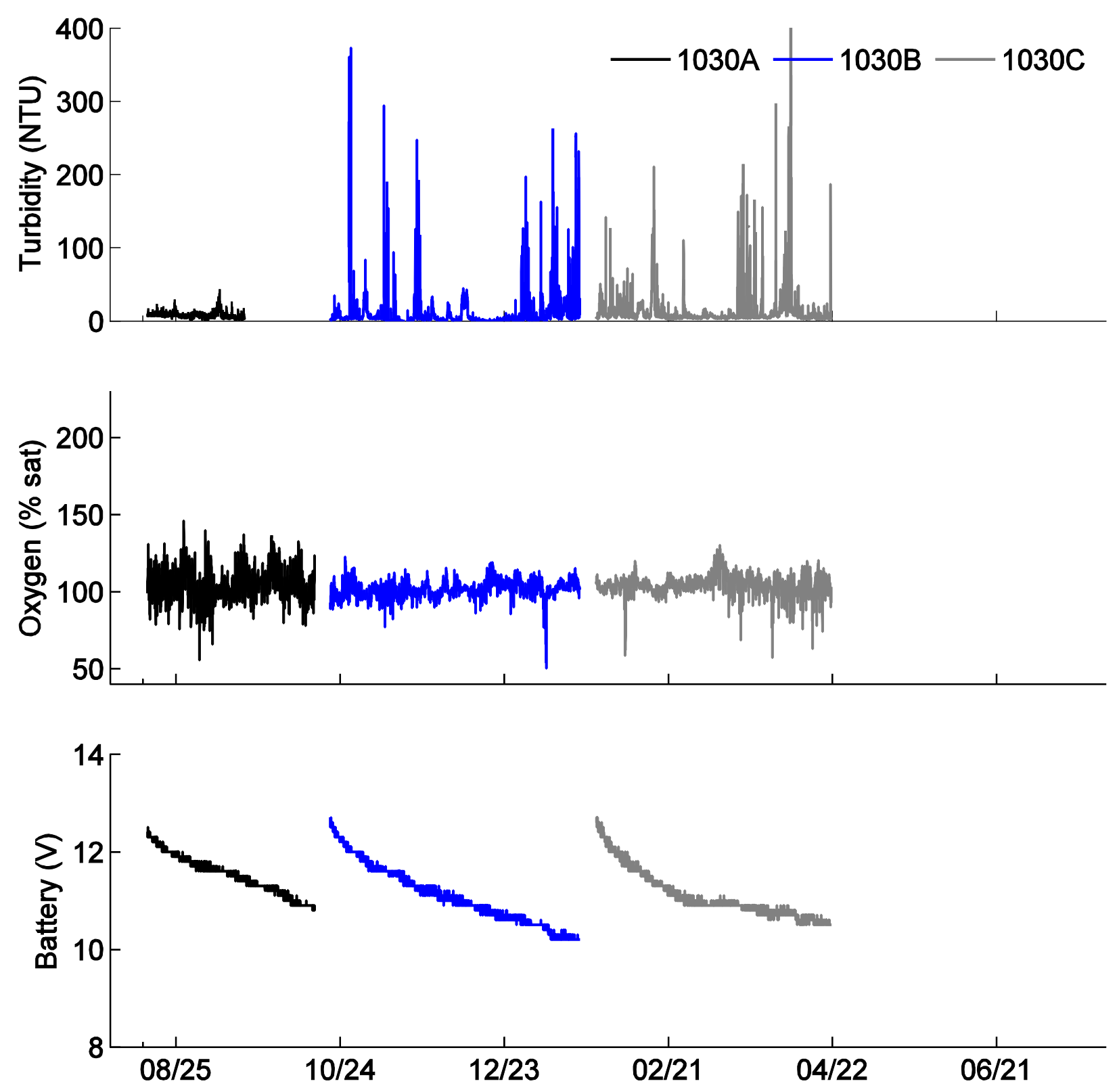

Figure 62. Graphs showing turbidity, oxygen saturation, and battery voltage from YSI 6600 multiparameter sonde data at mooring 1030 (CB12) from August 14, 2014, to April 21, 2015. NTU, nephelometric turbidity unit; \% sat, percent saturation; $\mathrm{V}$, volt. 

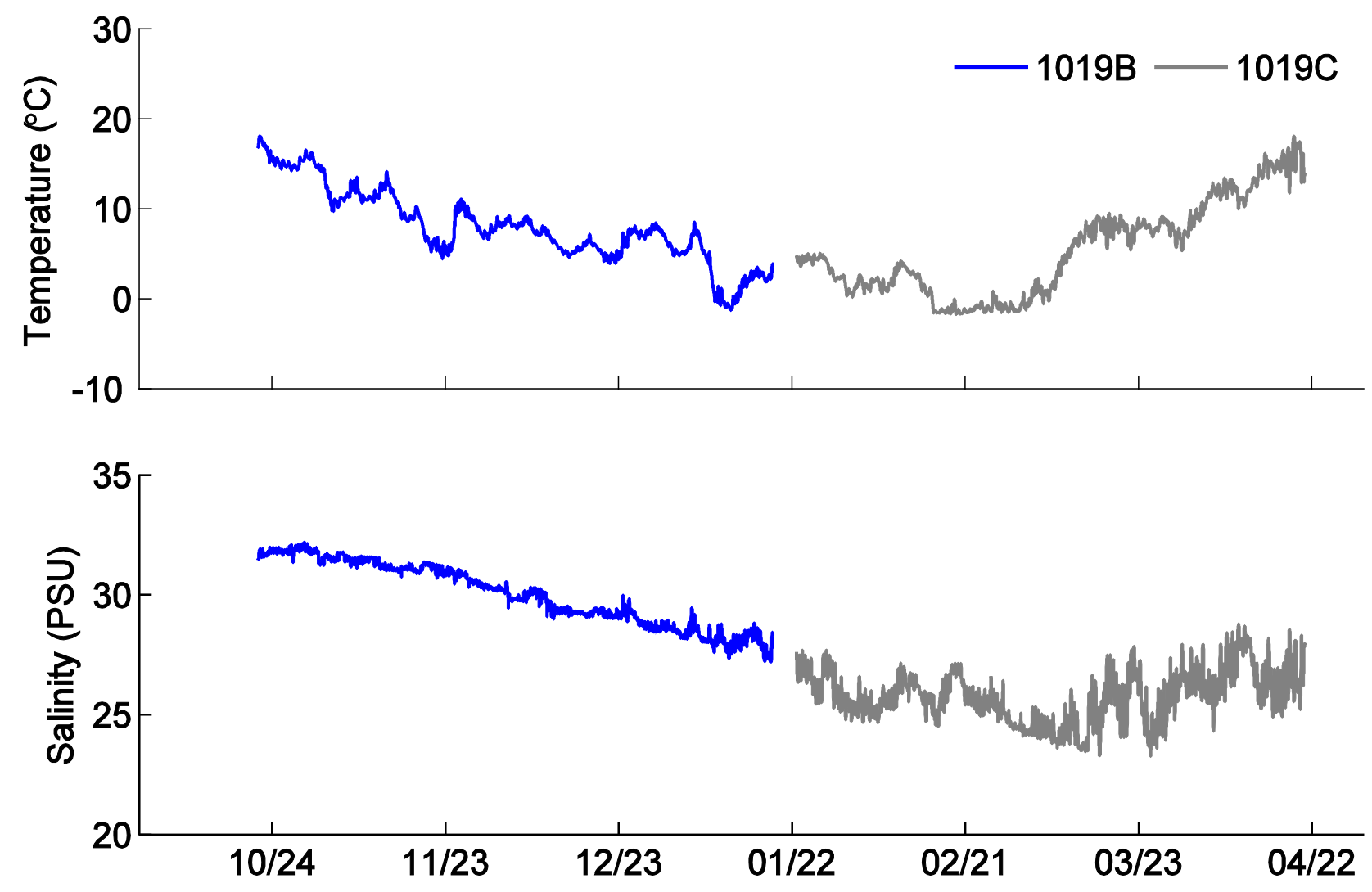

Figure 63. Graphs showing water temperature and salinity from Sea-Bird SBE 37-SM MicroCAT at mooring 1019 (CB02) from October 21, 2014, to April 20, 2015. ${ }^{\circ} \mathrm{C}$, degree Celsius; PSU, practical salinity unit. 

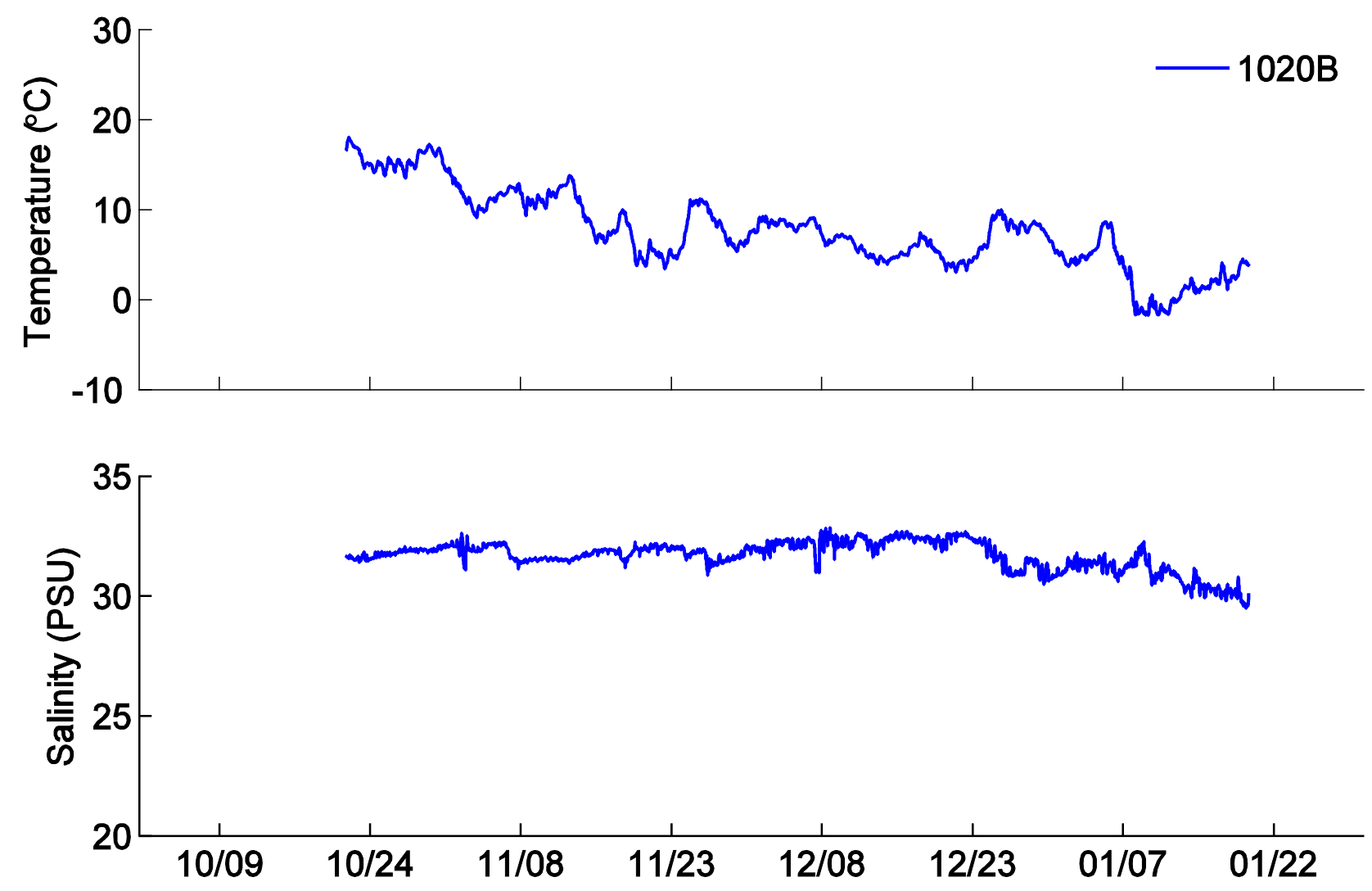

Figure 64. Graphs showing water temperature and salinity from Sea-Bird SBE 37-SM MicroCAT at mooring 1020 (CB03) from October 21,2014 , to January $19,2015 .{ }^{\circ} \mathrm{C}$, degree Celsius; PSU, practical salinity unit. 

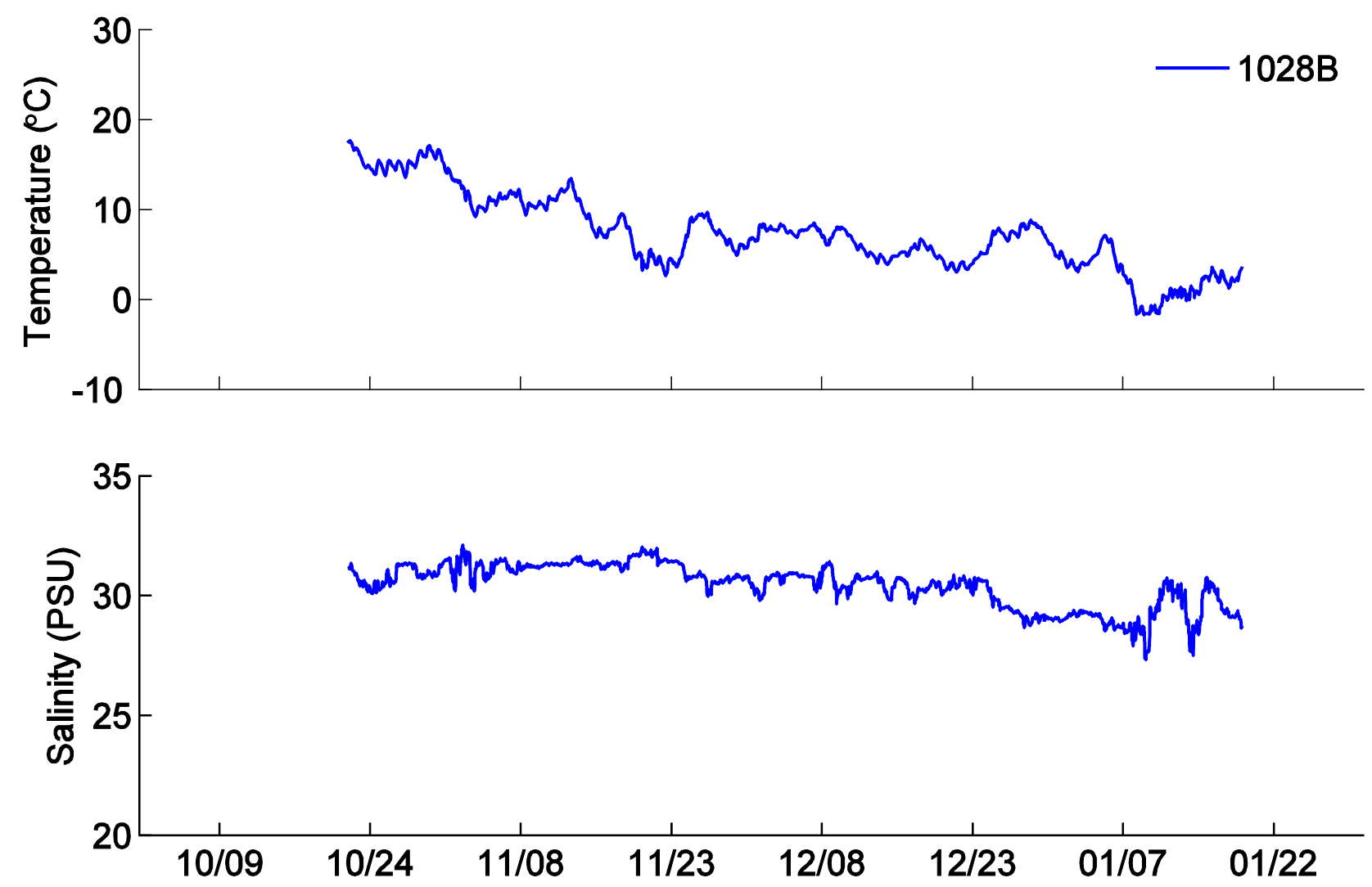

Figure 65. Graphs showing water temperature and salinity from Sea-Bird SBE 37-SM MicroCAT at mooring 1028 (CB10) from October 21,2014 , to January $18,2015 .{ }^{\circ} \mathrm{C}$, degree Celsius; PSU, practical salinity unit. 

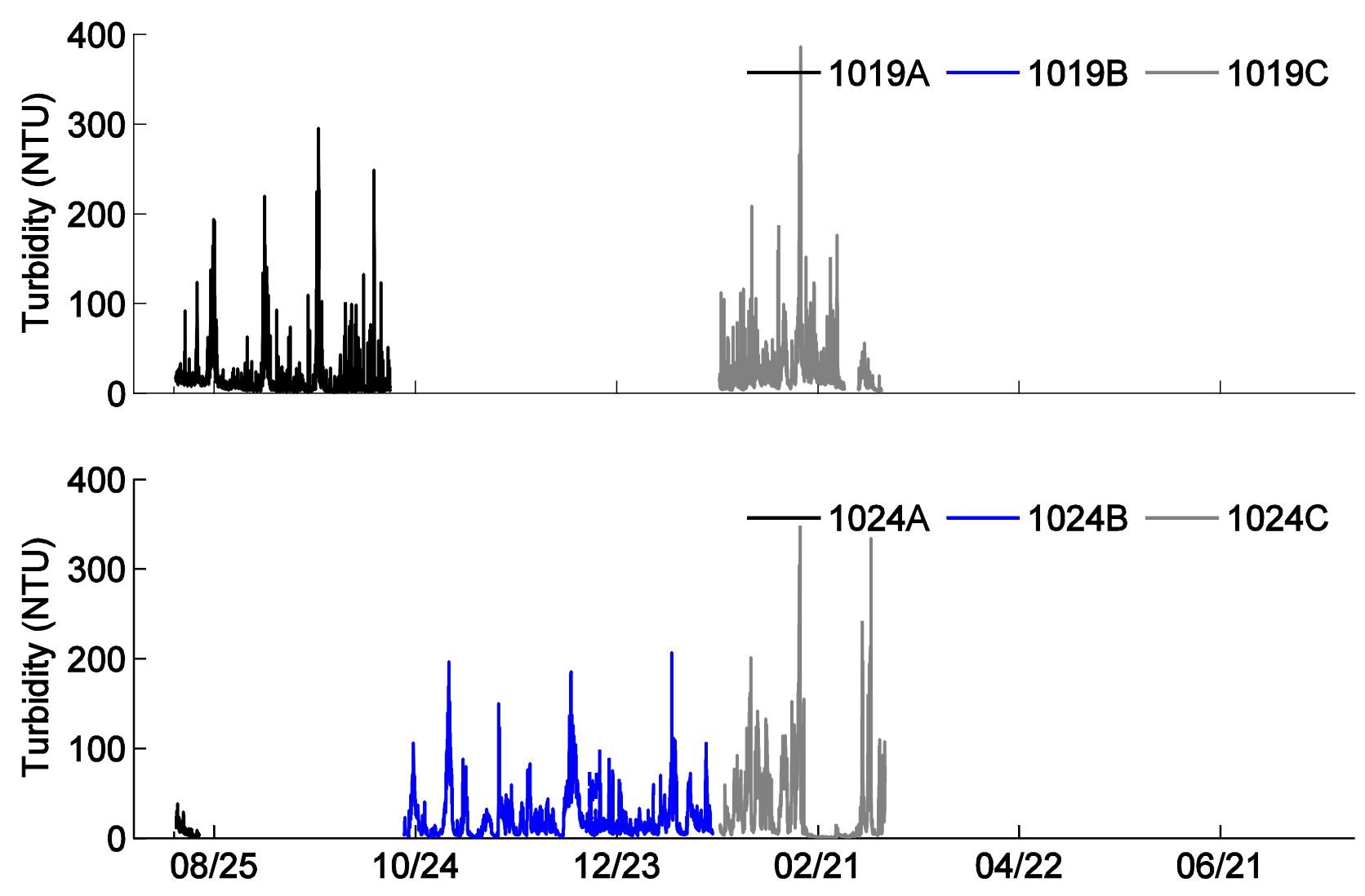

Figure 66. Graphs showing turbidity from WET Labs ECO-NTUSB at moorings 1019 (CB02) and 1024 (CB07) from August 13, 2014, to April 21, 2015. NTU, nephelometric turbidity unit. 

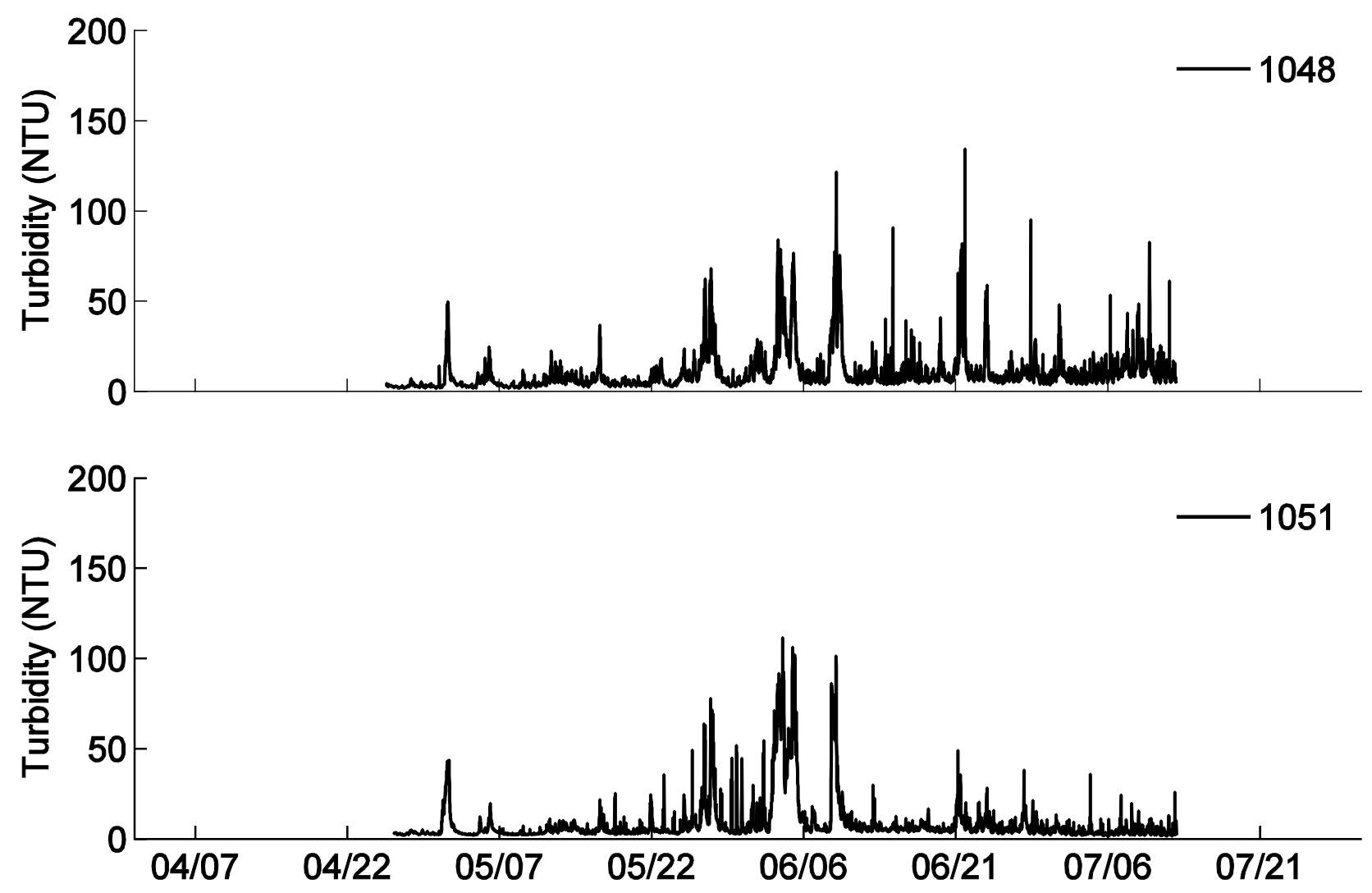

Figure 67. Graphs showing turbidity from WET Labs ECO-NTUSB at moorings 1048 (V1) and 1051 (V4) from April 25 to July 12, 2015. NTU, nephelometric turbidity unit. 

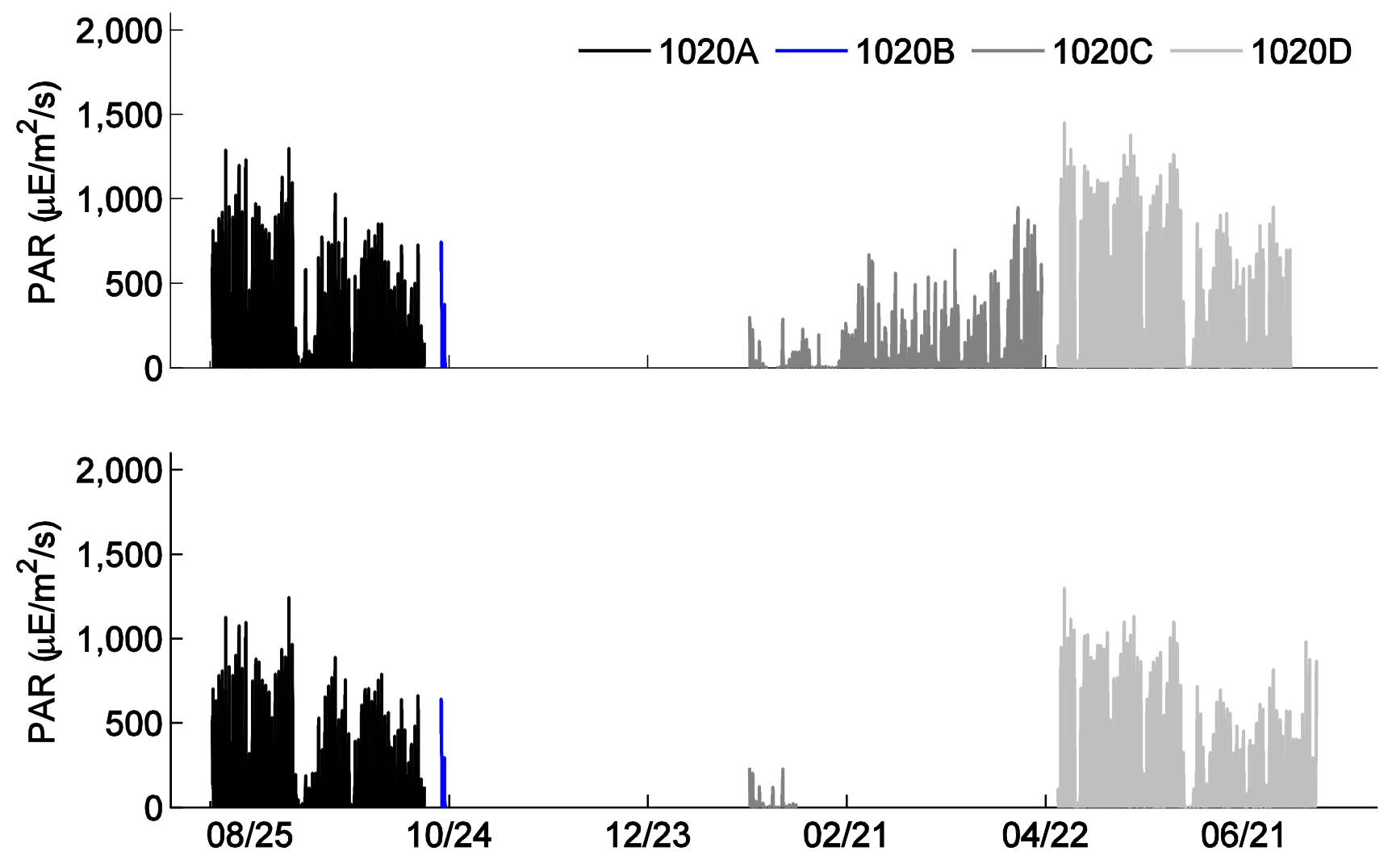

Figure 68. Graphs showing upper (top panel) and lower (bottom panel) light (photosynthetically active radiation [PAR]) data from WET Labs ECO-PARSB on shallow water irradiance platform deployments at mooring 1020 (CB03) from August 13, 2014, to July 12, 2015. $\mu \mathrm{E} / \mathrm{m}^{2} / \mathrm{s}$, microeinstein per square meter per second. 

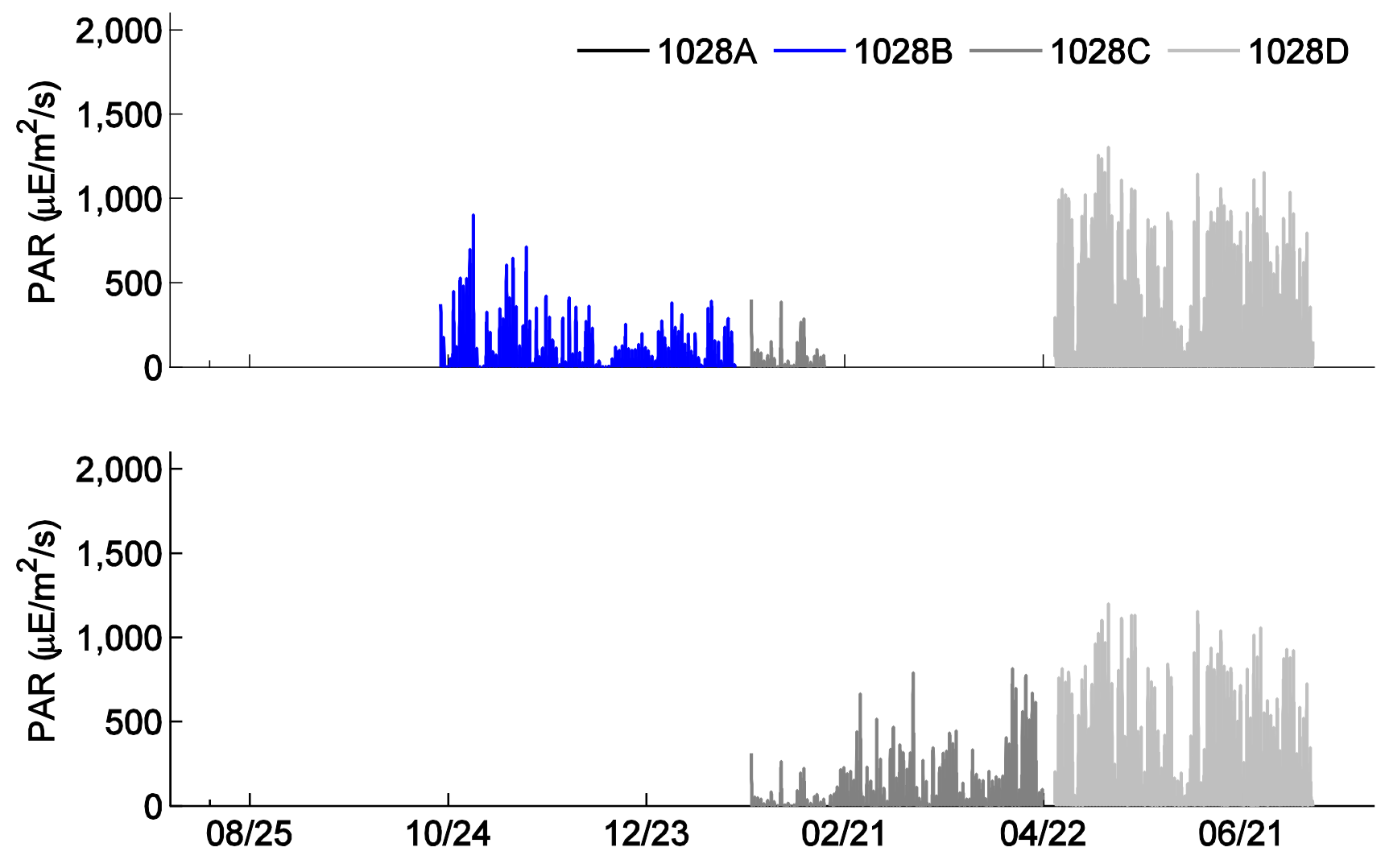

Figure 69. Graphs showing upper (top panel) and lower (bottom panel) light (photosynthetically active radiation [PAR]) data from WET Labs ECO-PARSB on shallow water irradiance platform deployments at mooring 1028 (CB10) from August 14, 2014, to July 12, 2015. $\mu \mathrm{E} / \mathrm{m}^{2} / \mathrm{s}$, microeinstein per square meter per second. 


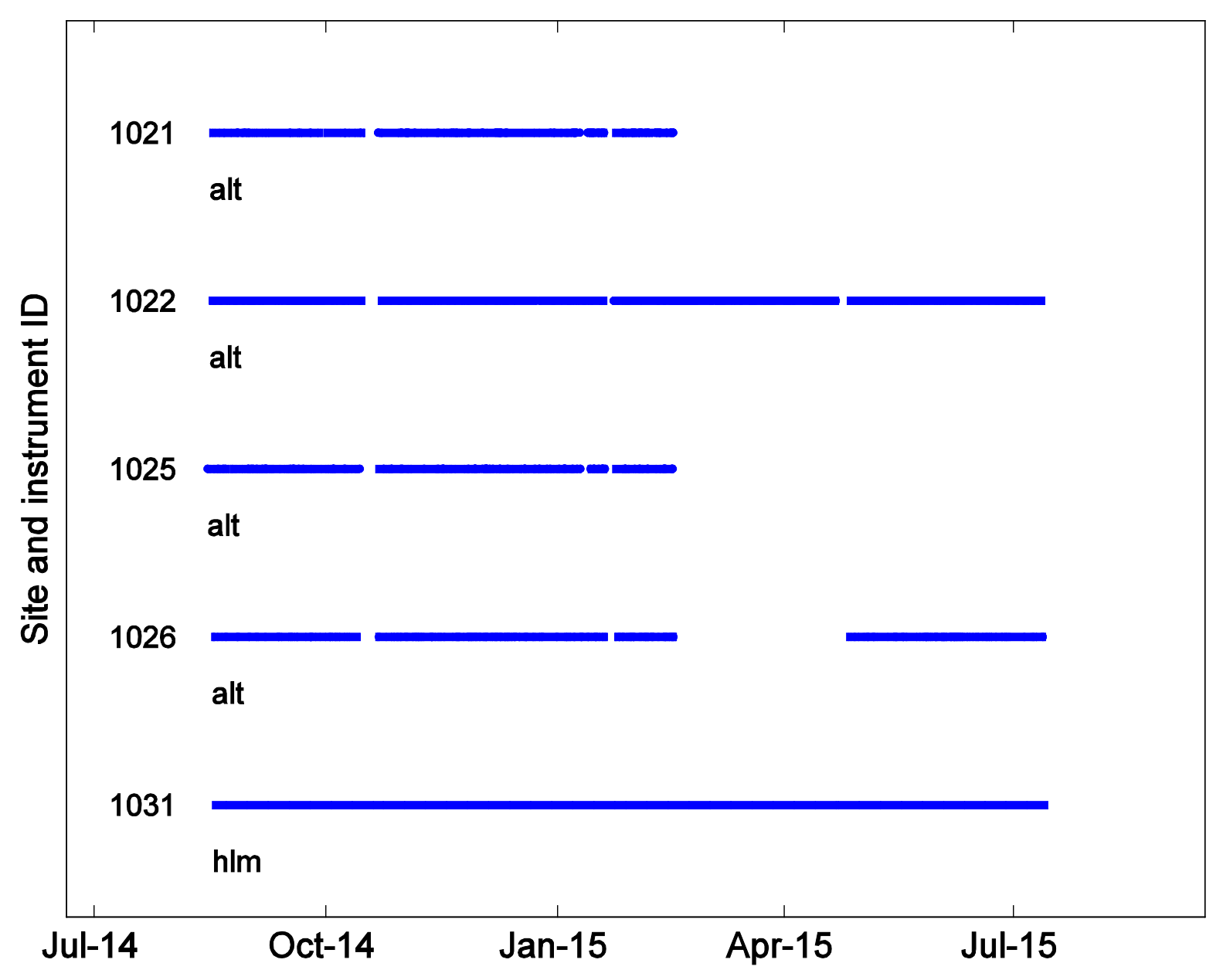

Figure 70. Chart showing the availability of seabed altimeter and meteorological data for Chincoteague Bay, Maryland and Virginia, for the Estuarine Physical Response to Storms study from August 2014 to July 2015. alt, Echologger AA400 altimeter; hlm, Hobo U30 weather station; ID, identification number. 

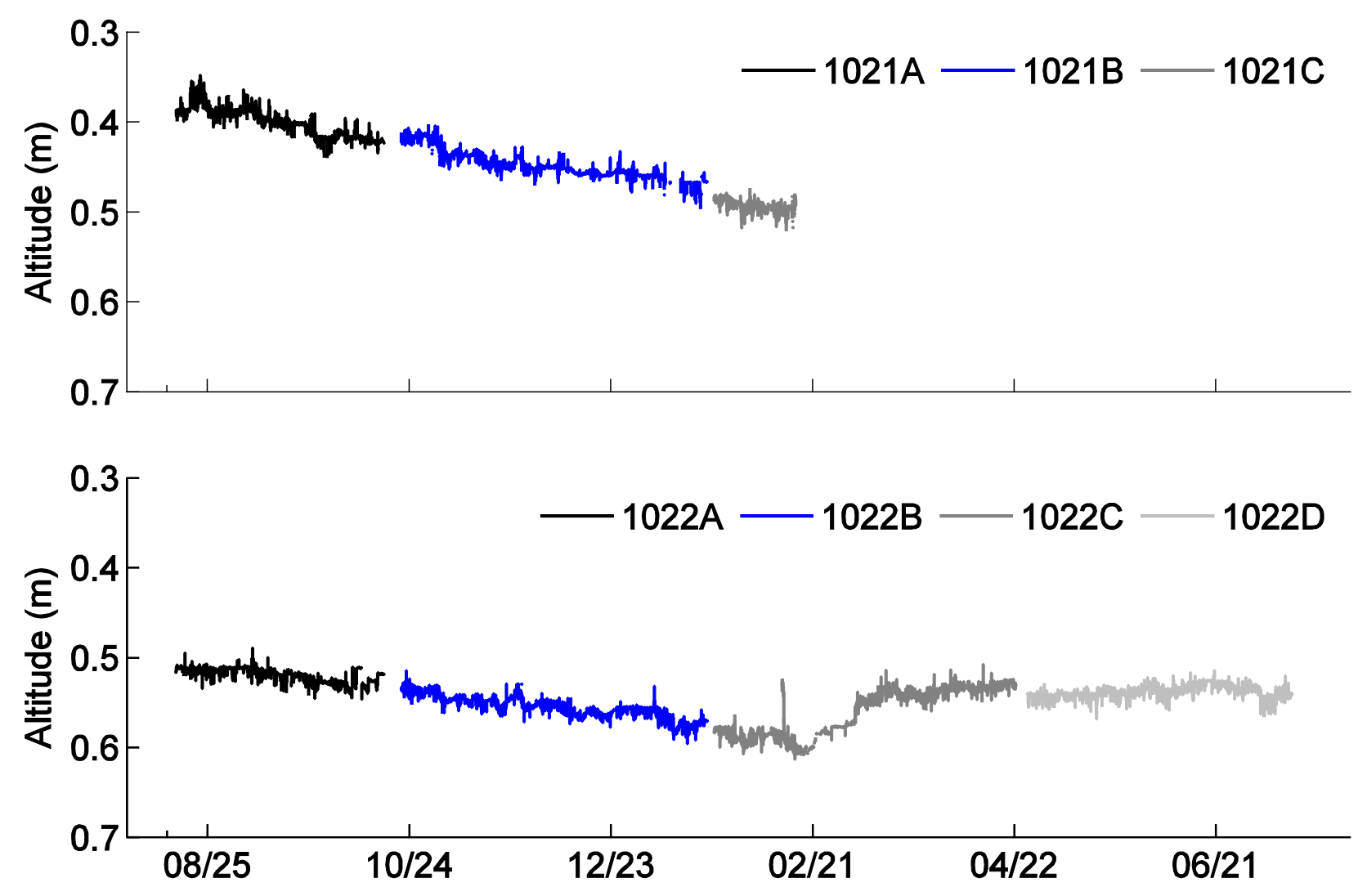

Figure 71. Graphs showing seabed elevation data from Echologger AA400 altimeters at moorings 1021 (CB04) and 1022 (CB05) from August 15, 2014, to July 13, 2015. Ice disturbed the altimeter mounting frame at mooring 1021 in February 2015. m, meter. 

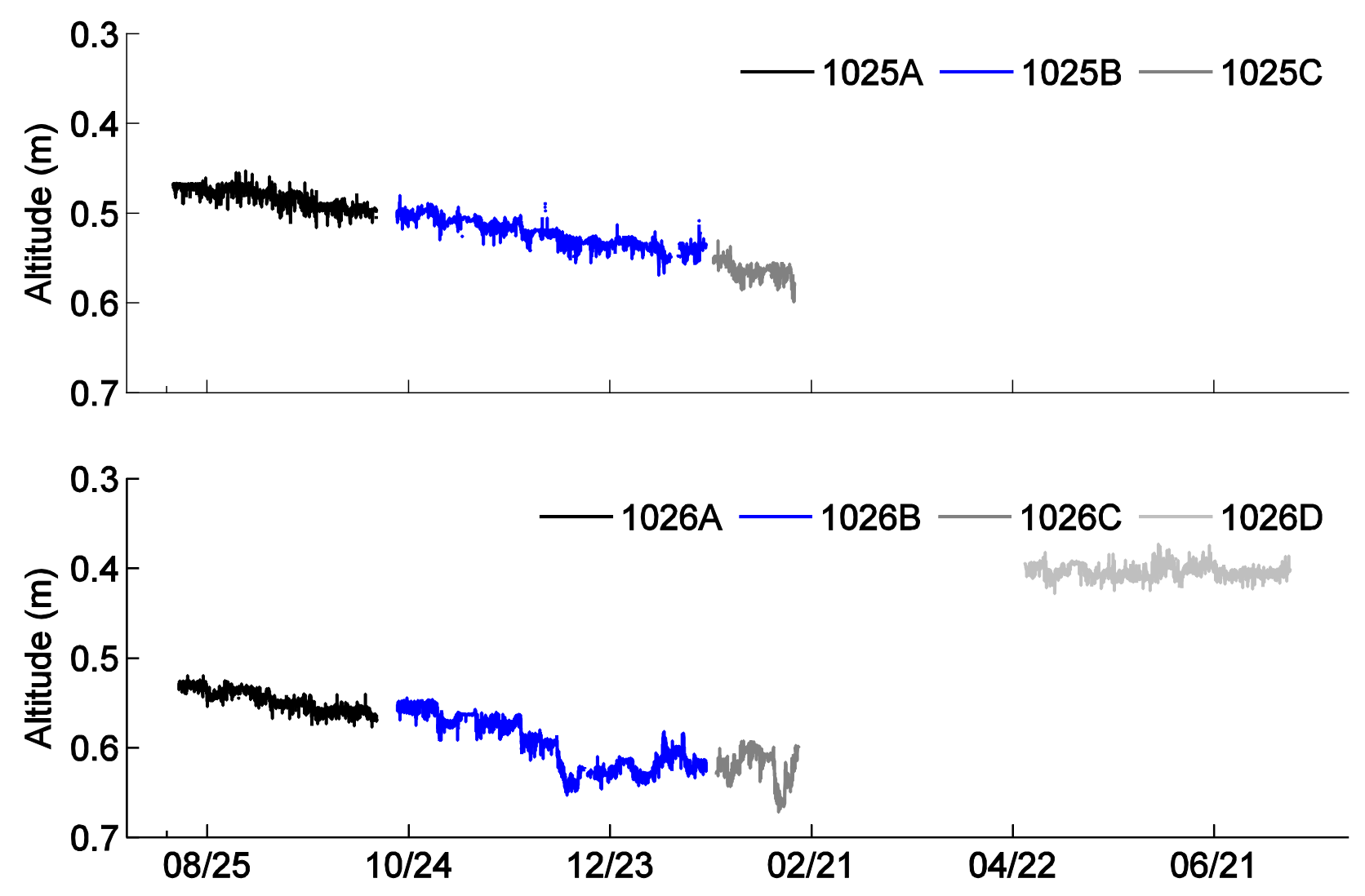

Figure 72. Graphs showing seabed elevation data from Echologger AA400 altimeters at moorings 1025 (CB07) and 1026 (CB08) from August 14, 2014, to July 13, 2015. Ice disturbed both altimeter mounting frames in February 2015; mooring 1026 was reestablished on April 25, 2015. The offset in altitude from the end of $1026 \mathrm{C}$ data in midFebruary to the beginning of $1026 \mathrm{D}$ data in April 2015 is due to resetting the frame and not any measured change in the seabed. $\mathrm{m}$, meter. 

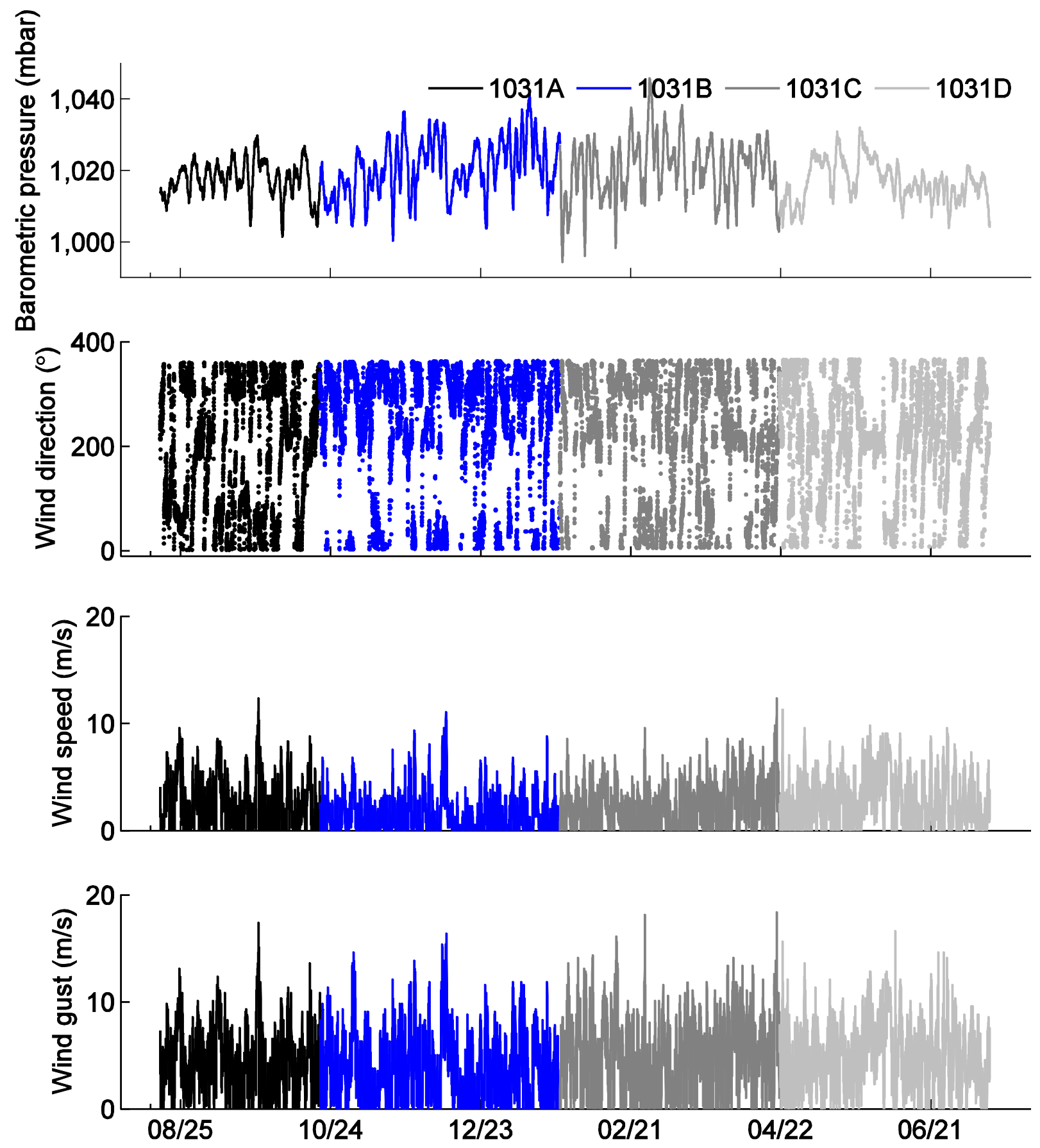

Figure 73. Graphs showing barometric pressure and wind data from Onset Hobo U30 weather station at mooring 1031 (CBWS) from August 16, 2014, to July 14, 2015. mbar, millibar; ${ }^{\circ}$, degree true; $\mathrm{m} / \mathrm{s}$, meter per second. 

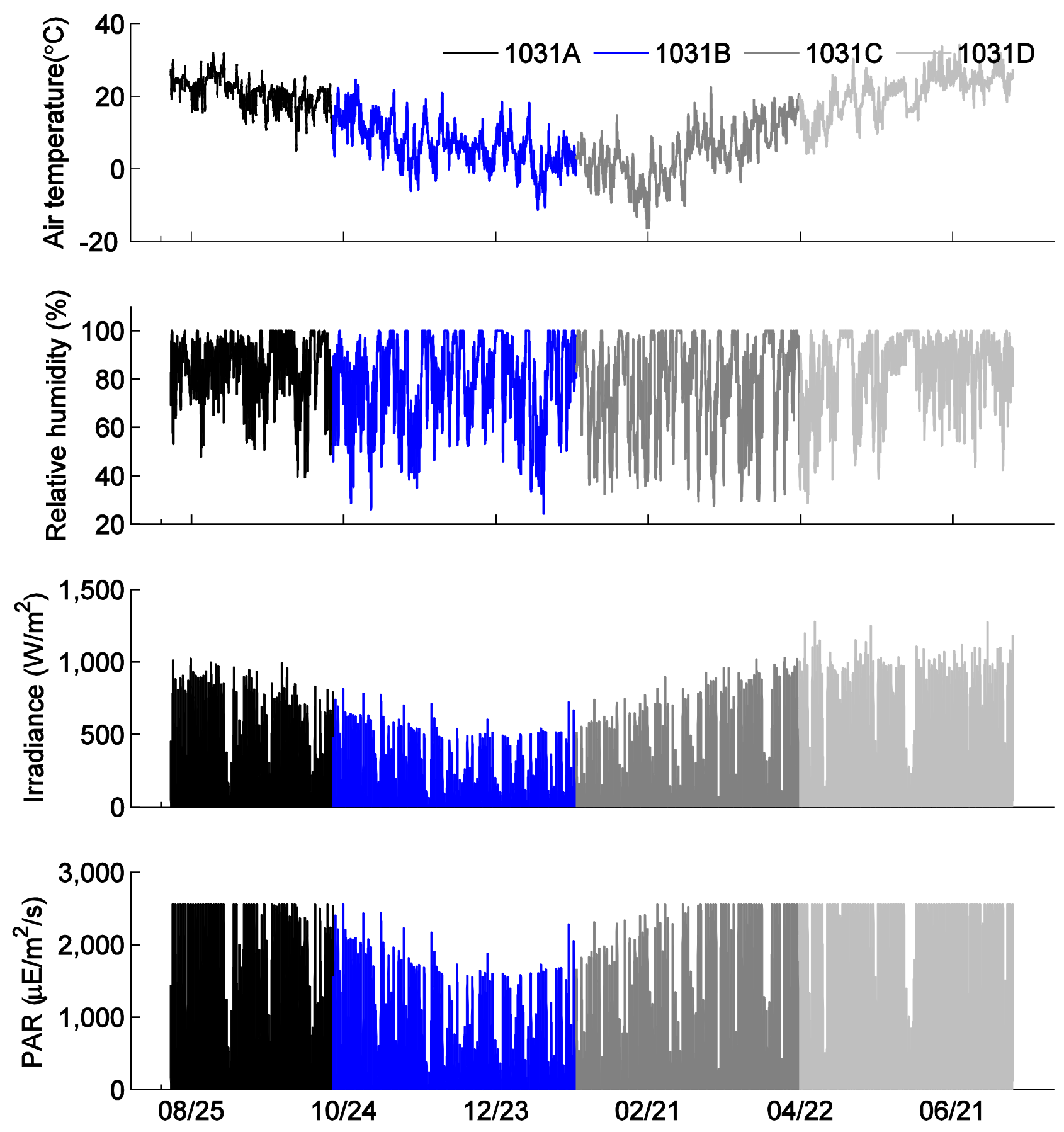

Figure 74. Graphs showing air temperature, relative humidity, solar irradiance, and photosynthetically active radiation (PAR) data from Onset Hobo U30 weather station at mooring 1031 (CBWS) from August 16, 2014, to July $14,2015 .{ }^{\circ} \mathrm{C}$, degree Celsius; $\%$, percent; $\mathrm{W} / \mathrm{m}^{2}$, watt per square meter; $\mu \mathrm{E} / \mathrm{m}^{2} / \mathrm{s}$, microeinstein per square meter per second. 
Table 1. Sensor deployment and location information for platforms deployed in Chincoteague Bay, Maryland and Virginia, August 2014 to July 2015.

[ID, identification number; N, north; $\mathrm{W}$, west; $\mathrm{m}$, meter; SWIP, shallow water irradiance platform; FG, fiberglass grate; --, no data]

\begin{tabular}{|c|c|c|c|c|c|c|}
\hline $\begin{array}{l}\text { Mooring } \\
\text { ID }\end{array}$ & Site ID & Mount/platform type & $\begin{array}{l}\text { Latitude } \\
\text { (N) }\end{array}$ & $\begin{array}{l}\text { Longitude } \\
\text { (W) }\end{array}$ & $\begin{array}{l}\text { Depth } \\
\text { (m) }\end{array}$ & Deployment period \\
\hline \multicolumn{7}{|c|}{ 1018-Toms Cove (old Coast Guard house pier) } \\
\hline $1018 \mathrm{~A}$ & CB01 & Pier piling & 37.8670 & 75.3683 & 1.0 & August 15, 2014-October 16, 2014 \\
\hline 1018B & CB01 & Pier piling & 37.8670 & 75.3683 & 1.0 & October 21, 2014-January 20, 2015 \\
\hline \multicolumn{7}{|c|}{ 1019-Cockle Point (channel) } \\
\hline 1019A & CB02 & FG bottom platform & 37.9810 & 75.3965 & 2.5 & August 13, 2014-October 16, 2014 \\
\hline 1019B & CB02 & FG bottom platform & 37.9813 & 75.3965 & 2.3 & October 21, 2014-January 18, 2015 \\
\hline 1019C & CB02 & FG bottom platform & 37.9813 & 75.3961 & 2.3 & January 22, 2015-April 20, 2015 \\
\hline 1019D & CB02 & FG bottom platform & 37.9813 & 75.3961 & 2.2 & April 25, 2015-July 12, 2015 \\
\hline \multicolumn{7}{|c|}{ 1020-Wildcat Point (seagrass meadow) } \\
\hline 1020A & CB03 & SWIP & 37.9750 & 75.3451 & 1.5 & August 13, 2014-October 16, 2014 \\
\hline 1020B & CB03 & SWIP & 37.9750 & 75.3451 & 1.0 & October 21, 2014-January 16, 2015 \\
\hline 1020C & CB03 & SWIP & 37.9749 & 75.3450 & 1.3 & January 22, 2015-April 20, 2015 \\
\hline 1020D & CB04 & SWIP & 37.9749 & 75.3450 & 1.5 & April 25, 2015-July 12, 2015 \\
\hline \multicolumn{7}{|c|}{ 1021-Ragged Point shallow (shoal) } \\
\hline $1021 \mathrm{~A}$ & CB04 & Aluminum H-Frame & 38.0100 & 75.3096 & 0.8 & August 15, 2014-October 16, 2014 \\
\hline 1021B & CB04 & Aluminum H-Frame & 38.0100 & 75.3096 & 0.7 & October 21, 2014-January 20, 2015 \\
\hline 1021C & CB04 & Aluminum H-Frame & 38.0100 & 75.3096 & 0.7 & -April 21, 2015 \\
\hline \multicolumn{7}{|c|}{ 1022-Ragged Point deep (shoal) } \\
\hline $1022 \mathrm{~A}$ & CB05 & Alum & 38.0 & 81 & 1.2 & August 15, \\
\hline 1022B & CB05 & Aluminum H-Frame & 38.0 & 75 & 1.0 & October 21, 201 \\
\hline $1022 \mathrm{C}$ & CB05 & Aluminum H-Frame & 38.0118 & 75.3081 & 1.2 & January 22, 2015-April 22, 2015 \\
\hline 1022D & CB05 & Aluminum H-Frame & 38.0118 & 75.3081 & 1.3 & April 25, 2015-July 13, 2015 \\
\hline \multicolumn{7}{|c|}{ 1023-Rattlesnake Island (channel) } \\
\hline $1023 \mathrm{~A}$ & CB06 & tform & 38.0913 & 75.2833 & 2.5 & August 13,2 \\
\hline 1023B & CB06 & FG bottom platform & 38.0913 & 75.2832 & 2.3 & October 20, 2014-January 19, 2015 \\
\hline 1023C & CB06 & FG bottom platform & 38.0914 & 75.2831 & 2.4 & January 23, 2015-April 21, 2015 \\
\hline 1023D & CB06 & FG bottom platform & 38.0914 & 75.2831 & 2.1 & April 25, 2015-July 12, 2015 \\
\hline \multicolumn{7}{|c|}{ 1024-Pirate Island south (shoal) } \\
\hline $1024 \mathrm{~A}$ & CB07 & FG b & 38.0901 & 75.2524 & 1.0 & August 13,2 \\
\hline 1024B & CB07 & FG bottom platform & 38.0901 & 75.2524 & 1.0 & October 20, 2014- \\
\hline 1024C & CB07 & FG bottom platform & 38.0902 & 75.2524 & 1.0 & January 22, 2015-April 21, 2015 \\
\hline \multicolumn{7}{|c|}{ 1025-Pirate Island south (shoal) } \\
\hline $1025 \mathrm{~A}$ & CB07 & rame & 38.0901 & 75.2523 & 1.0 & August 14,2 \\
\hline 1025B & CB07 & m H-Frame & 38.0901 & 75.2523 & 1.0 & October 20, 2014-January 20, 2015 \\
\hline 1025C & CB07 & Aluminum H-Frame & 38.0901 & 75.2523 & 0.9 & January 22, 2015-April 21, 2015 \\
\hline \multicolumn{7}{|c|}{ 1026-Pirate Island north (shoal) } \\
\hline $1026 \mathrm{~A}$ & CB08 & Aluminum H-Frame & 38.0983 & 75.2500 & 1.0 & August 16, 2014-October 14, 2014 \\
\hline 1026B & CB08 & um H-Frame & $38 .($ & & 1.0 & October 20, 2014 \\
\hline 1026C & CB08 & Aluminum H-Frame & 38.0983 & 75.2500 & 1.3 & January 23, 2015-April 21, 2015 \\
\hline 1026D & CB08 & Aluminum H-Frame & 38.0984 & 75.2499 & 1.1 & April 25, 2015-July 13, 2015 \\
\hline \multicolumn{7}{|c|}{ 1027-Public Landing (channel) } \\
\hline 1027A & CB09 & fform & 38.1491 & 75.2382 & 2.7 & August 13,20 \\
\hline 1027B & CB09 & latform & 38.1493 & 75.2380 & 2.5 & October 20, 2014-January 18, 2015 \\
\hline 1027C & CB09 & FG bottom platform & 38.1494 & 75.2379 & 2.4 & January 25, 2015-April 21, 2015 \\
\hline \multicolumn{7}{|c|}{ 1028-Tingle Island (shoal) } \\
\hline 1028A & CB10 & SWIP & 38.1585 & 75.2116 & 1.4 & August 14, 2014-October 14, 2014 \\
\hline 1028B & CB10 & SWIP & 38.1585 & 75.2116 & 1.0 & October 21, 2014-January 18, 2015 \\
\hline $1028 \mathrm{C}$ & CB10 & SWIP & 38.1584 & 75.2114 & 1.4 & January 23, 2015-April 21, 2015 \\
\hline 1028D & CB10 & SWIP & 38.1583 & 75.2114 & 1.1 & April 25, 2015-July 12, 2015 \\
\hline
\end{tabular}




\begin{tabular}{|c|c|c|c|c|c|c|}
\hline $\begin{array}{l}\text { Mooring } \\
\text { ID }\end{array}$ & Site ID & Mount/platform type & $\begin{array}{l}\text { Latitude } \\
\text { (N) }\end{array}$ & $\begin{array}{l}\text { Longitude } \\
\text { (W) }\end{array}$ & $\begin{array}{l}\text { Depth } \\
\text { (m) }\end{array}$ & Deployment period \\
\hline \multicolumn{7}{|c|}{ 1029-Newport Bay (channel) } \\
\hline 1029A & CB11 & FG bottom platform & 38.2395 & 75.2142 & 2.2 & August 13, 2014-October 14, 2014 \\
\hline 1029B & CB11 & FG bottom platform & 38.2396 & 75.2140 & 2.0 & October 20, 2014-January 18, 2015 \\
\hline 1029C & CB11 & FG bottom platform & 38.2397 & 75.2141 & 2.1 & January 25, 2015-April 21, 2015 \\
\hline \multicolumn{7}{|c|}{ 1030-Sinepuxent Bay (channel) } \\
\hline 1030A & CB12 & FG bottom platform & 38.2592 & 75.1397 & 1.8 & August 14, 2014-October 14, 2014 \\
\hline 1030B & CB12 & FG bottom platform & 38.2591 & 75.1396 & 1.8 & October 20, 2014-January 19, 2015 \\
\hline 1030C & CB12 & FG bottom platform & 38.2590 & 75.1395 & 2.4 & January 25, 2015-April 21, 2015 \\
\hline \multicolumn{7}{|c|}{ 1031-Public Landing (dock) } \\
\hline 1031A & CBWS & Pier piling & 38.1482 & 75.2863 & -- & August 16, 2014-October 19, 2014 \\
\hline 1031B & CBWS & Pier piling & 38.1482 & 75.2863 & -- & October 19, 2014-January 23, 2015 \\
\hline 1031C & CBWS & Pier piling & 38.1482 & 75.2863 & -- & January 23, 2015-April 21, 2015 \\
\hline 1031D & CBWS & Pier piling & 38.1482 & 75.2863 & -- & April 21, 2015-July 14, 2015 \\
\hline \multicolumn{7}{|c|}{ 1048-1052-Vegetation transect near Wildcat Point (seagrass meadow) } \\
\hline 1048 & V1 & FG bottom platform & 37.9714 & 75.3551 & 1.7 & April 25, 2015-July 12, 2015 \\
\hline 1049 & V2 & FG bottom platform & 37.9738 & 75.3533 & 1.5 & April 26, 2015-July 12, 2015 \\
\hline 1050 & V3 & FG bottom platform & 37.9770 & 75.3508 & 0.8 & April 26, 2015-July 12, 2015 \\
\hline 1051 & V4 & FG bottom platform & 37.9807 & 75.3473 & 1.0 & April 26, 2015-July 12, 2015 \\
\hline 1052 & V5 & $\begin{array}{l}\text { Mini-FG bottom } \\
\text { platform }\end{array}$ & 37.9865 & 75.3424 & 1.0 & April 26, 2015-July 12, 2015 \\
\hline
\end{tabular}


Table 2. Links to processed water flow (current velocity) data, by site and instrument, for platforms deployed in Chincoteague Bay, Maryland and Virginia.

[ID, identification number; no., number; mab, meters above bottom; MHz, megahertz; HR, high resolution]

\begin{tabular}{|c|c|c|c|c|}
\hline Mooring ID & Instrument & Serial no. & $\begin{array}{c}\text { Sensor } \\
\text { elevation } \\
\text { (mab) }\end{array}$ & Data file \\
\hline \multicolumn{5}{|c|}{ 1019_Cockle Point (channel) } \\
\hline 10191A & Nortek Aquadopp $1 \mathrm{MHz}$ & 5379 & 0.16 & 10191Aaqd-a.nc \\
\hline 10191B & Nortek Aquadopp 1MHz & 5379 & 0.15 & 10191Baqd-a.nc \\
\hline $10191 C$ & Nortek Aquadopp $1 \mathrm{MHz}$ & 5379 & 0.15 & 10191Caqd-a.nc \\
\hline 10191D & Nortek Aquadopp $1 \mathrm{MHz}$ & 5379 & 0.15 & 10191Daqd-a.nc \\
\hline \multicolumn{5}{|c|}{ 1020-Wildcat Point (seagrass meadow) } \\
\hline 10202A & Nortek Aquadopp HR & 5373 & 0.16 & 10202AHRaqds-a.nc \\
\hline 10202B & Nortek Aquadopp HR & 5373 & 0.15 & 10202BHRaqds-a.nc \\
\hline 10202C & Nortek Aquadopp HR & 5373 & 0.15 & 10202CHRaqds-a.nc \\
\hline 10202D & Nortek Aquadopp HR & 5373 & 0.15 & 10202DHRaqds-a.nc \\
\hline \multicolumn{5}{|c|}{ 1023-Rattlesnake Island (channel) } \\
\hline $10231 \mathrm{~A}$ & Nortek Aquadopp 1MHz & 6409 & 0.16 & 10231Aaqd-a.nc \\
\hline 10231B & Nortek Aquadopp 1MHz & 6459 & 0.15 & 10231Baqd-a.nc \\
\hline 10231C & Nortek Aquadopp 1MHz & 6459 & 0.15 & 10231Caqd-a.nc \\
\hline 10231D & Nortek Aquadopp 1MHz & 6459 & 0.15 & 10231Daqd-a.nc \\
\hline \multicolumn{5}{|c|}{ 1024-Pirate Island south (shoal) } \\
\hline $10241 \mathrm{~A}$ & Nortek Aquadopp $2 \mathrm{MHz}$ & 11507 & 0.15 & 10241Aaqd-a.nc \\
\hline 10241B & Nortek Aquadopp 2MHz & 11507 & 0.15 & 10241Baqd-a.nc \\
\hline $10241 C$ & Nortek Aquadopp 2MHz & 11507 & 0.15 & 10241Caqd-a.nc \\
\hline \multicolumn{5}{|c|}{ 1027-Public Landing (channel) } \\
\hline $10271 \mathrm{~A}$ & Nortek Aquadopp $1 \mathrm{MHz}$ & 9781 & 0.15 & 10271Aaqd-a.nc \\
\hline 10271B & Nortek Aquadopp 1MHz & 9781 & 0.15 & 10271Baqd-a.nc \\
\hline $10271 C$ & Nortek Aquadopp 1MHz & 9781 & 0.15 & 10271Caqd-a.nc \\
\hline \multicolumn{5}{|c|}{ 1028-Tingle Island (shoal) } \\
\hline 10282A & Nortek Aquadopp 2MHz & 11819 & 0.17 & 10282Aaqd-a.nc \\
\hline 10282B & Nortek Aquadopp 2MHz & 11819 & 0.17 & 10282Baqd-a.nc \\
\hline 10282C & Nortek Aquadopp 2MHz & 11819 & 0.17 & 10282Caqd-a.nc \\
\hline 10282D & Nortek Aquadopp 2MHz & 11507 & 0.16 & 10282Daqd-a.nc \\
\hline \multicolumn{5}{|c|}{ 1029-Newport Bay (channel) } \\
\hline $10291 \mathrm{~A}$ & Nortek Aquadopp 2MHz & 2290 & 0.16 & 10291Aaqd-a.nc \\
\hline 10291B & Nortek Aquadopp 2MHz & 2290 & 0.17 & 10291Baqd-a.nc \\
\hline $10291 \mathrm{C}$ & Nortek Aquadopp 2MHz & 2290 & 0.17 & 10291Caqd-a.nc \\
\hline \multicolumn{5}{|c|}{ 1030-Sinepuxent Bay (channel) } \\
\hline 10301A & Nortek Aquadopp 2MHz & 1757 & 0.16 & 10301Aaqd-a.nc \\
\hline 10301B & Nortek Aquadopp 2MHz & 1757 & 0.17 & 10301Baqd-a.nc \\
\hline $10301 C$ & Nortek Aquadopp 2MHz & 1757 & 0.17 & 10301Caqd-a.nc \\
\hline \multicolumn{5}{|c|}{ 1048-Vegetation transect near Wildcat Point (seagrass meadow) } \\
\hline 10481 & Nortek Aquadopp 2MHz & 11819 & 0.16 & 10481aqd-a.nc \\
\hline
\end{tabular}


Table 3. Links to processed wave (directional and nondirectional) data, by site and instrument, for platforms deployed in Chincoteague Bay, Maryland and Virginia.

[ID, identification number; no., number; mab, meters above bottom; MHz, megahertz; Y, yes; N, no]

\begin{tabular}{|c|c|c|c|c|c|}
\hline Mooring ID & Instrument & Serial no. & $\begin{array}{c}\text { Sensor } \\
\text { elevation } \\
\text { (mab) }\end{array}$ & Data file & Direction \\
\hline \multicolumn{6}{|c|}{ 1019-Cockle Point (channel) } \\
\hline 10191A & Nortek Aquadopp $1 \mathrm{MHz}$ & 5379 & 0.16 & 10191Aaqdwvs diwasp-cal.nc & $\mathrm{Y}$ \\
\hline 10191B & Nortek Aquadopp $1 \mathrm{MHz}$ & 5379 & 0.15 & $\overline{10191 B a q d w v s \text { diwasp-cal.nc }}$ & $\mathrm{Y}$ \\
\hline 10191C & Nortek Aquadopp $1 \mathrm{MHz}$ & 5379 & 0.15 & $\overline{10191 \text { Caqdwvs diwasp-cal.nc }}$ & $\mathrm{Y}$ \\
\hline 10191D & Nortek Aquadopp $1 \mathrm{MHz}$ & 5379 & 0.15 & 10191Daqdwvs diwasp-cal.nc & $\mathrm{Y}$ \\
\hline 10192A & RBR Virtuoso D|wave & 55023 & 0.15 & 10192Adws-a.nc & $\mathrm{N}$ \\
\hline 10192B & RBR Virtuoso D|wave & 55023 & 0.14 & 10192Bdws-a.nc & $\mathrm{N}$ \\
\hline $10192 \mathrm{C}$ & RBR Virtuoso D|wave & 55023 & 0.14 & 10192Cdws-a.nc & $\mathrm{N}$ \\
\hline \multicolumn{6}{|c|}{ 1020-Wildcat Point (seagrass meadow) } \\
\hline $10204 \mathrm{~A}$ & RBR Virtuoso D|wave & 55107 & 0.15 & 10204Adws-a.nc & $\mathrm{N}$ \\
\hline $10204 \mathrm{~B}$ & RBR Virtuoso D|wave & 55107 & 0.15 & 10204Bdws-a.nc & $\mathrm{N}$ \\
\hline 10204C & RBR Virtuoso D|wave & 55109 & 0.15 & 10204 Cdws-a.nc & $\mathrm{N}$ \\
\hline 10204D & RBR Virtuoso D|wave & 55109 & 0.14 & 10204Ddws-a.nc & $\mathrm{N}$ \\
\hline \multicolumn{6}{|c|}{ 1023-Rattlesnake Island (channel) } \\
\hline $10231 \mathrm{~A}$ & Nortek Aquadopp $1 \mathrm{MHz}$ & 6409 & 0.16 & 10231Aaqdwvs diwasp-cal.nc & $\mathrm{Y}$ \\
\hline 10231B & Nortek Aquadopp $1 \mathrm{MHz}$ & 6459 & 0.15 & 10231Baqdwvs diwasp-cal.nc & $\mathrm{Y}$ \\
\hline 10231C & Nortek Aquadopp $1 \mathrm{MHz}$ & 6459 & 0.15 & $\overline{10231 \text { Caqdwvs diwasp-cal.nc }}$ & $\mathrm{Y}$ \\
\hline 10231D & Nortek Aquadopp $1 \mathrm{MHz}$ & 6459 & 0.15 & 10231Daqdwvs diwasp-cal.nc & $\mathrm{Y}$ \\
\hline \multicolumn{6}{|c|}{ 1024-Pirate Island south (shoal) } \\
\hline $10241 \mathrm{~A}$ & Nortek Aquadopp $2 \mathrm{MHz}$ & 11507 & 0.17 & 10241Aaqdwvs diwasp-cal.nc & $\mathrm{Y}$ \\
\hline 10241B & Nortek Aquadopp $2 \mathrm{MHz}$ & 11507 & 0.15 & 10241Baqdwvs diwasp-cal.nc & $\mathrm{Y}$ \\
\hline 10241C & Nortek Aquadopp 2MHz & 11507 & 0.15 & $\overline{10241 C a q d w v s \text { diwasp-cal.nc }}$ & $\mathrm{Y}$ \\
\hline 10242A & RBR Virtuoso D|wave & 55108 & 0.16 & 10242Adws-a.nc & $\mathrm{N}$ \\
\hline 10242B & RBR Virtuoso D|wave & 55108 & 0.14 & $\overline{10242 B d w s-a . n c}$ & $\mathrm{~N}$ \\
\hline $10242 \mathrm{C}$ & RBR Virtuoso D|wave & 55108 & 0.15 & $\overline{10242 C d w s-a . n c}$ & $\mathrm{~N}$ \\
\hline \multicolumn{6}{|c|}{ 1027-Public Landing (channel) } \\
\hline $10271 \mathrm{~A}$ & Nortek Aquadopp $1 \mathrm{MHz}$ & 9781 & 0.15 & 10271Aaqdwvs diwasp-cal.nc & $\mathrm{Y}$ \\
\hline 10271B & Nortek Aquadopp $1 \mathrm{MHz}$ & 9781 & 0.15 & 10271Baqdwvs diwasp-cal.nc & $\mathrm{Y}$ \\
\hline 10271C & Nortek Aquadopp $1 \mathrm{MHz}$ & 9781 & 0.15 & 10271Caqdwvs diwasp-cal.nc & $\mathrm{Y}$ \\
\hline 10273A & RBR Virtuoso Dwave & 55109 & 0.14 & 10273Adws-a.nc & $\mathrm{N}$ \\
\hline 10273B & RBR Virtuoso Dwave & 55109 & 0.14 & $\overline{10273 B d w s-a . n c}$ & $\mathrm{~N}$ \\
\hline $10273 C$ & RBR Virtuoso Dwave & 55107 & 0.14 & 10273 Cdws-a.nc & $\mathrm{N}$ \\
\hline \multicolumn{6}{|c|}{ 1028-Tingle Island (shoal) } \\
\hline 10282D & Nortek Aquadopp 2MHz & 11507 & 0.16 & 10282Daqdwvs diwasp-cal.nc & $\mathrm{Y}$ \\
\hline 10284A & RBR Virtuoso D|wave & 55110 & 0.12 & 10284Adws-a.nc & $\mathrm{N}$ \\
\hline 10284B & RBR Virtuoso D|wave & 55110 & 0.15 & 10284Bdws-a.nc & $\mathrm{N}$ \\
\hline $10284 \mathrm{C}$ & RBR Virtuoso D|wave & 55110 & 0.15 & 10284Cdws-a.nc & $\mathrm{N}$ \\
\hline \multicolumn{6}{|c|}{ 1029-Newport Bay (channel) } \\
\hline $10293 \mathrm{~A}$ & RBR Virtuoso D|wave & 55025 & 0.15 & 10293Adws-a.nc & $\mathrm{N}$ \\
\hline 10293B & RBR Virtuoso D|wave & 55025 & 0.15 & 10293Bdws-a.nc & $\mathrm{N}$ \\
\hline $10293 \mathrm{C}$ & RBR Virtuoso D|wave & 55025 & 0.15 & 10293 Cdws-a.nc & $\mathrm{N}$ \\
\hline \multicolumn{6}{|c|}{ 1048-1052-Vegetation transect near Wildcat Point (seagrass meadow) } \\
\hline 10481 & Nortek Aquadopp $2 \mathrm{MHz}$ & 11819 & 0.16 & 10481aqdwvs diwasp-cal.nc & $\mathrm{Y}$ \\
\hline 10491 & RBR Virtuoso D|wave & 55110 & 0.14 & 10491dws-a.nc & $\mathrm{N}$ \\
\hline 10501 & RBR Virtuoso D|wave & 55023 & 0.15 & $\overline{10501 d w s-a . n c}$ & $\mathrm{~N}$ \\
\hline 10511 & RBR Virtuoso D|wave & 55025 & 0.14 & 10511dws-a.nc & $\mathrm{N}$ \\
\hline 10521 & RBR Virtuoso D|wave & 55108 & 0.08 & 10521dws-a.nc & $\mathrm{N}$ \\
\hline
\end{tabular}


Table 4. Links to processed water-quality data, by site and instrument, for platforms deployed in Chincoteague Bay, Maryland and Virginia.

[ID, identification number; no., number; mab, meters above bottom]

\begin{tabular}{|c|c|c|c|c|}
\hline Mooring ID & Instrument & $\begin{array}{c}\text { Serial } \\
\text { no. }\end{array}$ & $\begin{array}{c}\text { Sensor } \\
\text { elevation } \\
\text { (mab) }\end{array}$ & Data file \\
\hline \multicolumn{5}{|c|}{ 1018-Toms Cove (old Coast Guard house pier) } \\
\hline 10181A & YSI 6600 & 625 & 0.5 & 10181Aysi-a.nc \\
\hline 10181B & YSI 6600 & 625 & 0.5 & No data \\
\hline \multicolumn{5}{|c|}{ 1019-Cockle Point (channel) } \\
\hline 10193A & WET Labs ECO-NTUSB & 509 & 0.13 & 10193Aecn-a.nc \\
\hline 10193B & WET Labs ECO-NTUSB & 509 & 0.13 & No data \\
\hline 10193C & WET Labs ECO-NTUSB & 509 & 0.13 & 10193Cecn-a.nc \\
\hline 10194B & SBE 37-SMMicroCAT & 0310 & 0.16 & 10194Bmc-a.nc \\
\hline 10194C & SBE 37-SM MicroCAT & 0465 & 0.14 & 10194Cmc-a.nc \\
\hline 10195D & YSI EXO2 & 0204 & 0.13 & 10195Dexo-a.nc \\
\hline \multicolumn{5}{|c|}{ 1020-Wildcat Point (seagrass meadow) } \\
\hline $10201 \mathrm{~A}$ & WET Labs ECO-PARSB & 274 & 0.45 & 10201Aecp-a.nc \\
\hline 10201B & WET Labs ECO-PARSB & 274 & 0.45 & 10201Becp-a.nc \\
\hline 10201C & WET Labs ECO-PARSB & 274 & 0.45 & 10201Cecp-a.nc \\
\hline 10201D & WET Labs ECO-PARSB & 274 & 0.45 & $\overline{10201 D e c p-a . n c}$ \\
\hline $10203 \mathrm{~A}$ & YSI EXO2 & 0015 & 0.15 & $\overline{10203 A \text { exo-a.nc }}$ \\
\hline 10203B & YSI EXO2 & 0015 & 0.15 & $\overline{10203 B e x o-a . n c}$ \\
\hline $10203 \mathrm{C}$ & YSI EXO2 & 0015 & 0.15 & $\overline{10203 \text { Cexo-a.nc }}$ \\
\hline 10203D & YSI EXO2 & 0015 & 0.16 & $\overline{10203 \text { Dexo-a.nc }}$ \\
\hline $10205 \mathrm{~A}$ & WET Labs ECO-PARSB & 273 & 0.15 & $\overline{10205 A e c p-a . n c}$ \\
\hline 10205B & WET Labs ECO-PARSB & 273 & 0.15 & $\overline{10205 B e c p-a . n c}$ \\
\hline $10205 \mathrm{C}$ & WET Labs ECO-PARSB & 273 & 0.15 & $\overline{10205 C e c p-a . n c}$ \\
\hline 10205D & WET Labs ECO-PARSB & 273 & 0.16 & $\overline{10205 \text { Decp-a.nc }}$ \\
\hline 10206B & SBE 37-SM MicroCAT & 0463 & 0.14 & $\overline{10206 B m c-a . n c}$ \\
\hline \multicolumn{5}{|c|}{ 1023-Rattlesnake Island (channel) } \\
\hline $10232 \mathrm{~A}$ & YSI EXO2 & 3375 & 0.17 & 10232Aexo-a.nc \\
\hline 10232B & YSI EXO2 & 3375 & 0.13 & $\overline{10232 B e x o-a . n c}$ \\
\hline $10232 \mathrm{C}$ & YSI EXO2 & 3375 & 0.13 & $\overline{10232 \text { Cexo-a.nc }}$ \\
\hline 10232D & YSI EXO2 & 3375 & 0.13 & $\overline{\text { 10232Dexo-a.nc }}$ \\
\hline \multicolumn{5}{|c|}{ 1024-Pirate Island south (shoal) } \\
\hline $10243 \mathrm{~A}$ & WET Labs ECO-NTUSB & 547 & 0.14 & 10243Aecn-a.nc \\
\hline 10243B & WET Labs ECO-NTUSB & 434 & 0.13 & 10243Becn-a.nc \\
\hline $10243 \mathrm{C}$ & WET Labs ECO-NTUSB & 547 & 0.13 & 10243Cecn-a.nc \\
\hline \multicolumn{5}{|c|}{ 1027-Public Landing (channel) } \\
\hline 10272A & YSI 6600 & 626 & 0.15 & 10272Aysi-a.nc \\
\hline 10272B & YSI 6600 & 626 & 0.15 & 10272Bysi-a.nc \\
\hline 10272C & YSI 6600 & 626 & 0.15 & 10272Cysi-a.nc \\
\hline \multicolumn{5}{|c|}{ 1028-Tingle Island (shoal) } \\
\hline $10281 \mathrm{~A}$ & WET Labs ECO-PARSB & 406 & 0.45 & No data \\
\hline 10281B & WET Labs ECO-PARSB & 391 & 0.45 & 10281Becp-a.nc \\
\hline 10281C & WET Labs ECO-PARSB & 454 & 0.45 & 10281Cecp-a.nc \\
\hline 10281D & WET Labs ECO-PARSB & 454 & 0.45 & 10281Decp-a.nc \\
\hline 10283A & YSI EXO2 & 0014 & 0.15 & 10283Aexo-a.nc \\
\hline 10283B & YSI EXO2 & 0014 & 0.15 & 10283Bexo-a.nc \\
\hline $10283 \mathrm{C}$ & YSI EXO2 & 0014 & 0.15 & 10283Cexo-a.nc \\
\hline 10283D & YSI EXO2 & 0014 & 0.15 & $\overline{10283 \text { Dexo-a.nc }}$ \\
\hline
\end{tabular}




\begin{tabular}{|c|c|c|c|c|}
\hline Mooring ID & Instrument & $\begin{array}{c}\text { Serial } \\
\text { no. }\end{array}$ & $\begin{array}{l}\text { Sensor } \\
\text { elevation } \\
\text { (mab) }\end{array}$ & Data file \\
\hline $10285 \mathrm{~A}$ & WET Labs ECO-PARSB & 405 & 0.15 & No data \\
\hline 10285B & SBE 37-SM MicroCAT & 0465 & 0.15 & 10285Bmc-a.nc \\
\hline 10285C & WET Labs ECO-PARSB & 455 & 0.15 & 10285Cecp-a.nc \\
\hline 10285D & WET Labs ECO-PARSB & 455 & 0.16 & 10285Decp-a.nc \\
\hline \multicolumn{5}{|c|}{ 1029-Newport Bay (channel) } \\
\hline 10292A & YSI EXO2 & 0204 & 0.15 & 10292Aexo-a.nc \\
\hline 10292B & YSI EXO2 & 0204 & 0.15 & 10292Bexo-a.nc \\
\hline 10292C & YSI EXO2 & 0204 & 0.15 & 10292Cexo-a.nc \\
\hline \multicolumn{5}{|c|}{ 1030-Sinepuxent Bay (channel) } \\
\hline 10302A & YSI 6600 & 627 & 0.16 & 10302Aysi-a.nc \\
\hline 10302B & YSI 6600 & 627 & 0.15 & $\overline{10302 \text { Bysi-a.nc }}$ \\
\hline 10302C & YSI 6600 & 627 & 0.16 & $\overline{10302 \text { Cysi-a.nc }}$ \\
\hline \multicolumn{5}{|c|}{1048 and 1051-Vegetation transect near Wildcat Point (seagrass meadow) } \\
\hline 10482 & WET Labs ECO-NTUSB & 509 & 0.14 & 10482ecn-a.nc \\
\hline 10512 & WET Labs ECO-NTUSB & 434 & 0.14 & $\overline{10512 \text { ecn-a.nc }}$ \\
\hline
\end{tabular}


Table 5. Links to processed seabed elevation data, by site and instrument, for frames deployed in Chincoteague Bay, Maryland and Virginia.

[ID, identification number; no., number; mab, meters above bottom]

\begin{tabular}{|c|c|c|c|c|}
\hline Mooring ID & Instrument & Serial no. & $\begin{array}{c}\text { Sensor } \\
\text { elevation } \\
\text { (mab) }\end{array}$ & Data file \\
\hline \multicolumn{5}{|c|}{ 1021-Ragged Point shallow (shoal) } \\
\hline 10211A & Echologger AA400 & 0074 & 0.41 & 10211Aalt-a.nc \\
\hline 10211B & Echologger AA400 & 0074 & 0.44 & $\overline{10211 B a l t-a . n c}$ \\
\hline 10211C & Echologger AA400 & 0074 & 0.48 & $\overline{10211 C a l t-a . n c}$ \\
\hline \multicolumn{5}{|c|}{ 1022-Ragged Point deep (shoal) } \\
\hline $10221 \mathrm{~A}$ & Echologger AA400 & 0083 & 0.50 & 10221Aalt-a.nc \\
\hline 10221B & Echologger AA400 & 0083 & 0.55 & $\overline{\text { 10221Balt-a.nc }}$ \\
\hline $10221 \mathrm{C}$ & Echologger AA400 & 0083 & 0.60 & 10221Calt-a.nc \\
\hline 10221D & Echologger AA400 & 0083 & 0.57 & $\overline{10221 \text { Dalt-a.nc }}$ \\
\hline \multicolumn{5}{|c|}{ 1025-Pirate Island south (shoal) } \\
\hline $10251 \mathrm{~A}$ & Echologger AA400 & 0084 & 0.53 & 10251Aalt-a.nc \\
\hline 10251B & Echologger AA400 & 0084 & 0.52 & 10251Balt-a.nc \\
\hline 10251C & Echologger AA400 & 0084 & 0.55 & $\overline{10251 \text { Calt-a.nc }}$ \\
\hline \multicolumn{5}{|c|}{ 1026-Pirate Island north (shoal) } \\
\hline $10261 \mathrm{~A}$ & Echologger AA400 & 0085 & 0.51 & 10261Aalt-a.nc \\
\hline 10261B & Echologger AA400 & 0085 & 0.57 & $\overline{10261 \text { Balt-a.nc }}$ \\
\hline 10261C & Echologger AA400 & 0085 & 0.63 & 10261Calt-a.nc \\
\hline 10261D & Echologger AA400 & 0085 & 0.42 & 10261Dalt-a.nc \\
\hline
\end{tabular}

Table 6. Links to meteorological data, by site and instrument, for weather stations deployed on a private dock at Public Landing, Maryland, on Chincoteague Bay.

[ID, identification number; no., number; mab, meters above bottom]

\begin{tabular}{llccc}
\hline Mooring ID & \multicolumn{1}{c}{ Instrument } & Serial no. & $\begin{array}{c}\text { Sensor } \\
\text { elevation } \\
\text { (mab) }\end{array}$ & Data file \\
\hline \multicolumn{5}{c}{ 1031_Public Landing (dock) } \\
\hline 10311A & Onset Hobo U30 weather station & 9528 & -3.80 & $\underline{10311 \mathrm{Ahlm}-\mathrm{a} \cdot \mathrm{nc}}$ \\
$10311 \mathrm{~B}$ & Onset Hobo U30 weather station & 9528 & -3.80 & $\underline{10311 \mathrm{Bh} / \mathrm{m}-\mathrm{a} \cdot \mathrm{nc}}$ \\
$10311 \mathrm{C}$ & Onset Hobo U30 weather station & 9528 & -3.80 & $\underline{10311 \mathrm{Ch} / \mathrm{m}-\mathrm{a} \cdot \mathrm{nc}}$ \\
$10311 \mathrm{D}$ & Onset Hobo U30 weather station & 9528 & -3.80 & $\underline{10311 \mathrm{Dh} / \mathrm{m}-\mathrm{a} \cdot \mathrm{nc}}$ \\
\hline
\end{tabular}




\section{Appendix 1. Burst Current and Pressure Data, Chincoteague Bay, Maryland and Virginia, 2014-15}

Table 1-1 provides access to burst data from Aquadopp and D|wave instruments set up to collect wave burst data and profile burst data from the Aquadopp HR instrument. These data are part of U.S. Geological Survey Oceanographic Time-Series Data release (Suttles and others, 2016).

Table 1-1. Links to burst current and pressure data, by site and instrument, for platforms deployed in Chincoteague Bay, Maryland and Virginia.

[ID, identification number; no., number; mab, meters above bottom; MHz, megahertz; HR, high resolution]

\begin{tabular}{|c|c|c|c|c|}
\hline Mooring ID & Instrument & Serial no. & $\begin{array}{c}\text { Sensor } \\
\text { elevation } \\
\text { (mab) }\end{array}$ & Data file \\
\hline \multicolumn{5}{|c|}{ 1019-Cockle Point (channel) } \\
\hline 10191A & Nortek Aquadopp 1MHz & 5379 & 0.16 & 10191Aaqdwvsb-cal.nc \\
\hline 10191B & Nortek Aquadopp 1MHz & 5379 & 0.15 & 10191Baqdwvsb-cal.nc \\
\hline 10191C & Nortek Aquadopp 1MHz & 5379 & 0.15 & 10191Caqdwvsb-cal.nc \\
\hline 10191D & Nortek Aquadopp 1MHz & 5379 & 0.15 & 10191Daqdwvsb-cal.nc \\
\hline 10192A & RBR Virtuoso D|wave & 55023 & 0.15 & 10192Adwb-cal.nc \\
\hline 10192B & RBR Virtuoso D|wave & 55023 & 0.14 & 10192Bdwb-cal.nc \\
\hline 10192C & RBR Virtuoso D|wave & 55023 & 0.14 & 10192Cdwb-cal.nc \\
\hline \multicolumn{5}{|c|}{ 1020-Wildcat Point (seagrass meadow) } \\
\hline $10202 \mathrm{~A}$ & Nortek Aquadopp HR & 5373 & 0.16 & 10202AHRaqdb-cal.nc \\
\hline 10202B & Nortek Aquadopp HR & 5373 & 0.15 & 10202BHRaqdb-cal.nc \\
\hline 10202C & Nortek Aquadopp HR & 5373 & 0.15 & $\overline{10202 C H R a q d b-c a l . n c}$ \\
\hline 10202D & Nortek Aquadopp HR & 5373 & 0.15 & $\overline{10202 D H R a q d b-c a l . n c}$ \\
\hline 10204A & RBR Virtuoso D|wave & 55107 & 0.15 & 10204Adwb-cal.nc \\
\hline 10204B & RBR Virtuoso D|wave & 55107 & 0.15 & $\overline{10204 B d w b-c a l . n c}$ \\
\hline 10204C & RBR Virtuoso D|wave & 55109 & 0.15 & $10204 C d w b-c a l . n c$ \\
\hline 10204D & RBR Virtuoso D|wave & 55109 & 0.14 & 10204Ddwb-cal.nc \\
\hline \multicolumn{5}{|c|}{ 1023-Rattlesnake Island (channel) } \\
\hline $10231 \mathrm{~A}$ & Nortek Aquadopp 1MHz & 6409 & 0.16 & 10231Aaqdwvsb-cal.nc \\
\hline 10231B & Nortek Aquadopp 1MHz & 6459 & 0.15 & $\overline{10231 B a q d w v s b-c a l . n c}$ \\
\hline 10231C & Nortek Aquadopp 1MHz & 6459 & 0.15 & $\overline{10231 \text { Caqdwvsb-cal.nc }}$ \\
\hline 10231D & Nortek Aquadopp 1MHz & 6459 & 0.15 & $\overline{\text { 10231Daqdwvsb-cal.nc }}$ \\
\hline \multicolumn{5}{|c|}{ 1024-Pirate Island south (shoal) } \\
\hline $10241 \mathrm{~A}$ & Nortek Aquadopp 2MHz & 11507 & 0.17 & 10241Aaqdwvsb-cal.nc \\
\hline 10241B & Nortek Aquadopp 2MHz & 11507 & 0.15 & $\overline{10241 B a q d w v s b-c a l . n c}$ \\
\hline 10241C & Nortek Aquadopp 2MHz & 11507 & 0.15 & 10241Caqdwvb-cal.nc \\
\hline 10242A & RBR Virtuoso D|wave & 55108 & 0.16 & 10242Adwb-cal.nc \\
\hline 10242B & RBR Virtuoso D|wave & 55108 & 0.14 & $\overline{10242 B d w b-c a l . n c}$ \\
\hline $10242 \mathrm{C}$ & RBR Virtuoso D|wave & 55108 & 0.15 & 10242 Cdwb-cal.nc \\
\hline \multicolumn{5}{|c|}{ 1027-Public Landing (channel) } \\
\hline $10271 \mathrm{~A}$ & Nortek Aquadopp 1MHz & 9781 & 0.15 & 10271Aaqdwvsb-cal.nc \\
\hline 10271B & Nortek Aquadopp 1MHz & 9781 & 0.15 & 10271Baqdwvsb-cal.nc \\
\hline 10271C & Nortek Aquadopp 1MHz & 9781 & 0.15 & 10271Caqdwvsb-cal.nc \\
\hline 10273A & RBR Virtuoso Dwave & 55109 & 0.14 & 10273Adwb-cal.nc \\
\hline 10273B & RBR Virtuoso Dwave & 55109 & 0.14 & $\overline{10273 B d w b-c a l . n c}$ \\
\hline 10273C & RBR Virtuoso Dwave & 55107 & 0.14 & $\underline{10273 \mathrm{Cdwb}-\mathrm{cal} . \mathrm{nc}}$ \\
\hline
\end{tabular}




\begin{tabular}{|c|c|c|c|c|}
\hline Mooring ID & Instrument & Serial no. & $\begin{array}{l}\text { Sensor } \\
\text { elevation } \\
\text { (mab) }\end{array}$ & Data file \\
\hline \multicolumn{5}{|c|}{ 1028-Tingle Island (shoal) } \\
\hline 10282D & Nortek Aquadopp $2 \mathrm{MHz}$ & 11507 & 0.16 & 10282Daqdwvsb-cal.nc \\
\hline 10284A & RBR Virtuoso D|wave & 55110 & 0.12 & 10284Adwb-cal.nc \\
\hline 10284B & RBR Virtuoso D|wave & 55110 & 0.15 & 10284Bdwb-cal.nc \\
\hline 10284C & RBR Virtuoso D|wave & 55110 & 0.15 & 10284Cdwb-cal.nc \\
\hline \multicolumn{5}{|c|}{ 1029-Newport Bay (channel) } \\
\hline 10293A & RBR Virtuoso D|wave & 55025 & 0.15 & 10293Adwb-cal.nc \\
\hline 10293B & RBR Virtuoso D|wave & 55025 & 0.15 & 10293Bdwb-cal.nc \\
\hline 10293C & RBR Virtuoso D|wave & 55025 & 0.15 & 10293Cdwb-cal.nc \\
\hline \multicolumn{5}{|c|}{ 1048-1052-Vegetation transect near Wildcat Point (seagrass meadow) } \\
\hline 10481 & Nortek Aquadopp $2 \mathrm{MHz}$ & 11819 & 0.16 & 10481aqdwvsb-cal.nc \\
\hline 10491 & RBR Virtuoso D|wave & 55110 & 0.14 & 10491dwb-cal.nc \\
\hline 10501 & RBR Virtuoso D|wave & 55023 & 0.15 & 10501dwb-cal.nc \\
\hline 10511 & RBR Virtuoso D|wave & 55025 & 0.14 & 10511dwb-cal.nc \\
\hline 10521 & RBR Virtuoso D|wave & 55108 & 0.08 & 10521dwb-cal.nc \\
\hline
\end{tabular}

\section{Reference Cited}

Suttles, S.E., Ganju, N.K., Brosnahan, S.M., Montgomery, E.T., Dickhudt, P.J., Borden, Jonathan, and Martini, M.A., 2016, Oceanographic and water-quality measurements in Chincoteague Bay, Maryland/Virginia, 2014-2015: U.S. Geological Survey data release, accessed June 14, 2016, at https://doi.org/10.5066/F7DF6PBV. 

For more information concerning this report, contact:

Director, Woods Hole Coastal and Marine Science Center U.S. Geological Survey

384 Woods Hole Road

Quissett Campus

Woods Hole, MA 02543-1598

WHSC_science_director@usgs.gov

508-548-8700 or 508-457-2200

or visit our Web site at:

https://woodshole.er.usgs.gov/

Publishing support provided by the Pembroke Publishing Service Center 
